MNORME DE RENDICIÓN DE CUENTAS 
copyright

(C) Salvador Palazón Ferrando. Inspección General de Servicios. 2019

(C) Gabino Martín-Serrano Rodríguez, maquetación y composición

(C) De esta edición: Universidad de Alicante

DOI: https://doi.org/10.14198/UA-Informe-rendicion-cuentas-2018 


\section{PRÓLOGO}

La Universidad de Alicante, como universidad de carácter público, debe marcarse como principio de transparencia la necesidad de informar a la sociedad sobre los resultados de sus actividades. El informe de rendición de cuentas que aquí se presenta surge de la necesidad de visibilizar sus principales logros en el año 2018. Mediante la síntesis de una serie de datos contrastados y seleccionados se muestra a la ciudadanía y a la comunidad universitaria dónde estamos, quiénes somos, con qué recursos contamos, qué resultados se han alcanzado, cómo hemos avanzado en los últimos cinco años y cuáles son los retos pendientes a los que deberemos enfrentarnos a corto y medio plazo. Además, este informe también ofrece datos de la Universidad de Alicante en relación con la media de las universidades públicas españolas y con todas las universidades públicas valencianas, así como sobre la posición que ocupa en las principales clasificaciones internacionales.

Quiero expresar mi agradecimiento a todas y cada una de las personas que componen nuestra Universidad, pues este informe es el reflejo de su compromiso y el fruto de su esfuerzo.

Por último, quiero reconocer la labor de la Inspección General de Servicios y de quienes han colaborado en la elaboración de este trabajo, en especial de Salvador Palazón, pues el resultado es un documento que responde, con rigor y calidad, a los objetivos que toda institución pública debe marcarse a la hora de rendir cuentas y generar el clima de confianza necesario para garantizar la autonomía universitaria.

Manuel Palomar Sanz

Rector de la Universidad de Alicante 


\section{PRESENTACIÓN}

La elaboración del informe de rendición de cuentas de la institución para el año 2018 se establece dentro del plan de actuaciones de la Inspección General de Servicios de la Universidad de Alicante para el curso académico 2019/2020.

Muy pocas universidades españolas elaboran este tipo de informes, por lo que la Universidad de Alicante, con este ejercicio de transparencia, puede demostrar a la sociedad cuál es su aportación concreta a los sistemas de educación superior y de ciencia y tecnología.

La información que genera una universidad a lo largo de un año es ingente y, por tanto, en el diseño de este informe de rendición de cuentas se ha partido de una serie de premisas destinadas a garantizar su elaboración este año, así como la posibilidad de continuar haciéndolo en años sucesivos, facilitando los datos precisos que permitan observar la evolución seguida por la institución a lo largo del tiempo. Por ese motivo, se ha realizado una selección de datos e indicadores, que incluye la comparación del papel que juega la Universidad de Alicante en el contexto internacional y en relación con el resto de universidades públicas españolas, en especial con las que componen el Sistema Universitario Público Valenciano.

El objetivo que pretende alcanzar el informe es ofrecer una síntesis de información relevante y contrastada que permita a la sociedad tener elementos suficientes a la hora de juzgar la respuesta de la Universidad de Alicante en relación a las necesidades del entorno, las funciones que tiene encomendadas y los recursos que tiene a su disposición.

La mayoría de los datos utilizados para la elaboración de este informe proceden del Sistema de Información de la Universidad de Alicante y de la información facilitada por la Gerencia, diferentes vicerrectorados y servicios de nuestra institución universitaria, además de la Unidad Técnica de Calidad. También se han consultado, entre otros, el Sistema Integrado de Información Universitaria (SIIU), impulsado y coordinado por la Secretaría General de Universidades; el Sistema de Información de las Universidades Valencianas Públicas (SIUVP), coordinado desde el IVIE; informes de organismos como la CRUE, y las páginas web de las instituciones que elaboran las principales clasificaciones internacionales.

La información ofrecida está referida siempre que ha sido posible al año 2018, en caso contrario se ha buscado ofrecer el dato existente del año o del curso académico más próximo para el que se dispone de información.

Las conclusiones extraídas, una vez consultado el informe, deben permitir visibilizar los principales logros alcanzados, posibilitar la realización de una valoración crítica de los resultados e identificar aquellos aspectos donde la Universidad de Alicante tiene margen para implementar acciones de mejora en un futuro próximo. 
ÍNDICE

1. ORGANIZACIÓN, ESPACIOS Y RECURSOS MATERIALES 7

2. COMUNIDAD UNIVERSITARIA 15

3. GESTIÓN FINANCIERA

4. RESULTADOS 39

5. INTERNACIONALIZACIÓN 53

6. RESPONSABILIDAD SOCIAL Y OBJETIVOS DE
DESARROLLO SOSTENIBLE

7. LA UNIVERSIDAD DE ALICANTE EN LOS SISTEMAS UNIVERSITARIOS VALENCIANO Y ESTATAL 65

8. RECONOCIMIENTO INTERNACIONAL 83 

Organización, espacios $y$ recursos materiales 


\subsection{Organización}

\section{A 31 de diciembre de 2018}
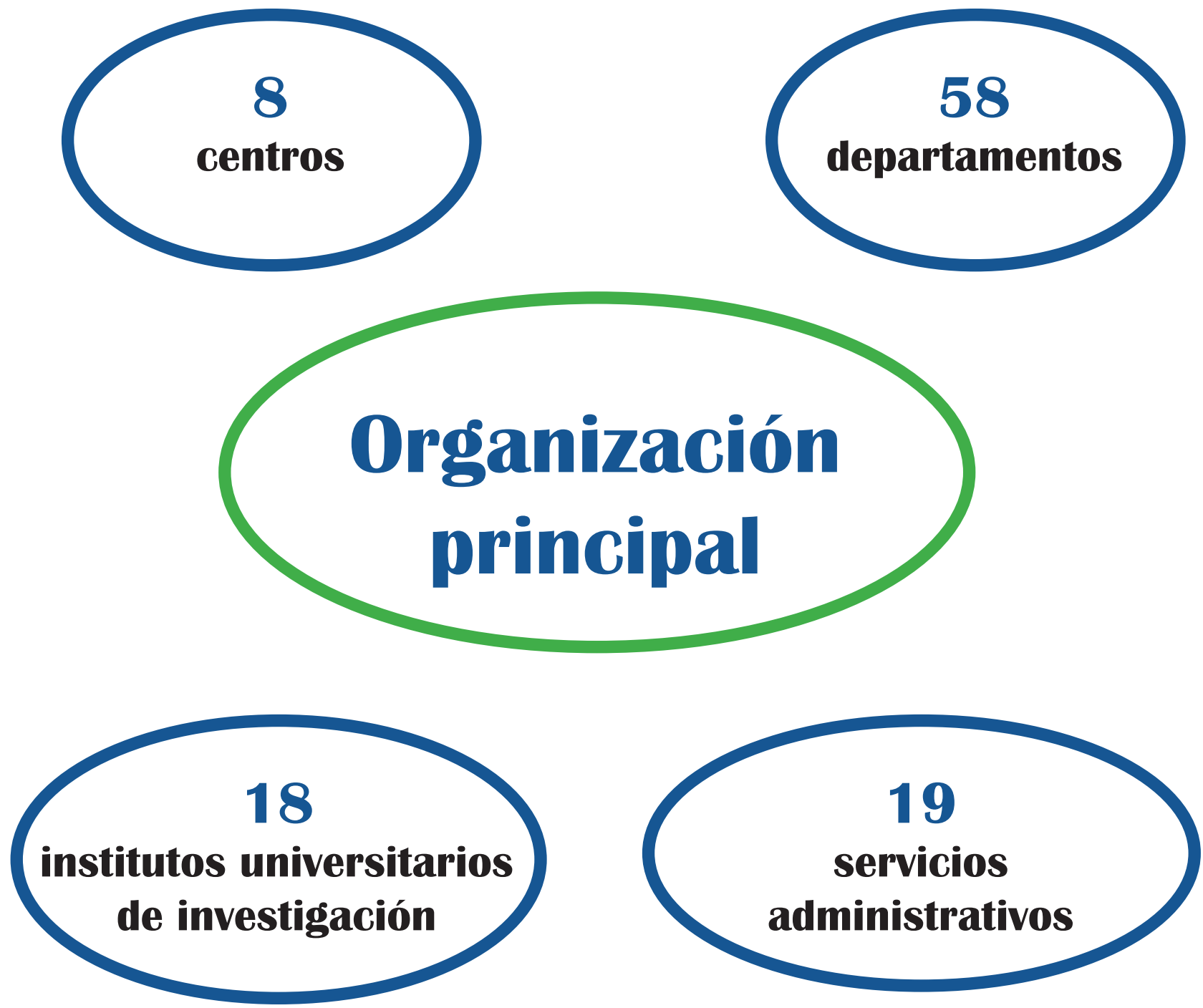


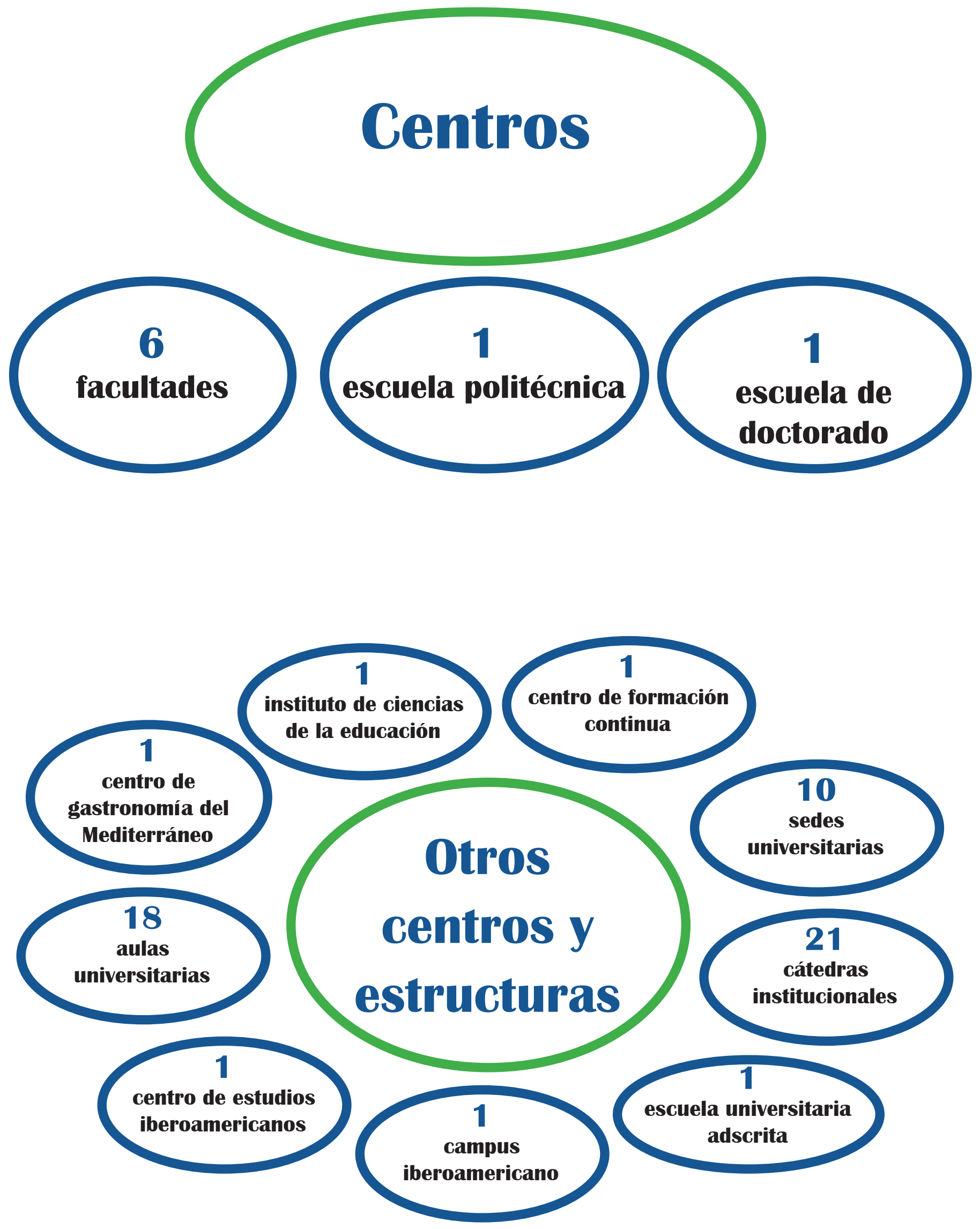




\subsection{Implantación territorial}

\section{A 31 de diciembre de 2018}

Fuente: Secretariado de Sedes UA.

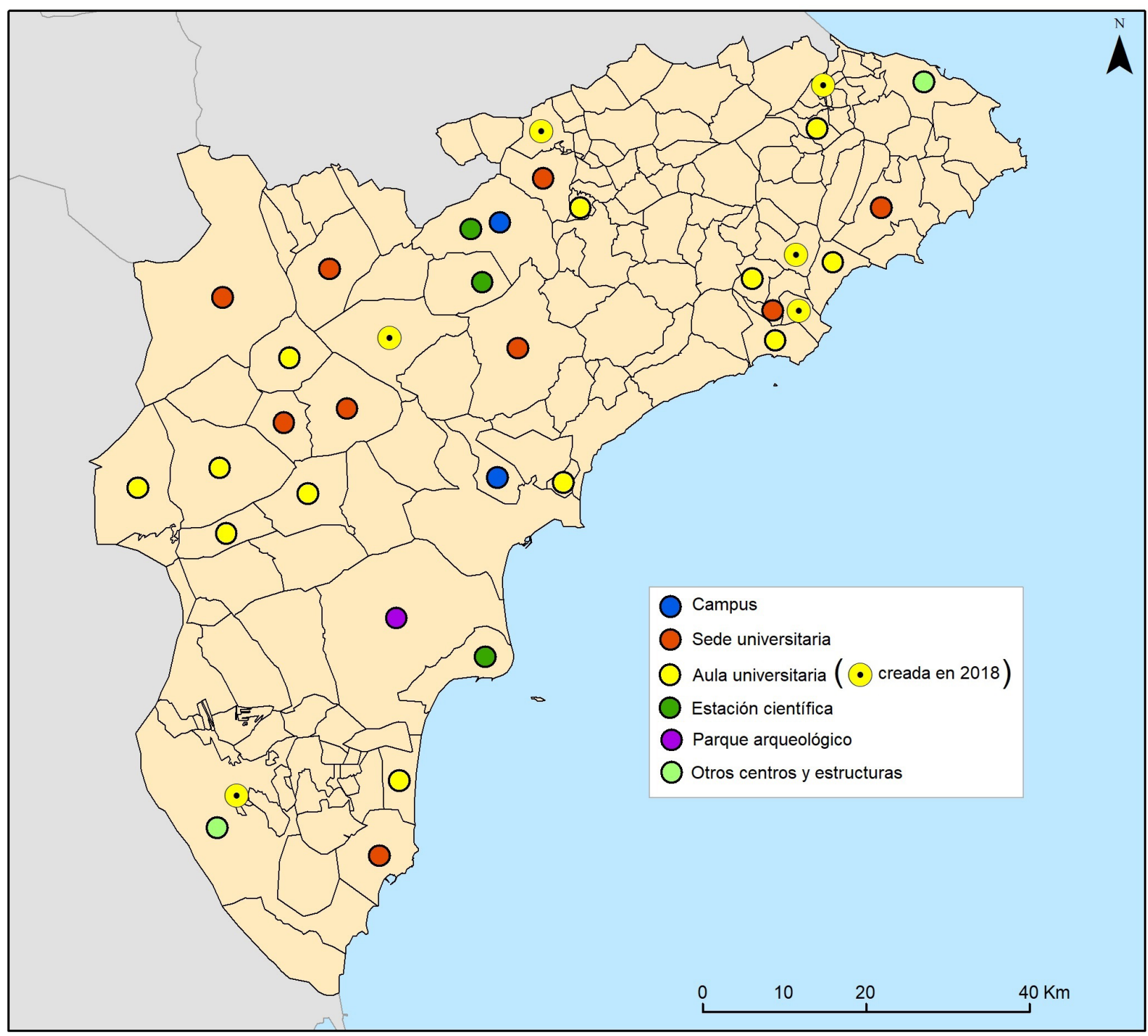

En la provincia de Alicante la UA tiene presencia en 34 municipios 


\subsection{Aulas y laboratorios}

A 31 de diciembre de 2018

Fuente: Sistema de Información de la Universidad de Alicante (SIUA).
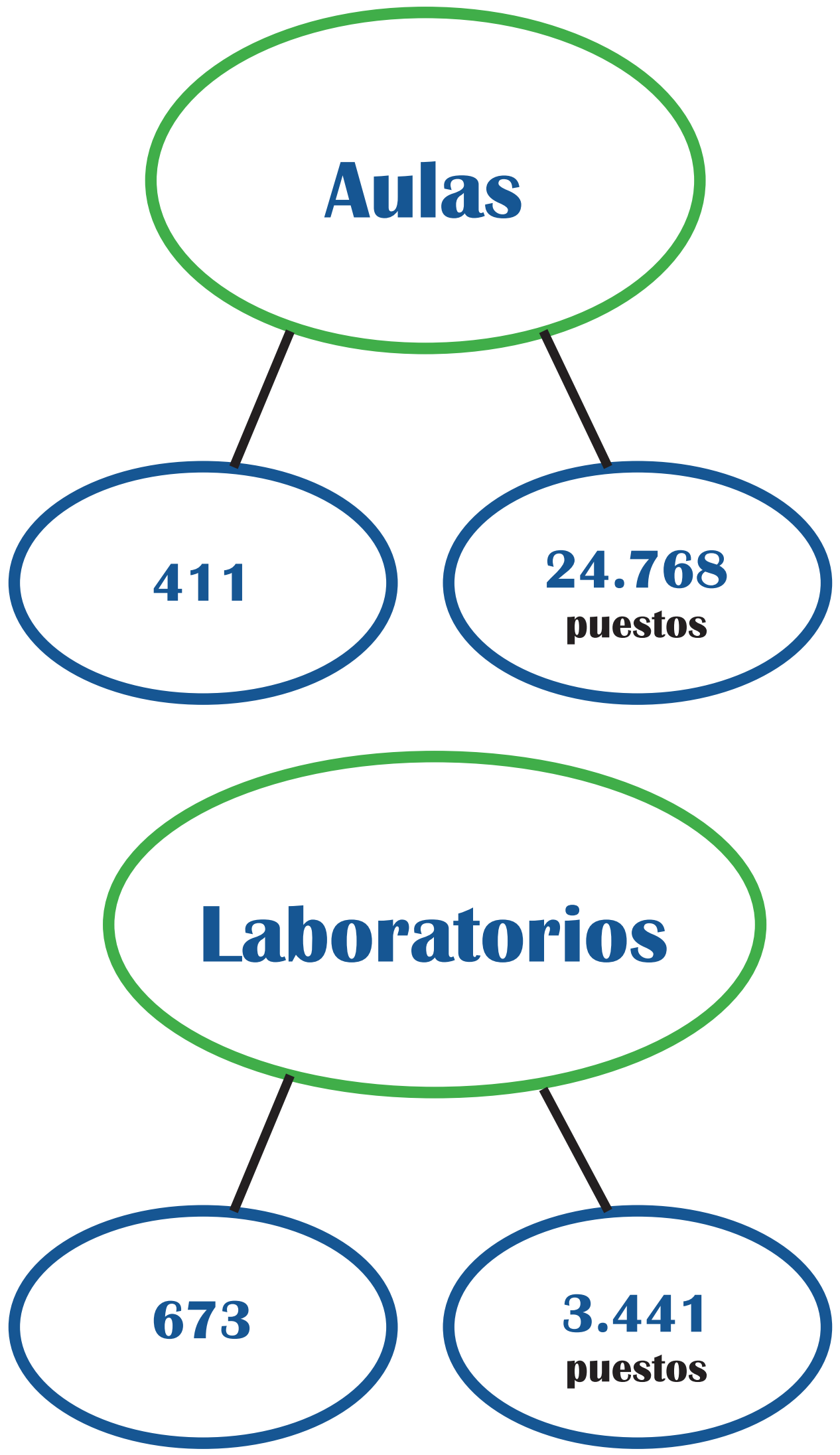
Universidad de Alicante

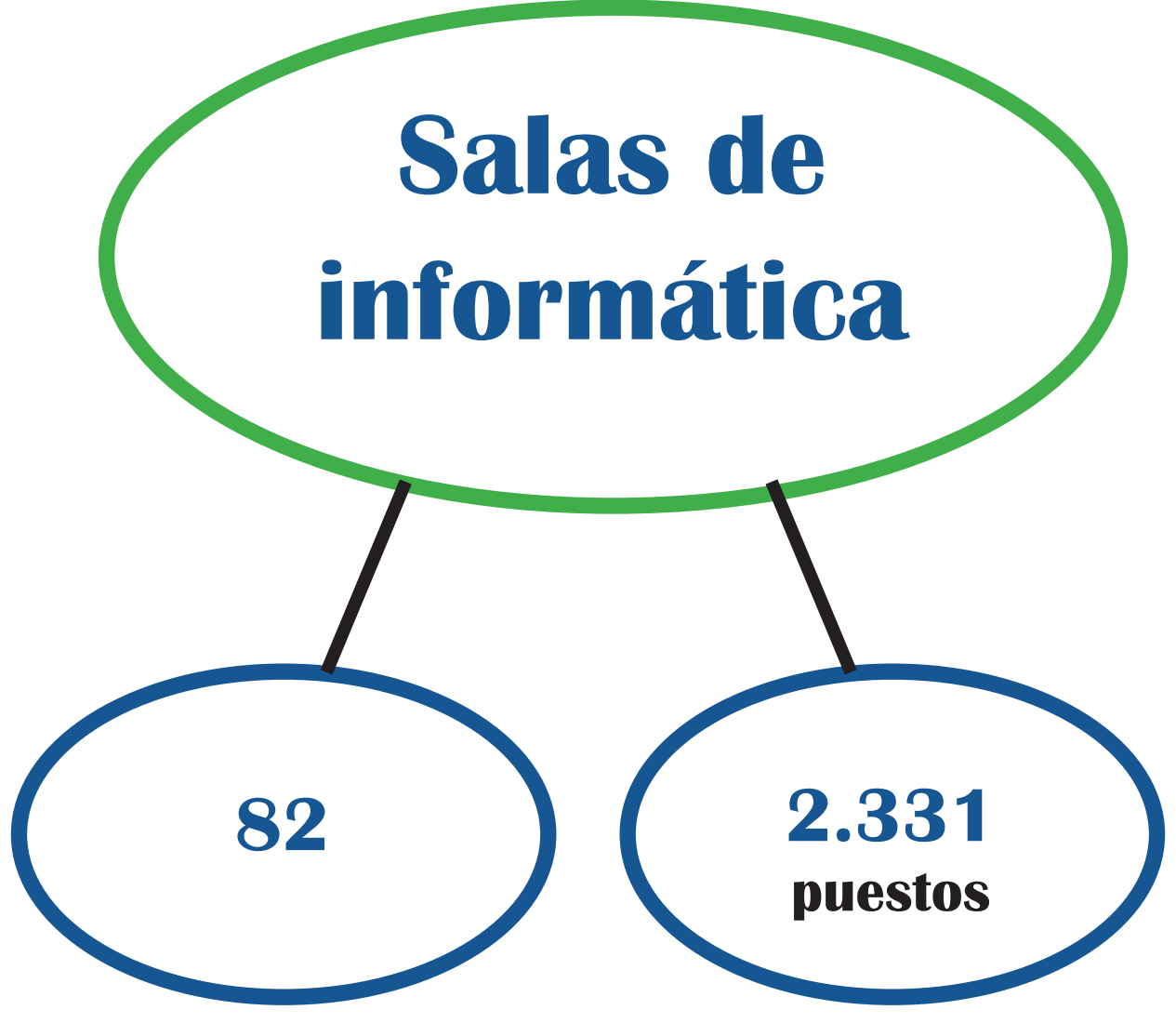




\subsection{Bibliotecas y recursos bibliográficos}

A 31 de diciembre de 2018

Fuente: Sistema de Información de la Universidad de Alicante (SIUA).

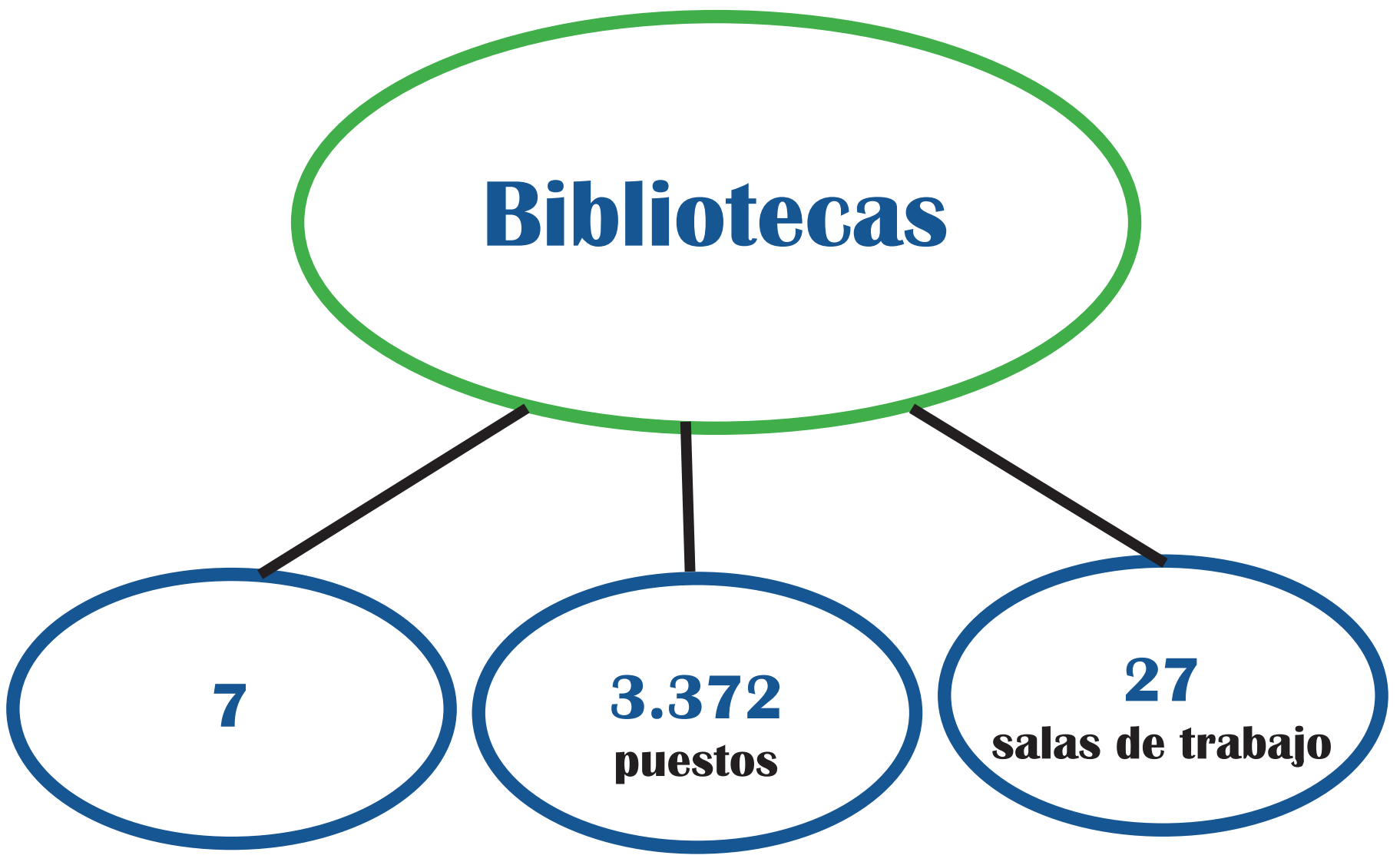



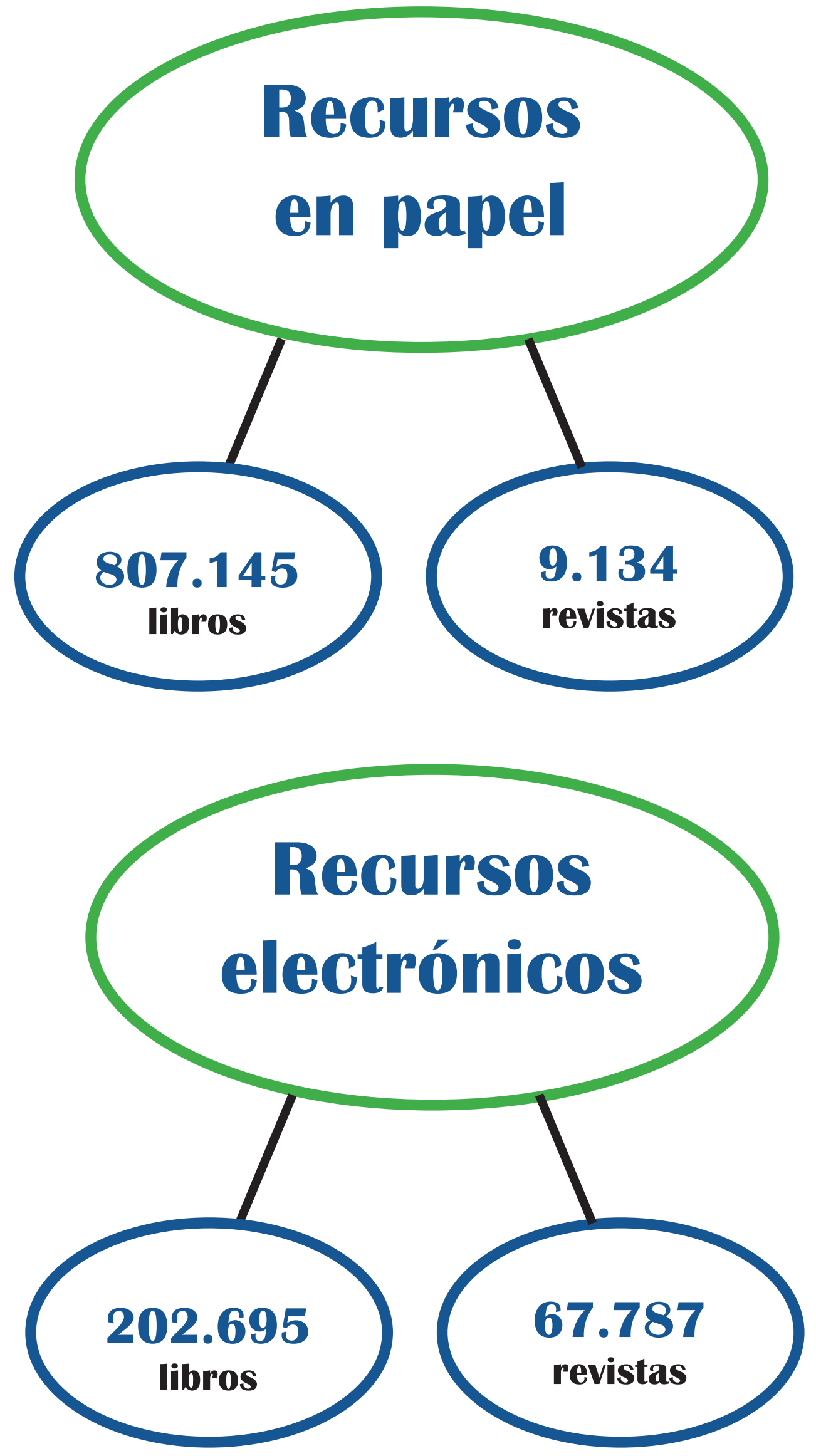
2

Comunidad universitaria 


\subsection{Estudiantes}

Curso académico 2018/2019

Fuentes: Sistema de Información de la Universidad de Alicante (SIUA) y Sistema de Información de las Universidades Valencianas Públicas (SIUVP).

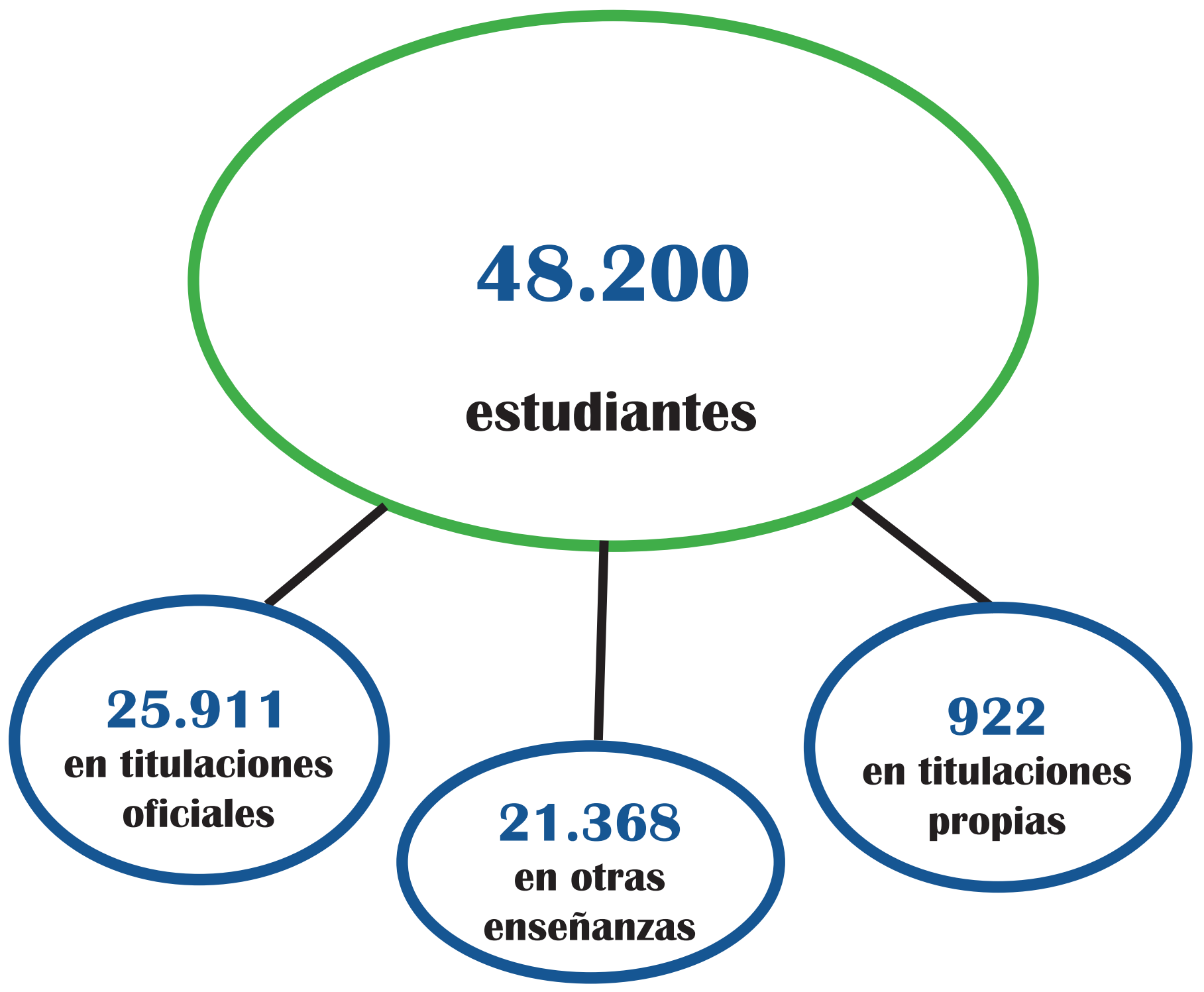




\section{Titulaciones oficiales}

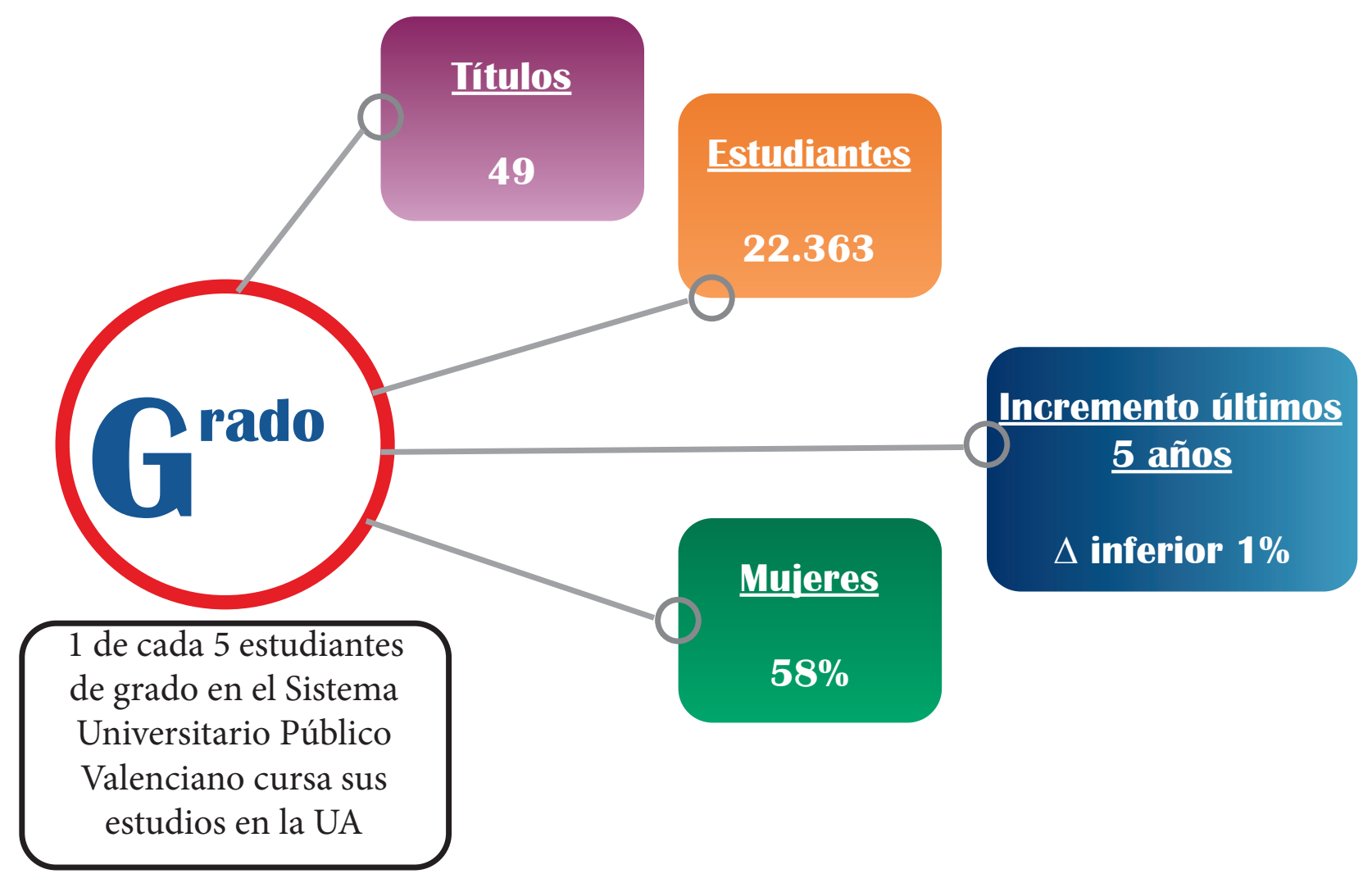

Distribución según rama de conocimiento y centro
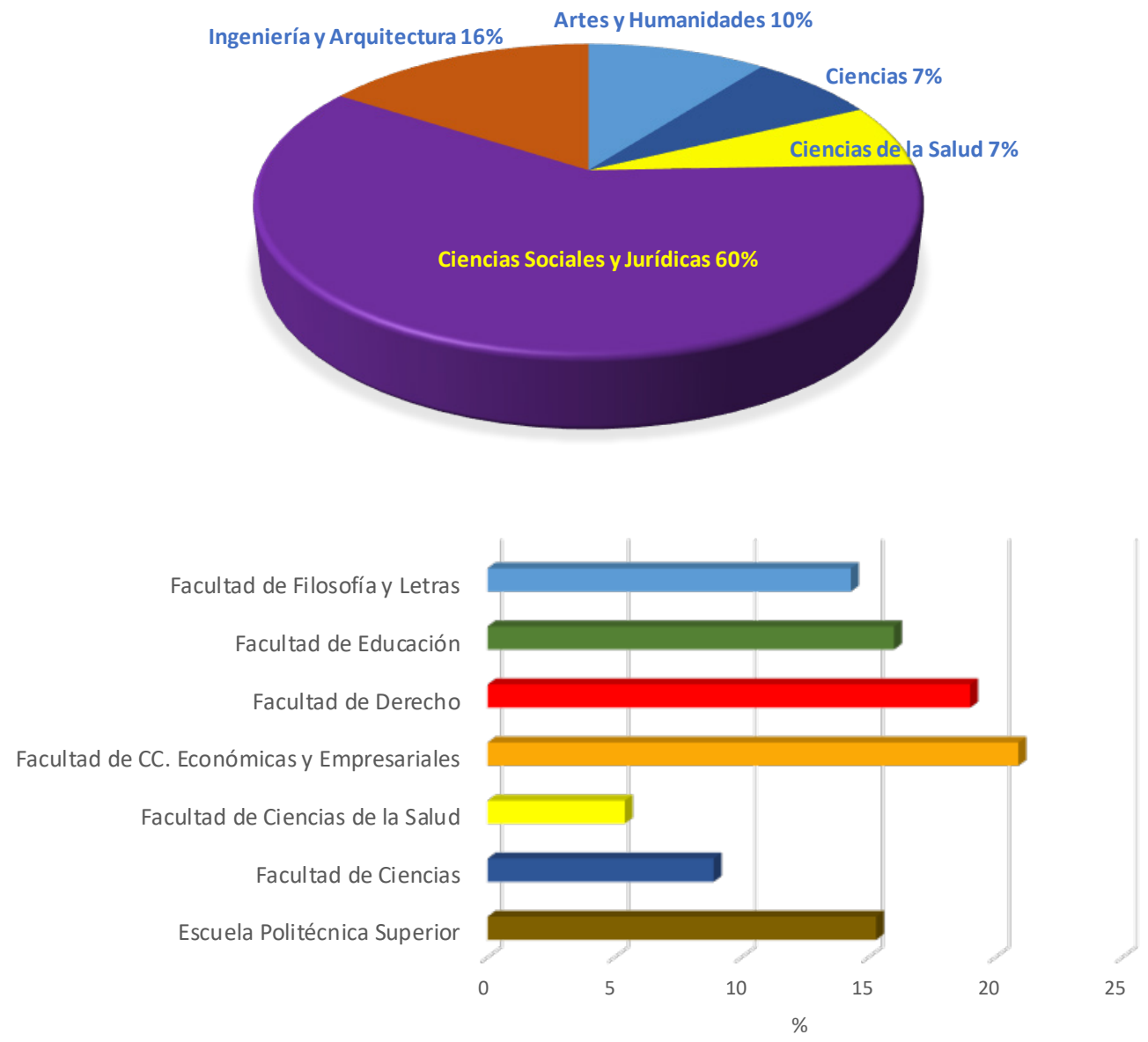


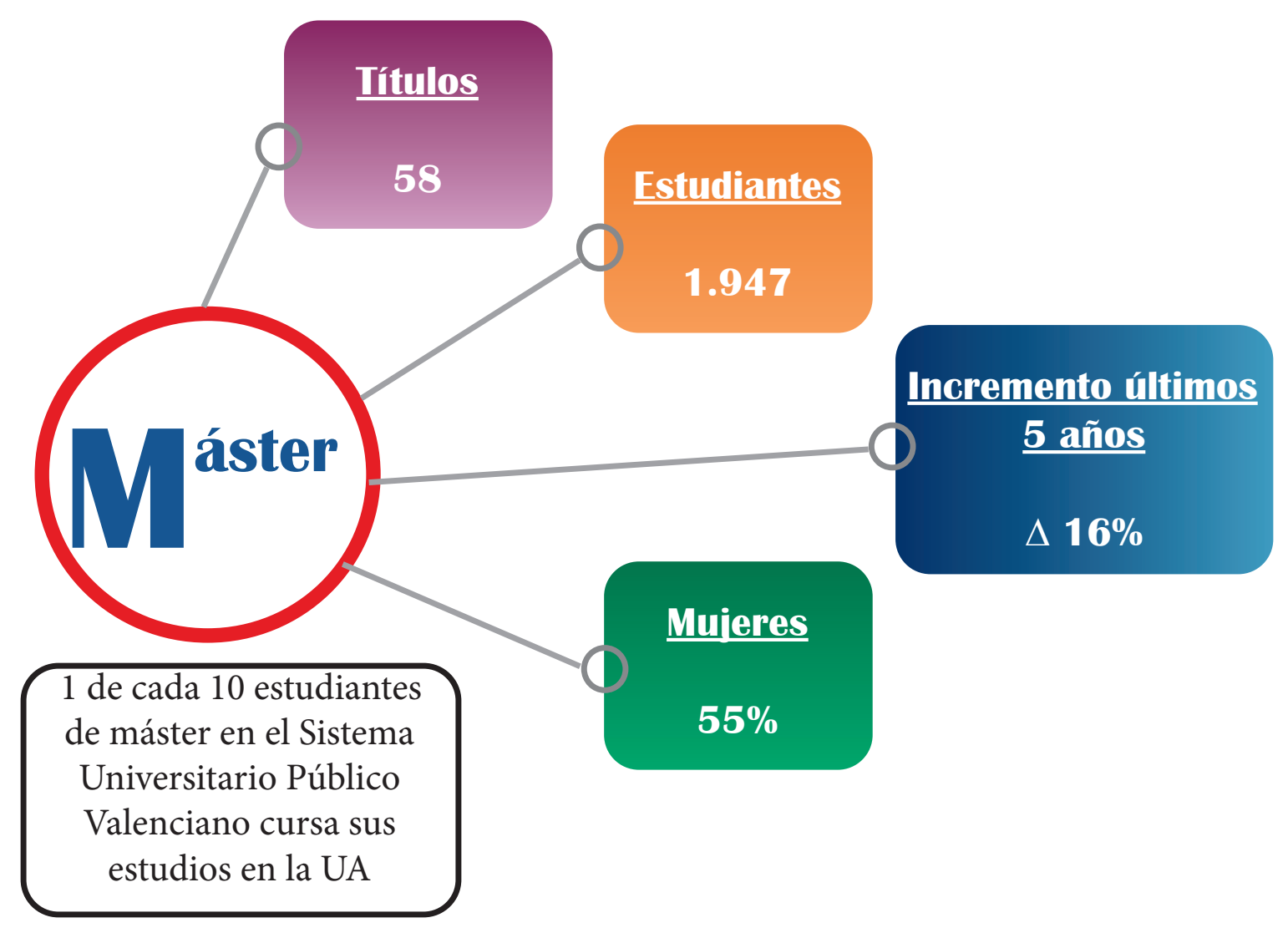

Distribución según rama de conocimiento y centro
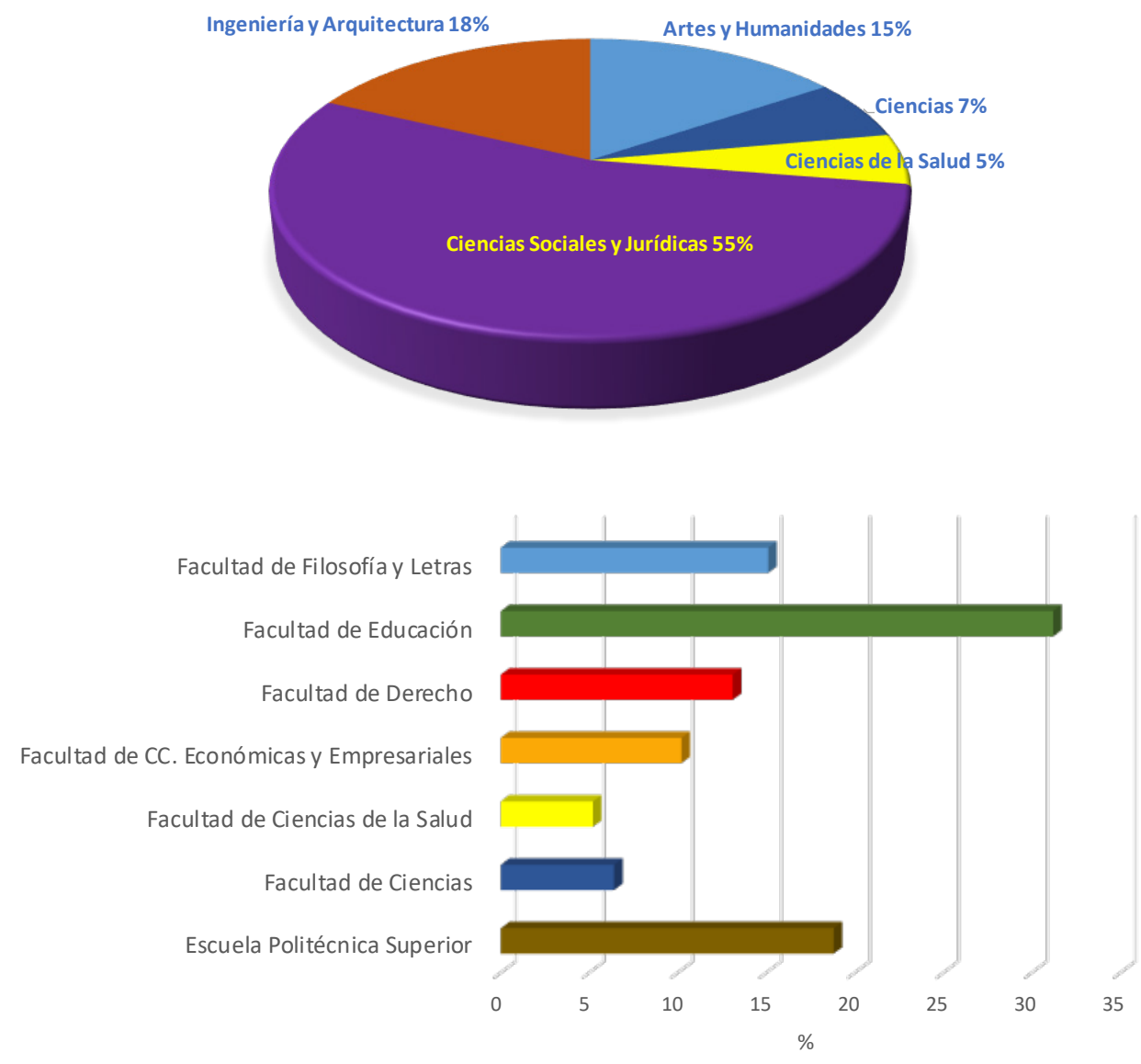


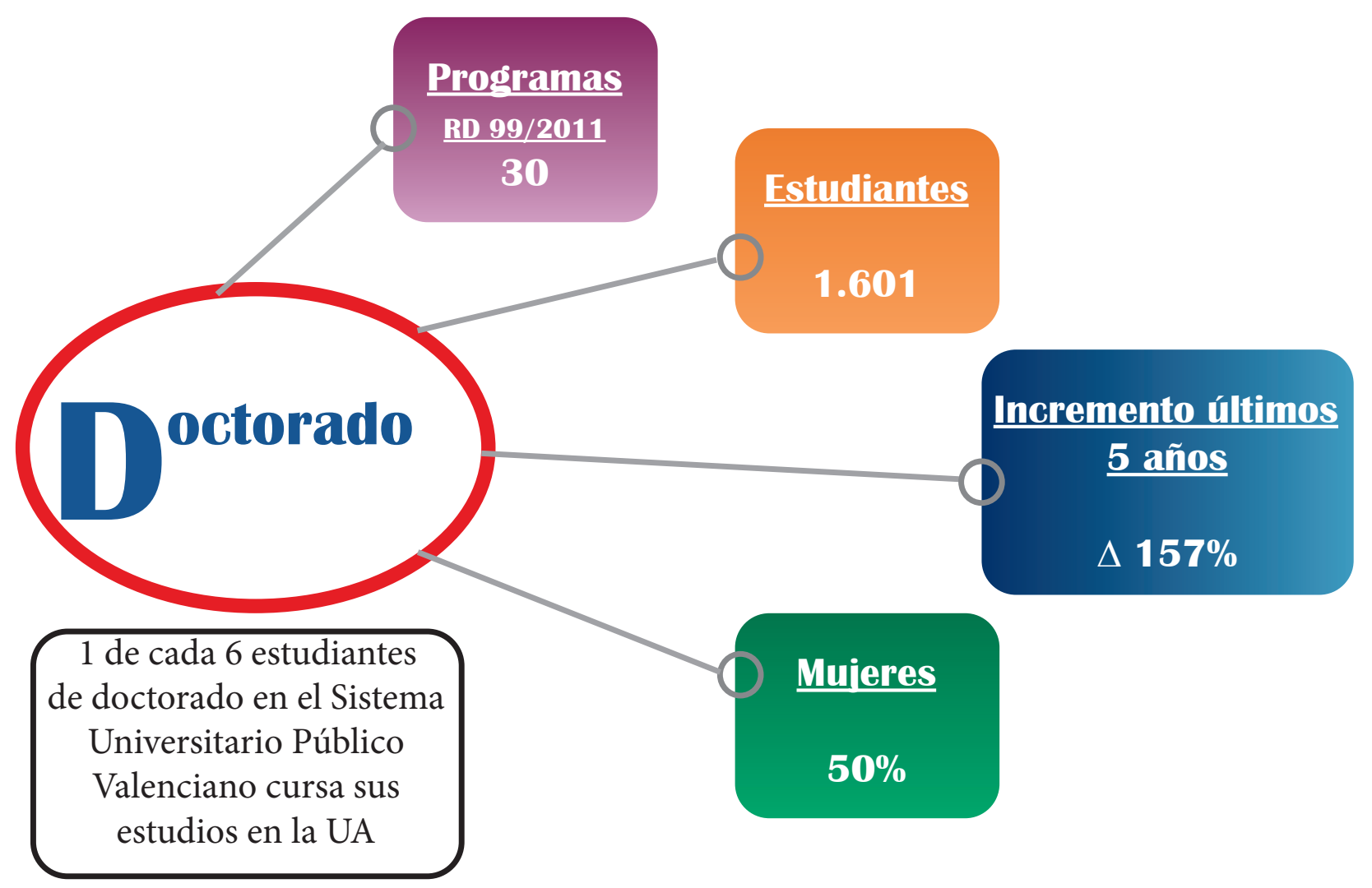

Distribución según rama de conocimiento

Ingeniería y Arquitectura 13\%

Artes y Humanidades $24 \%$

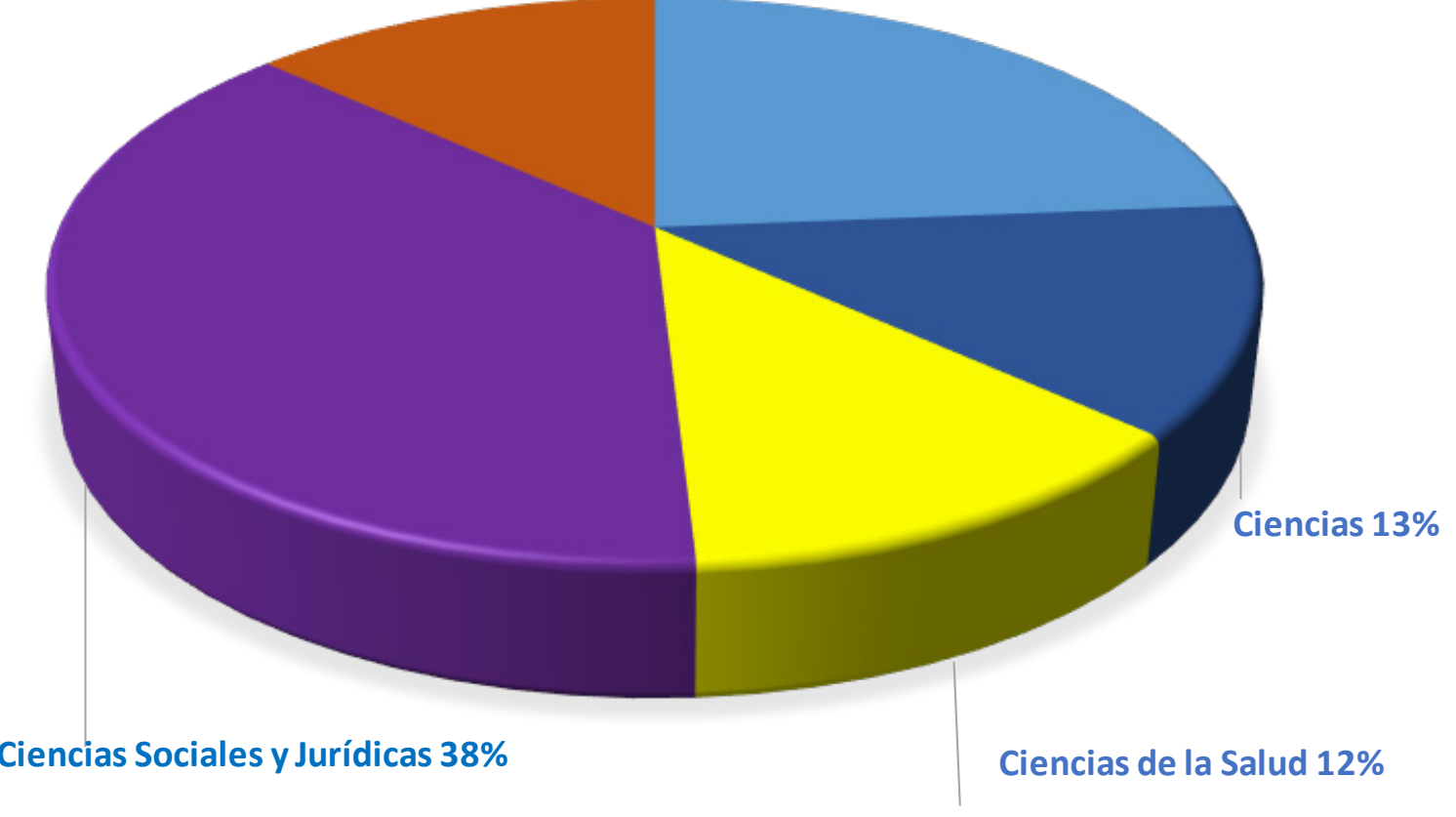




\section{Titulaciones propias}
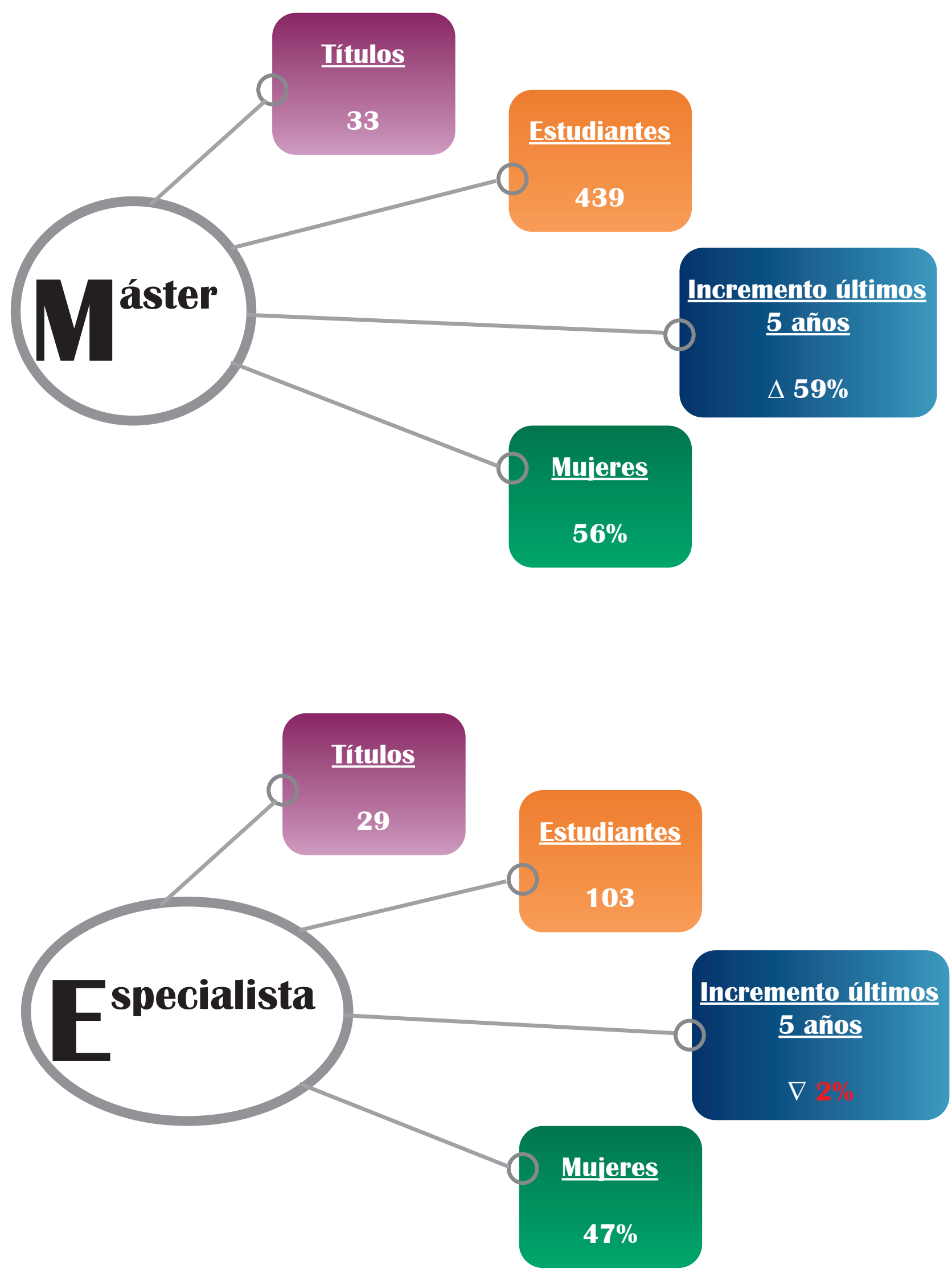


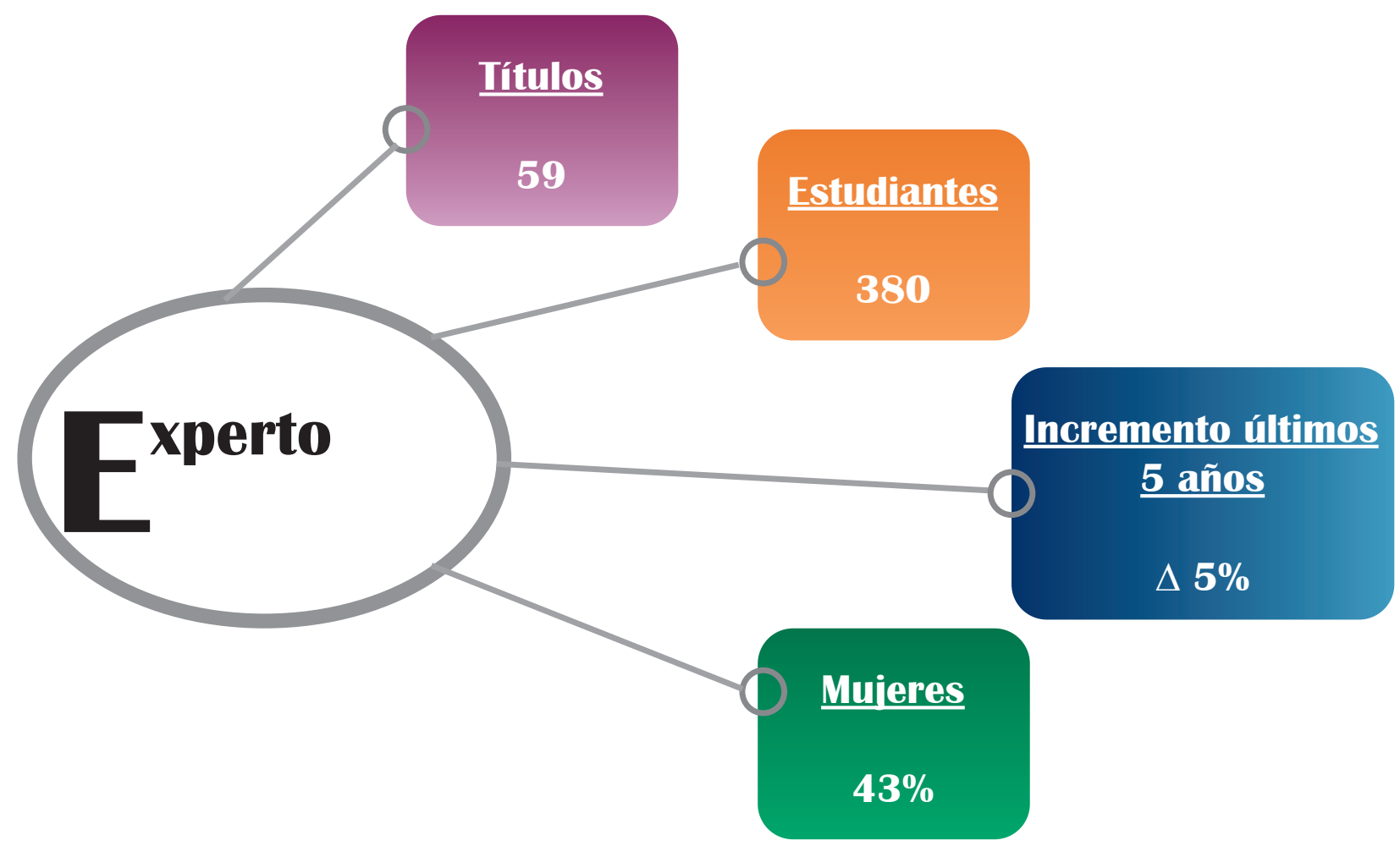

Otras enseñanzas

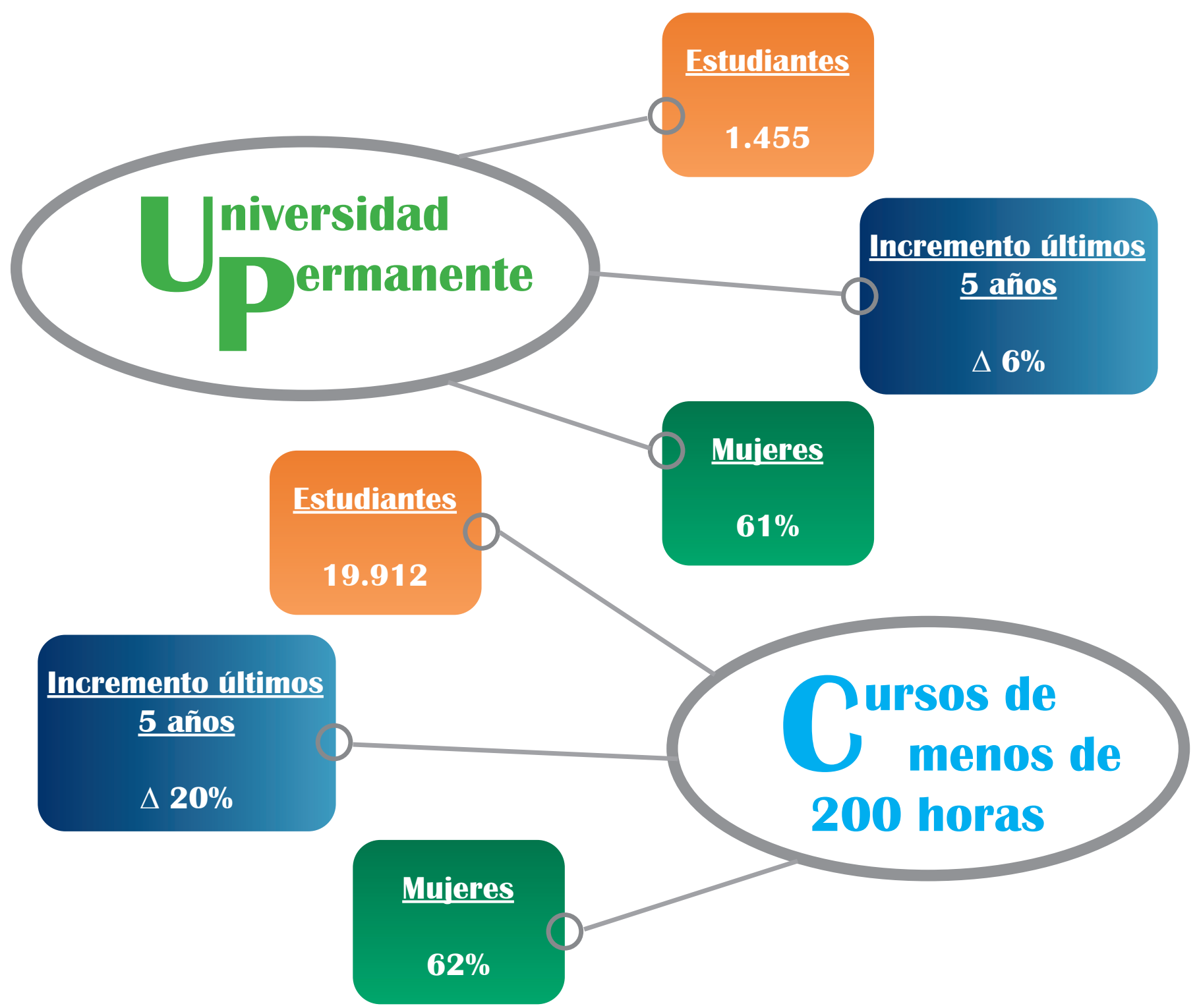




\subsection{Personal docente e investigador}

A 31 de diciembre de 2018

Fuentes: Servicio de Gestión de Personal UA y Sistema de Información de las Universidades Valencianas Públicas (siUVP).

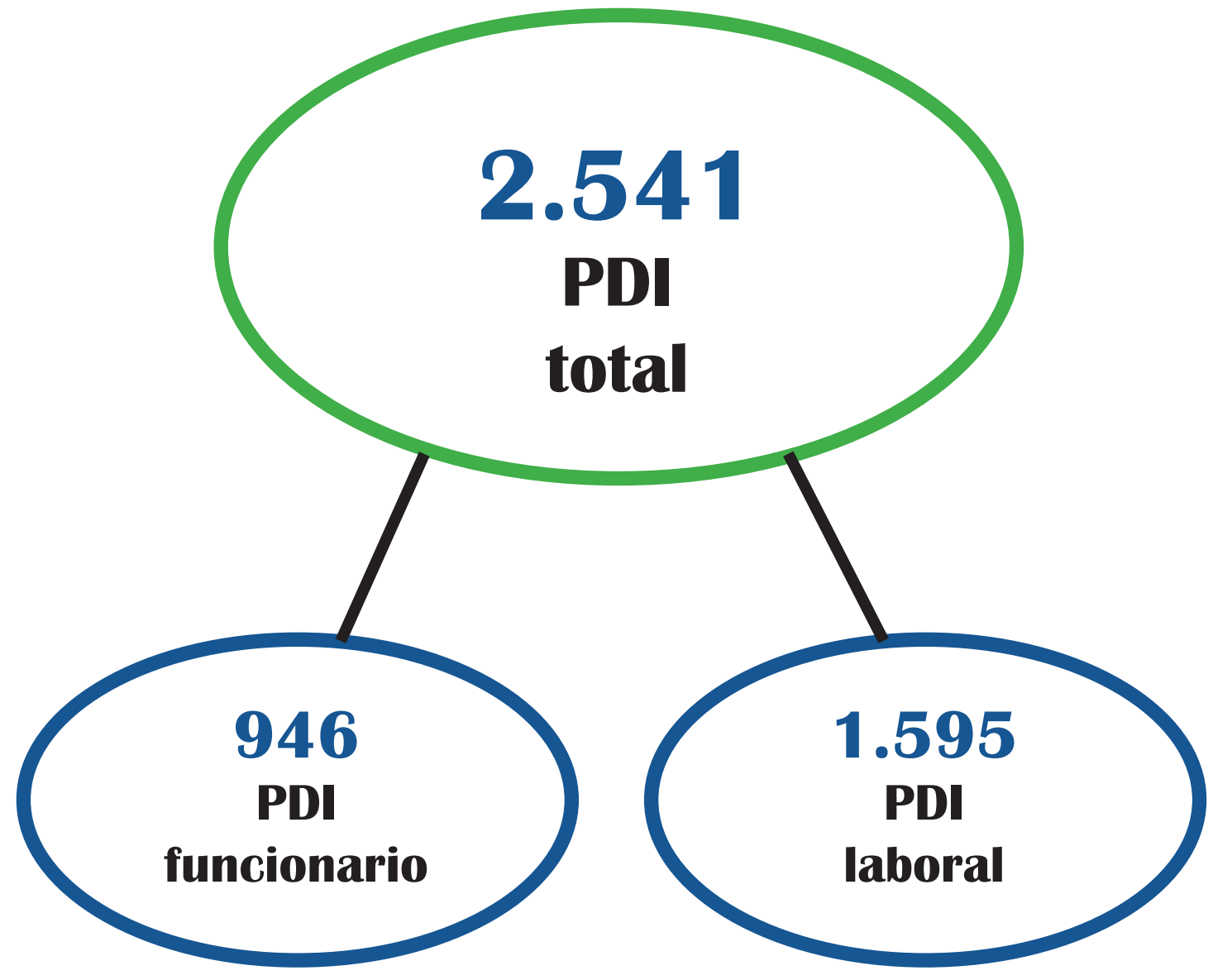

Estructura por edad y sexo

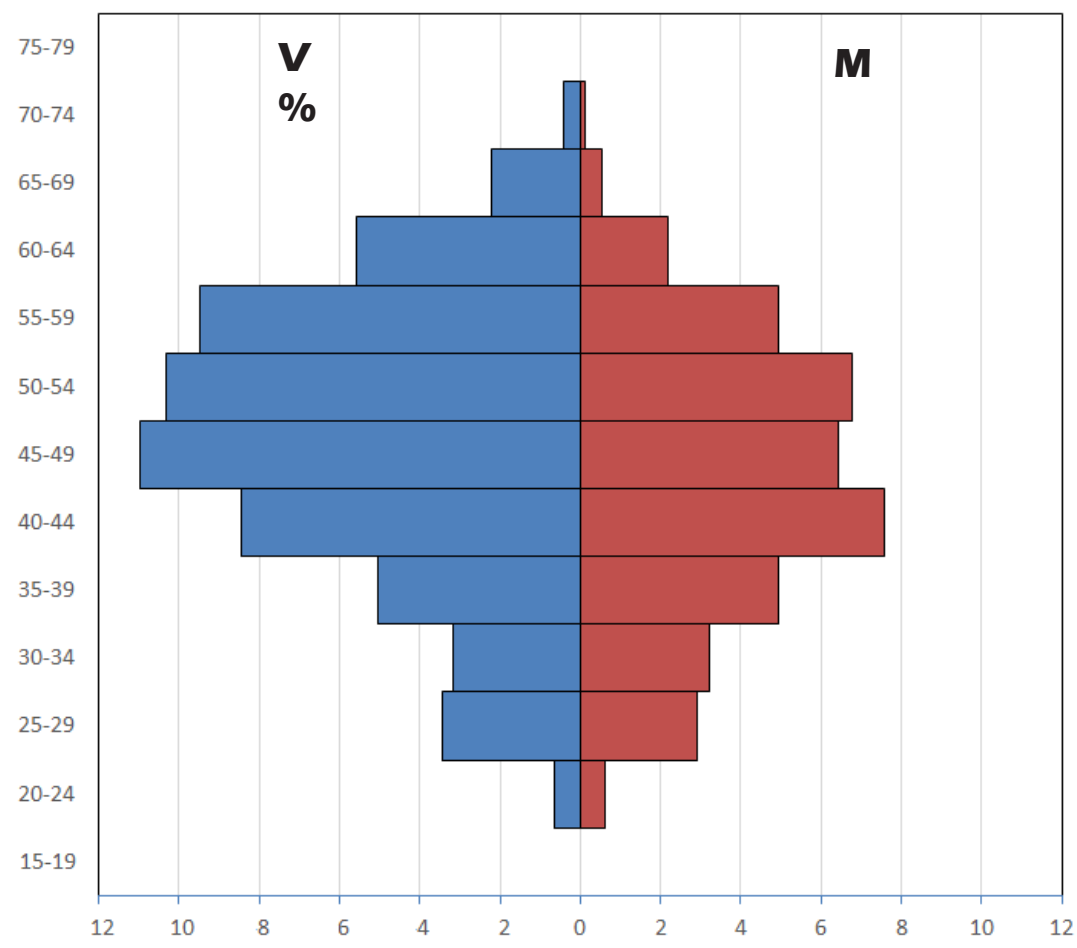




\section{Cuerpos docentes universitarios}
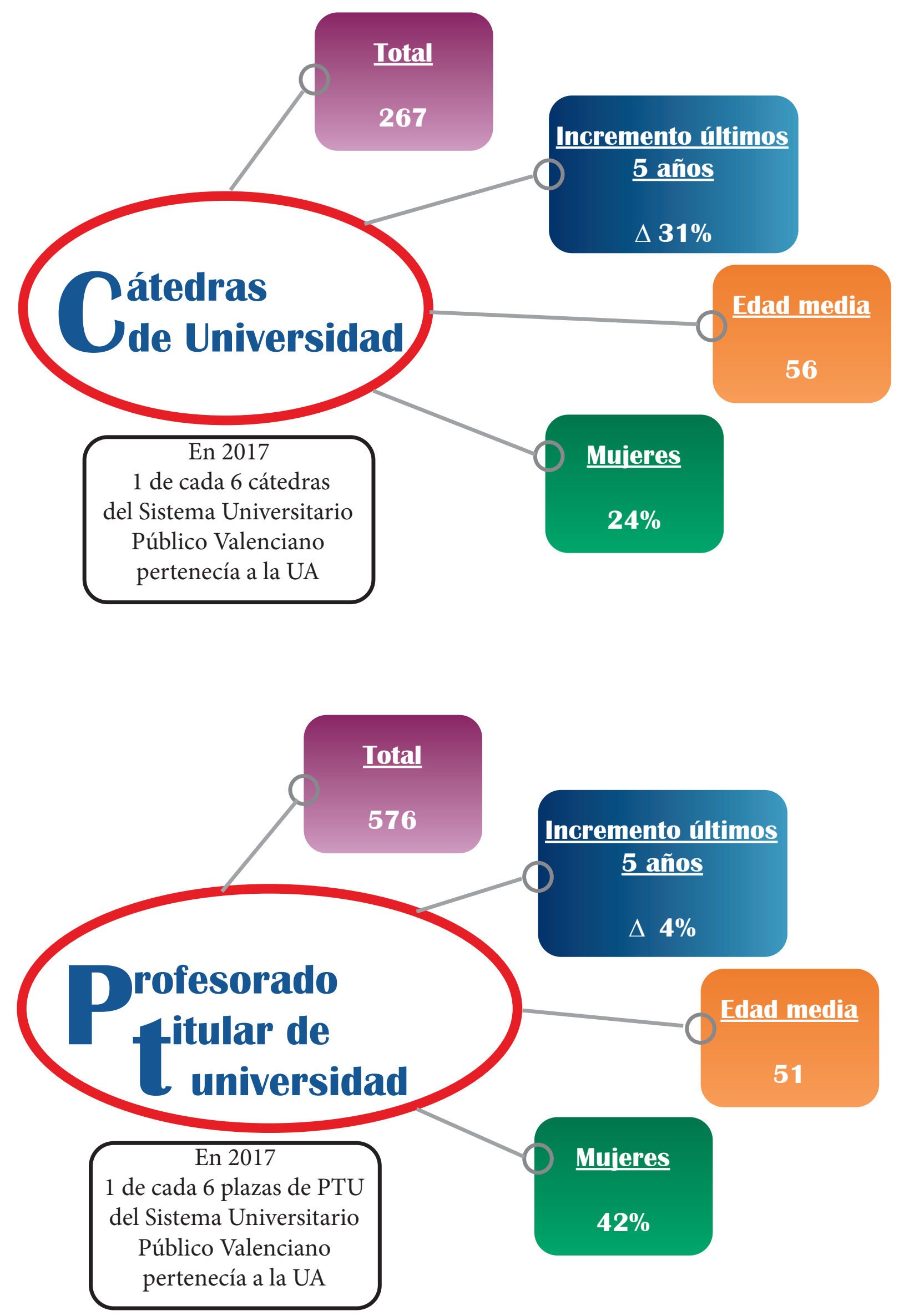

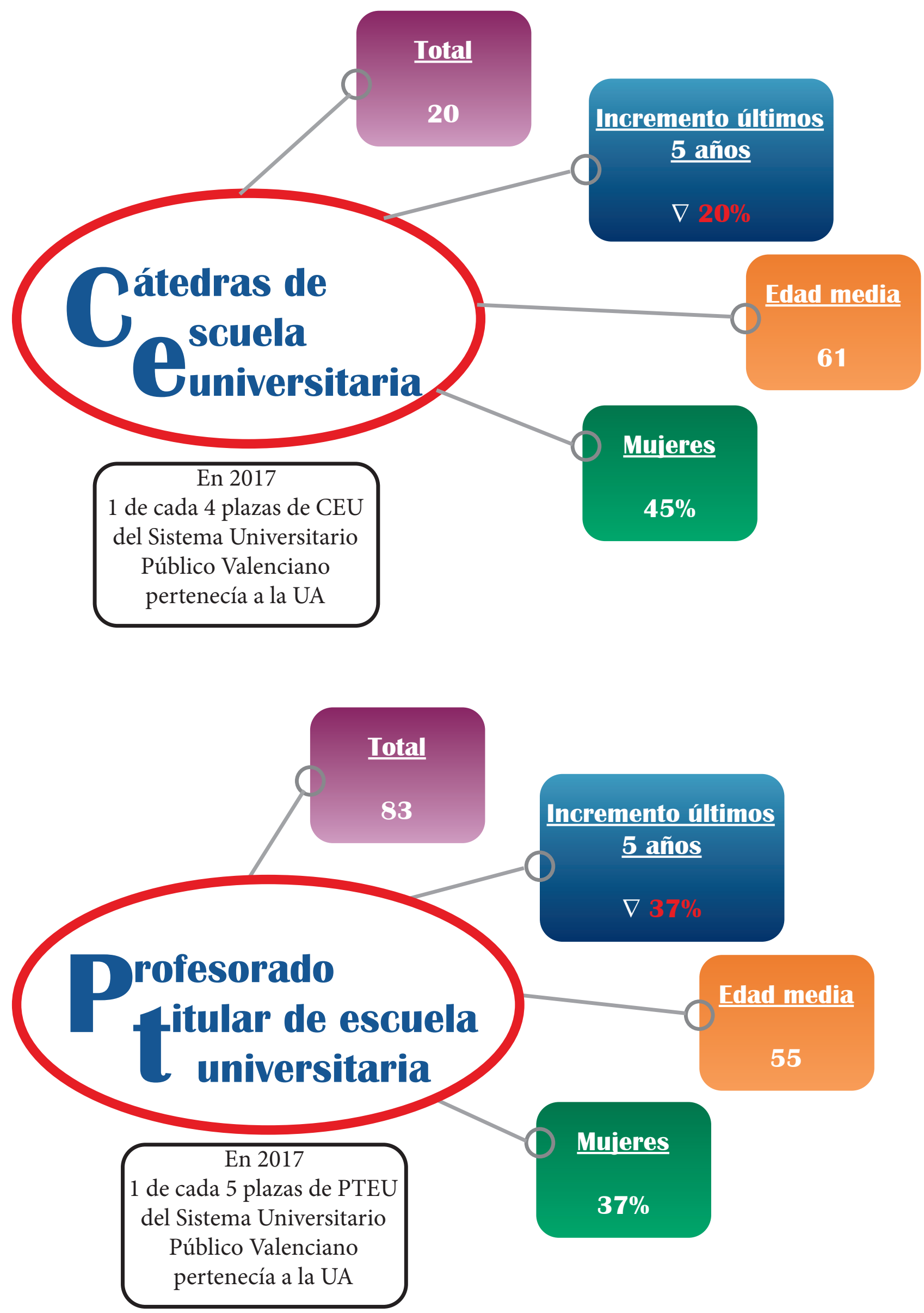


\section{Personal docente e investigador laboral}
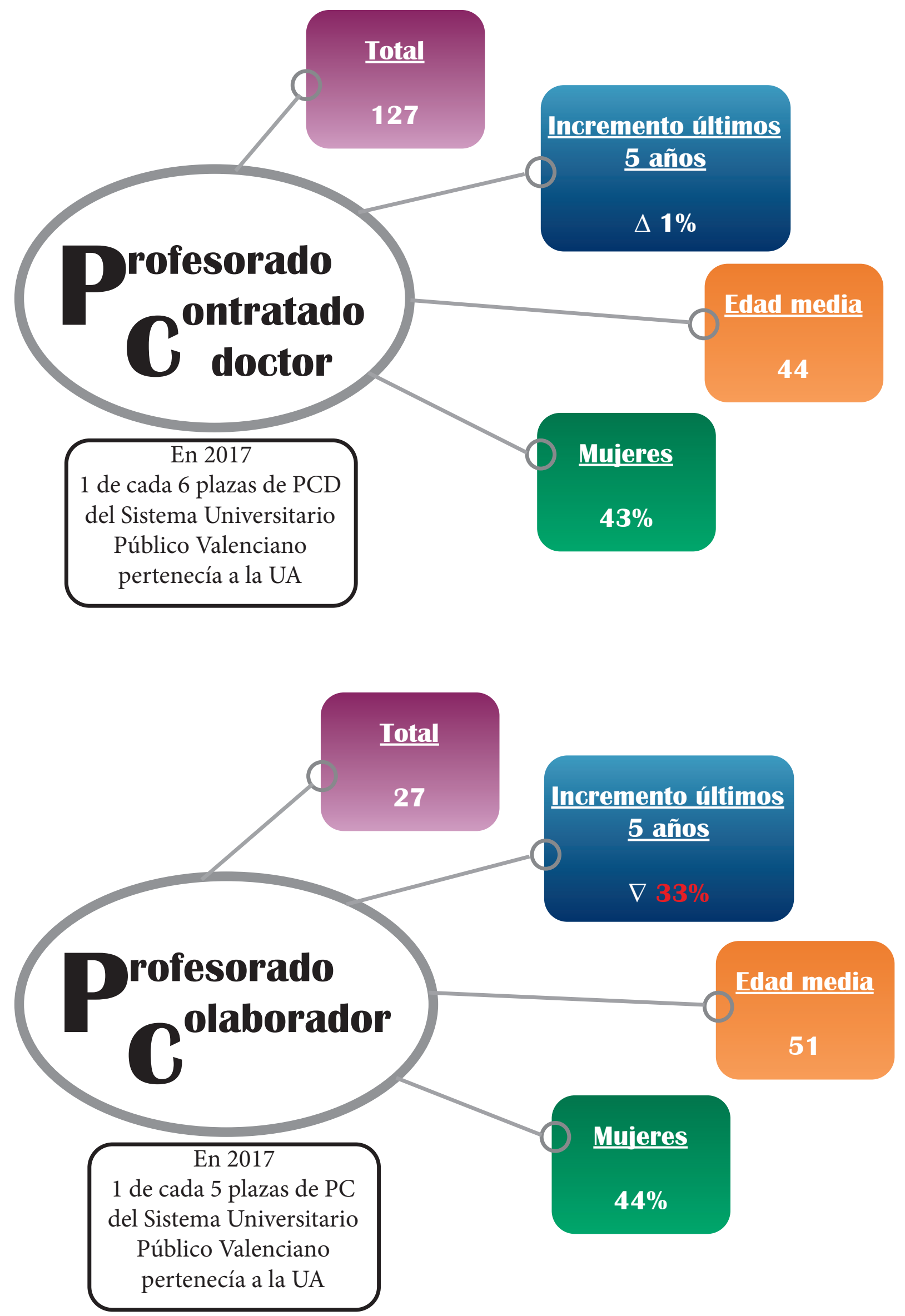

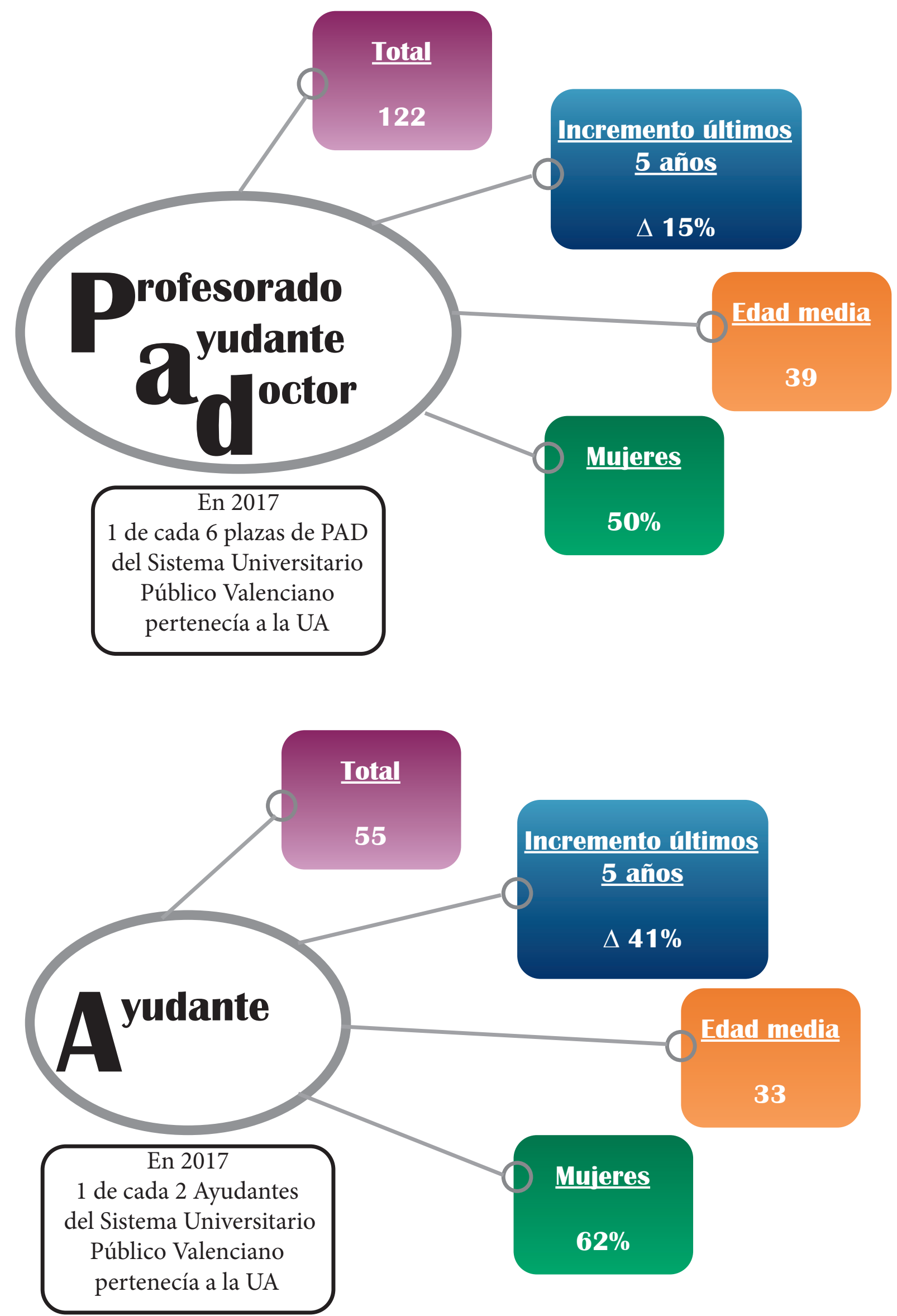

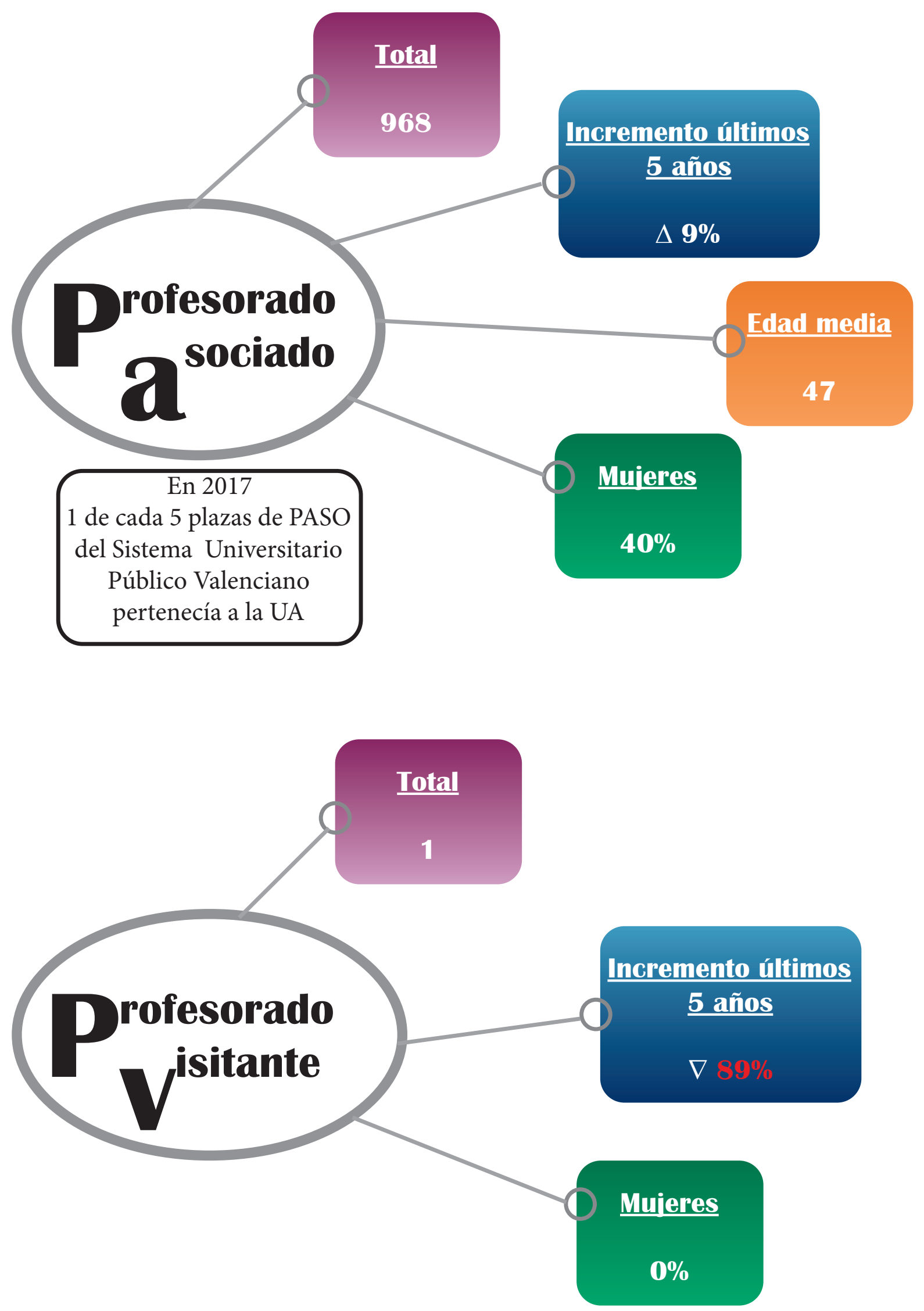

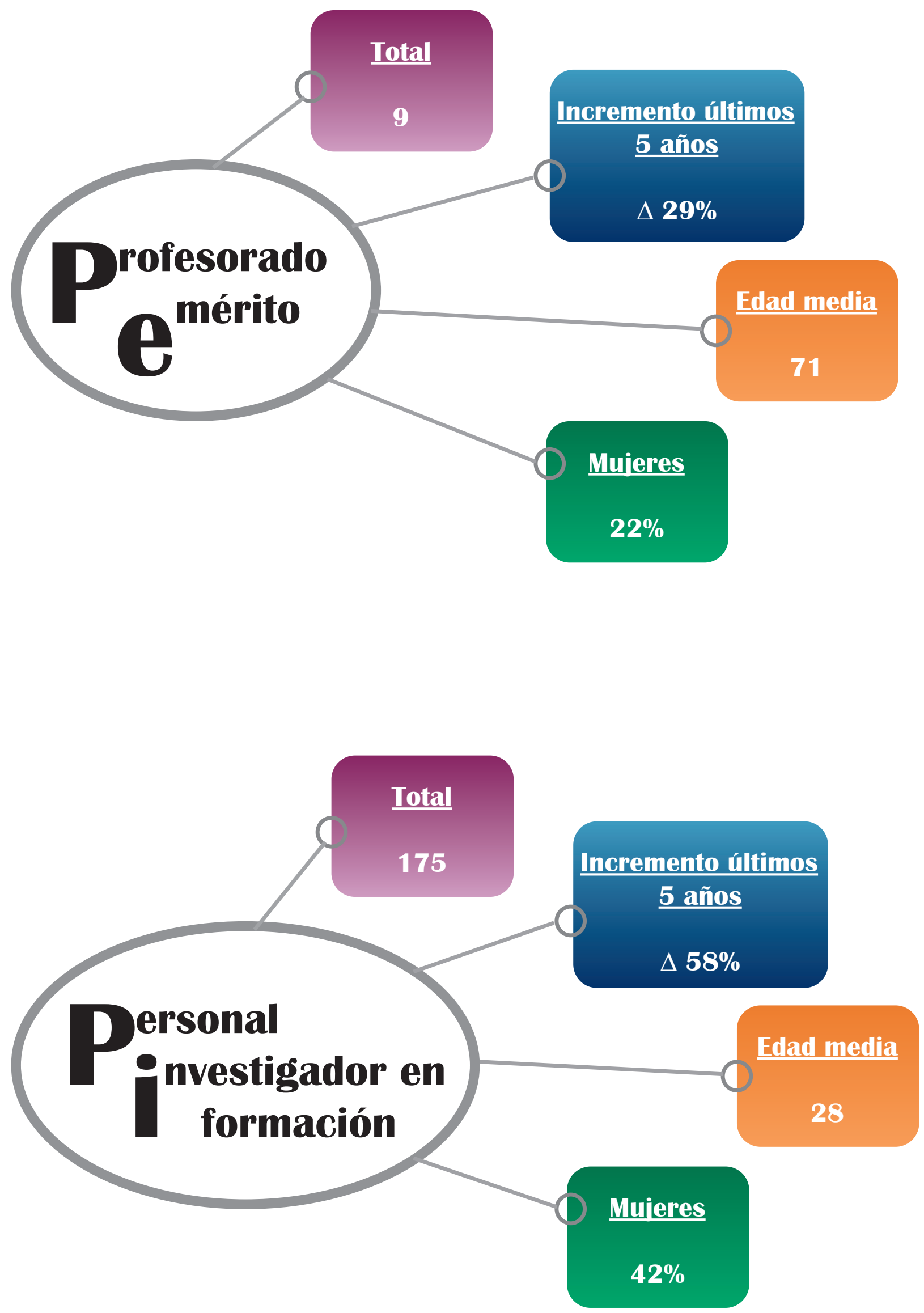


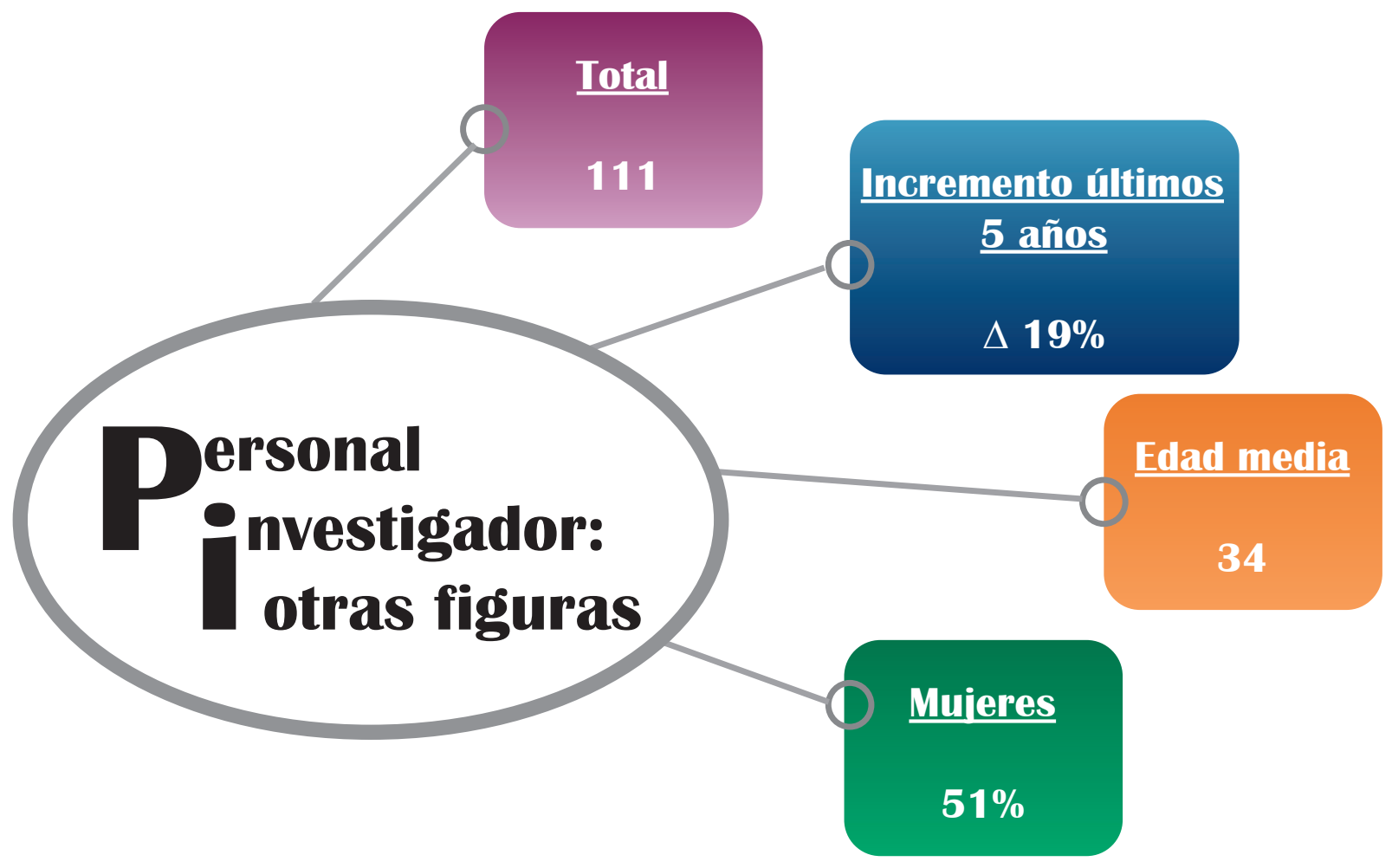




\subsection{Personal de administración y servicios}

\section{A 31 de diciembre de 2018}

Fuentes: Servicio de Gestión de Personal UA y Sistema de Información de las Universidades Valencianas Públicas (SIUVP).

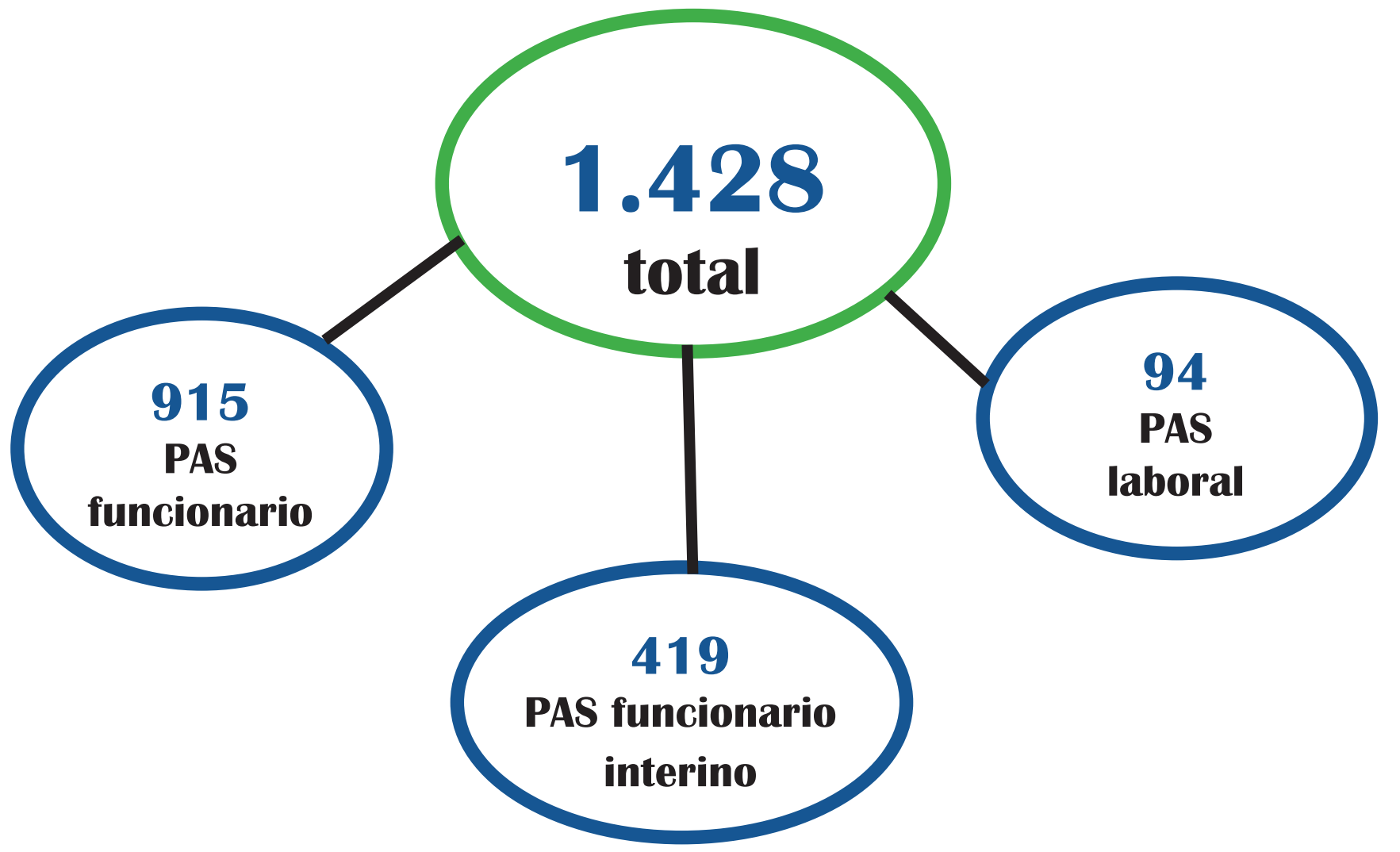

Estructura por edad y sexo

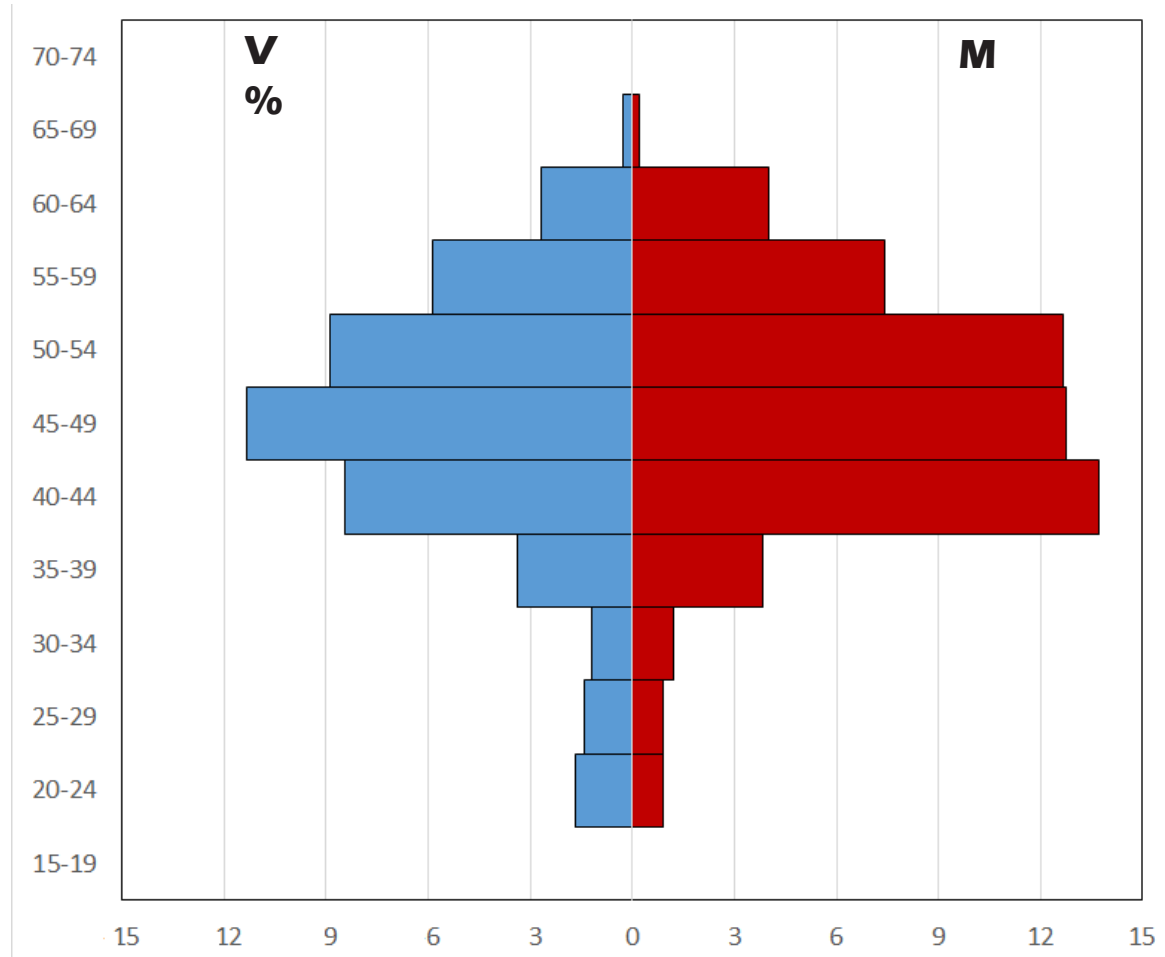



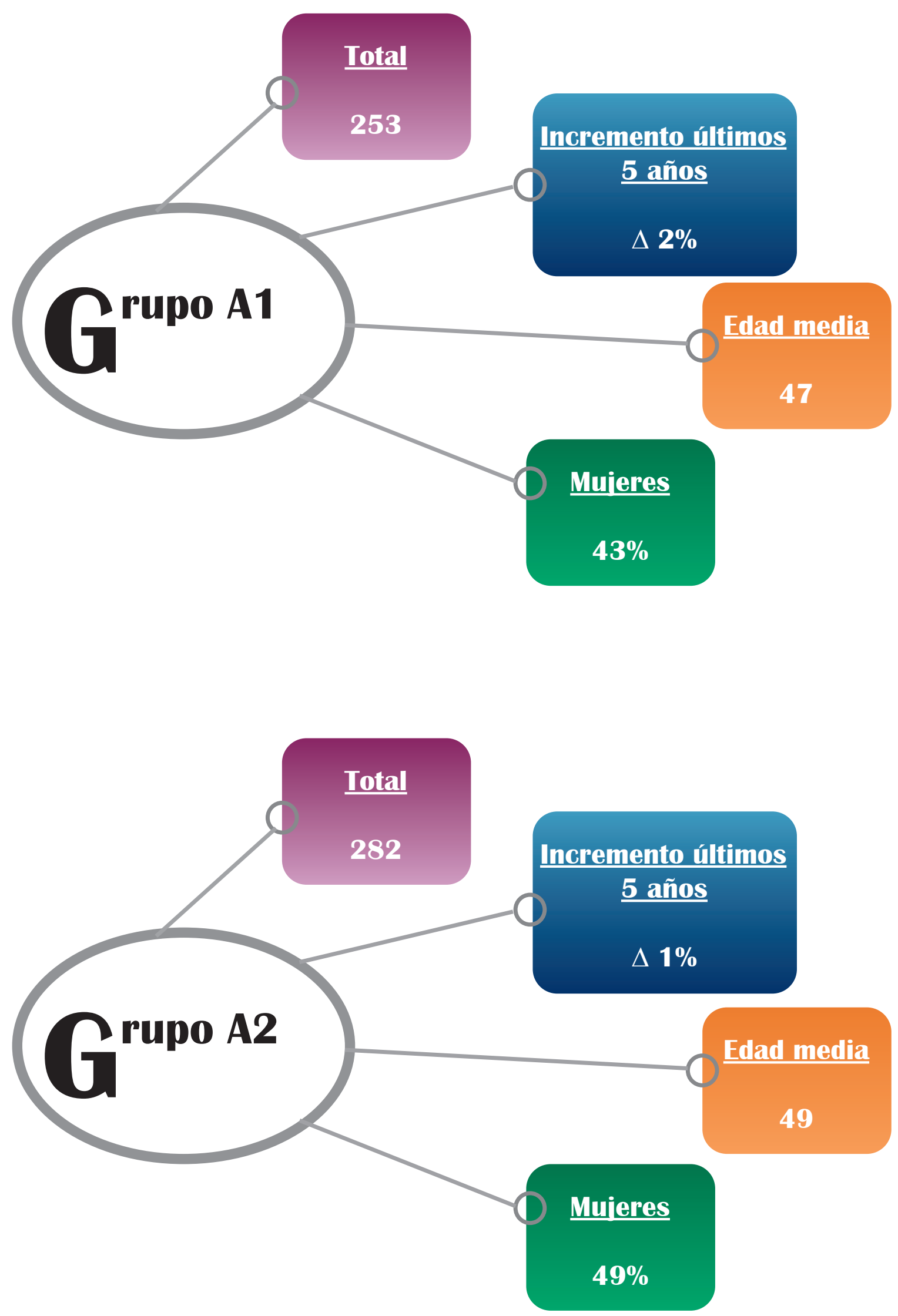

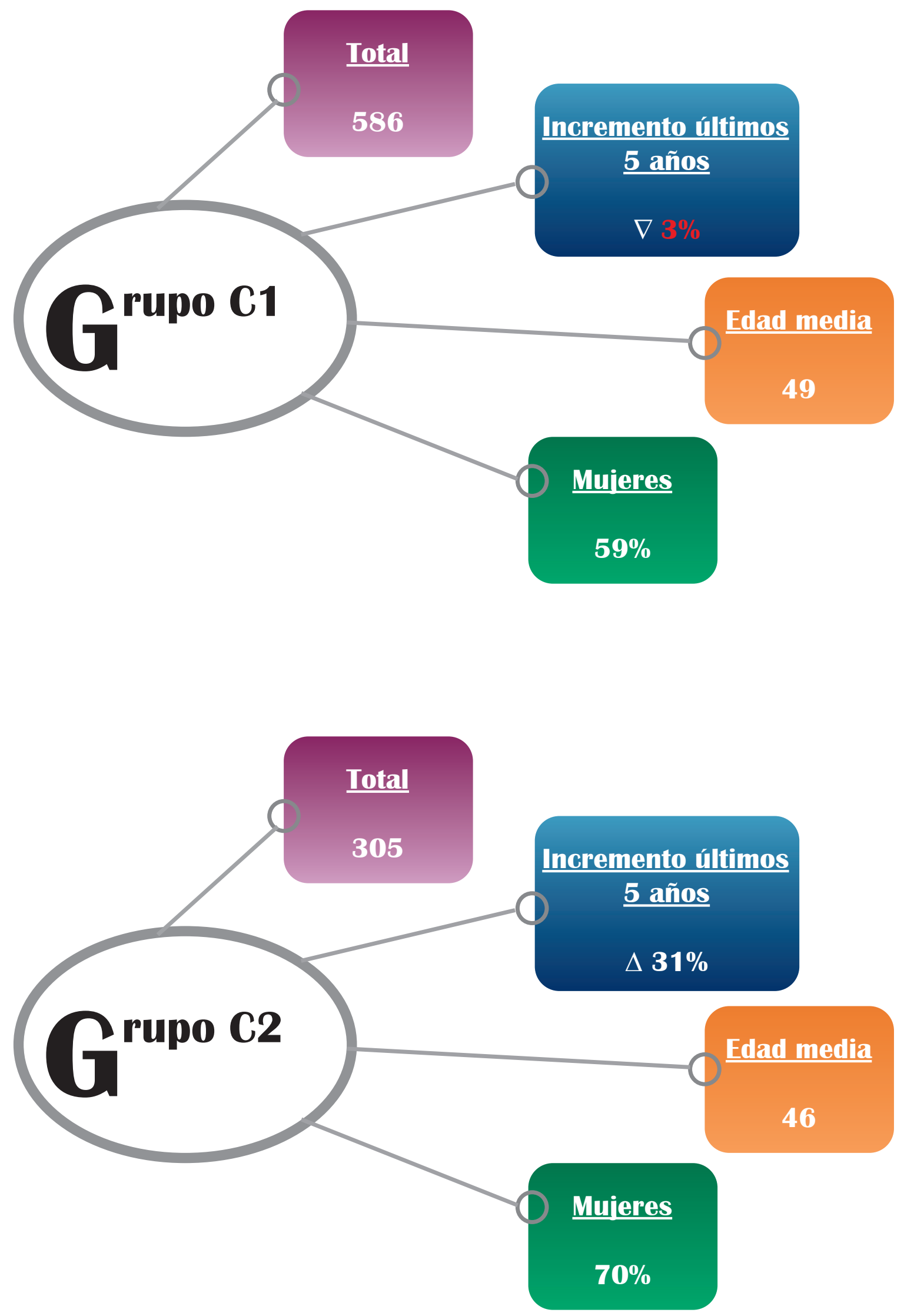


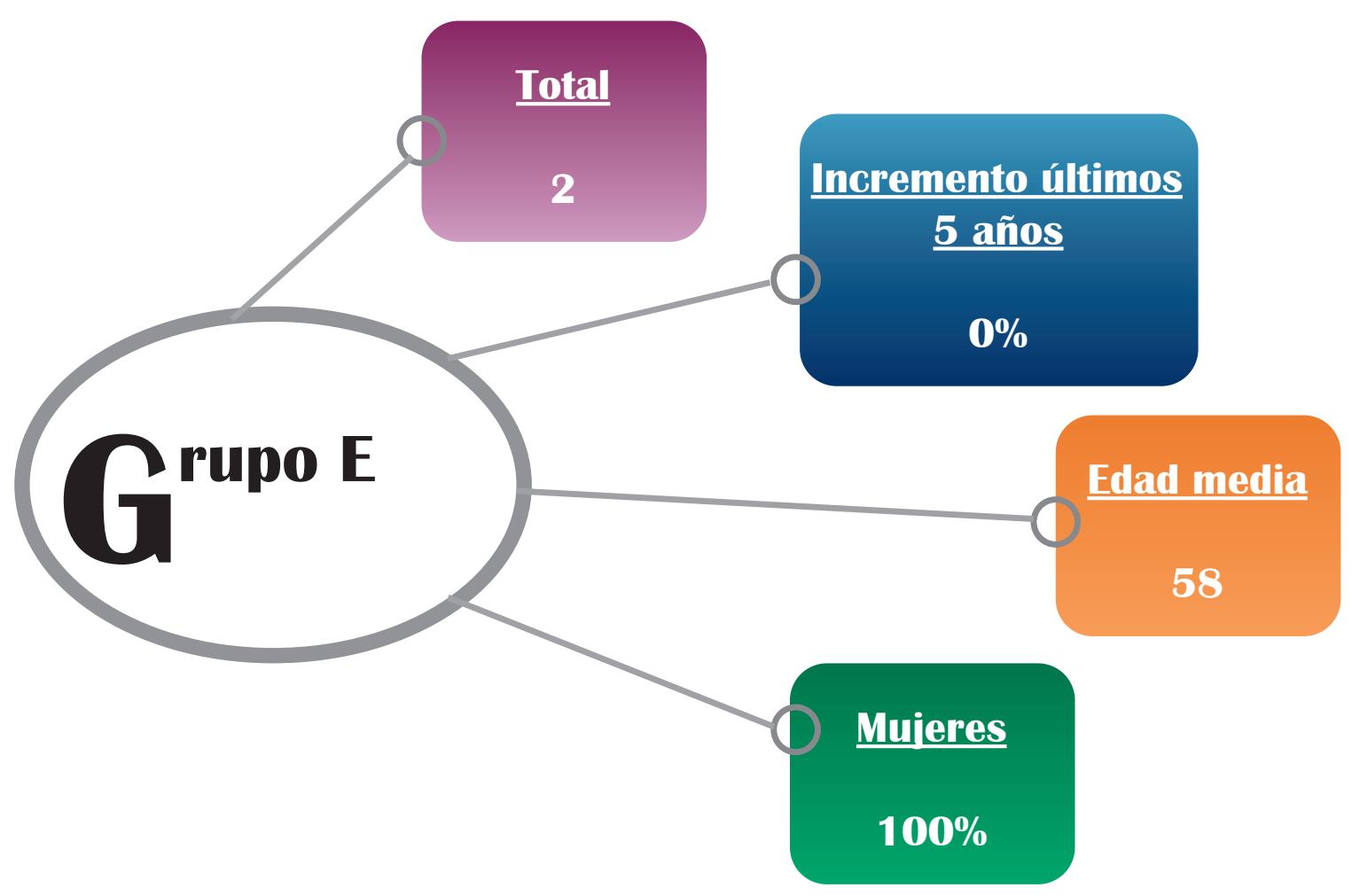


3

\section{Gestión financiera}




\subsection{Ingresos. Derechos reconocidos}

Año 2018

Fuente: Gerencia UA.

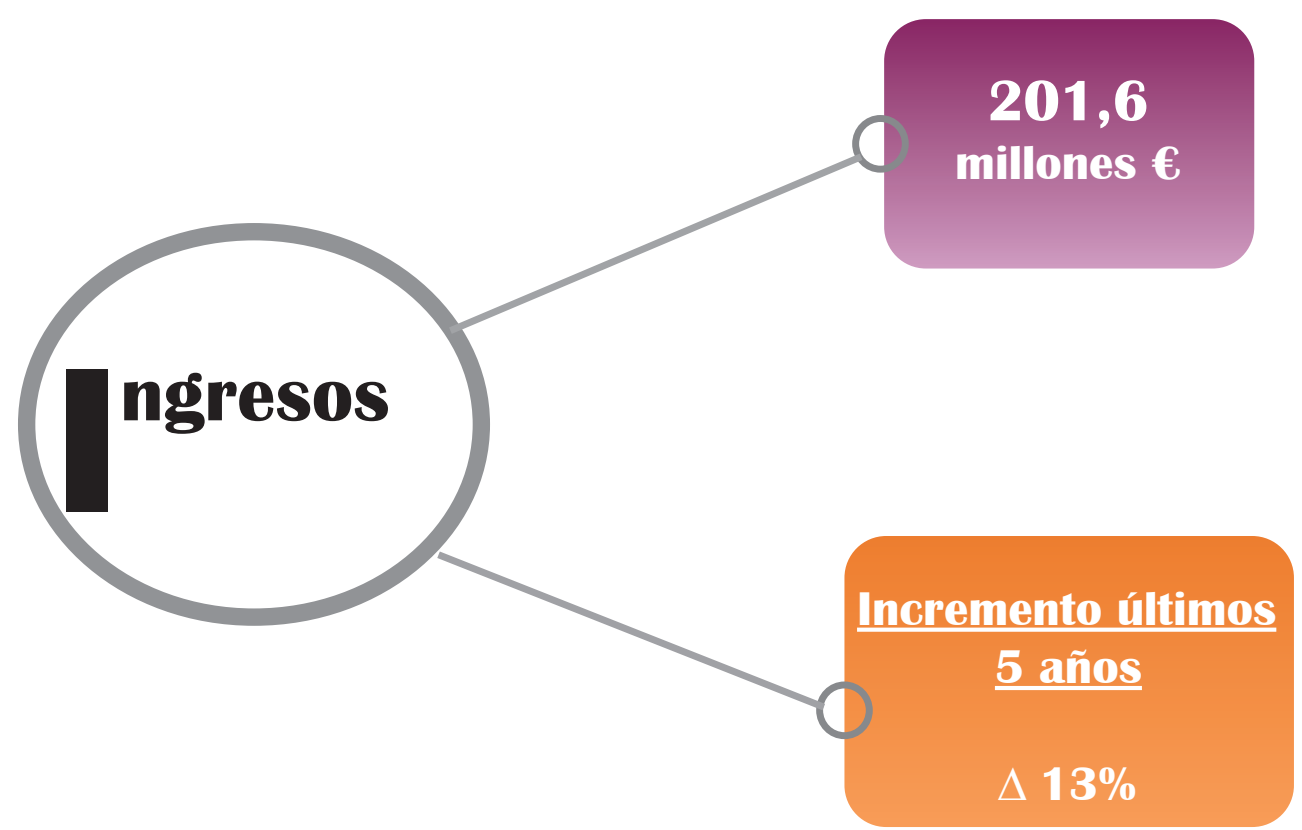

Distribución de los ingresos por conceptos (\%)

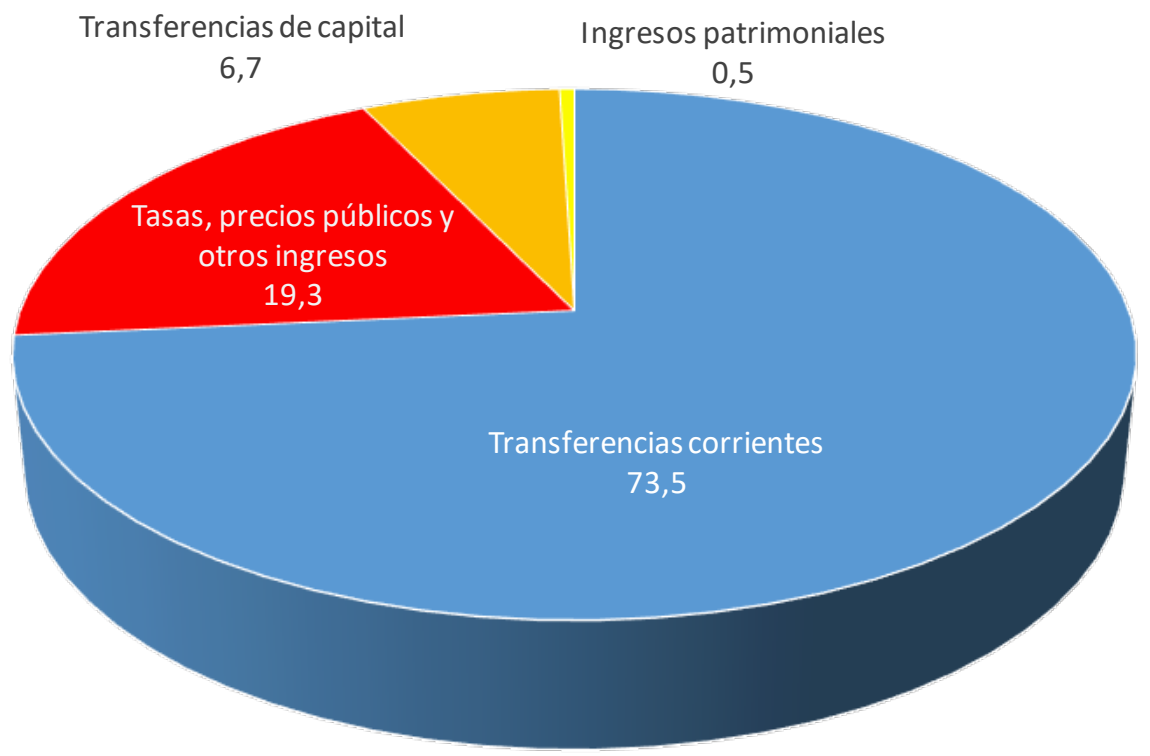




\subsection{Gastos. Obligaciones reconocidas}

Año 2018

Fuente: Gerencia UA.

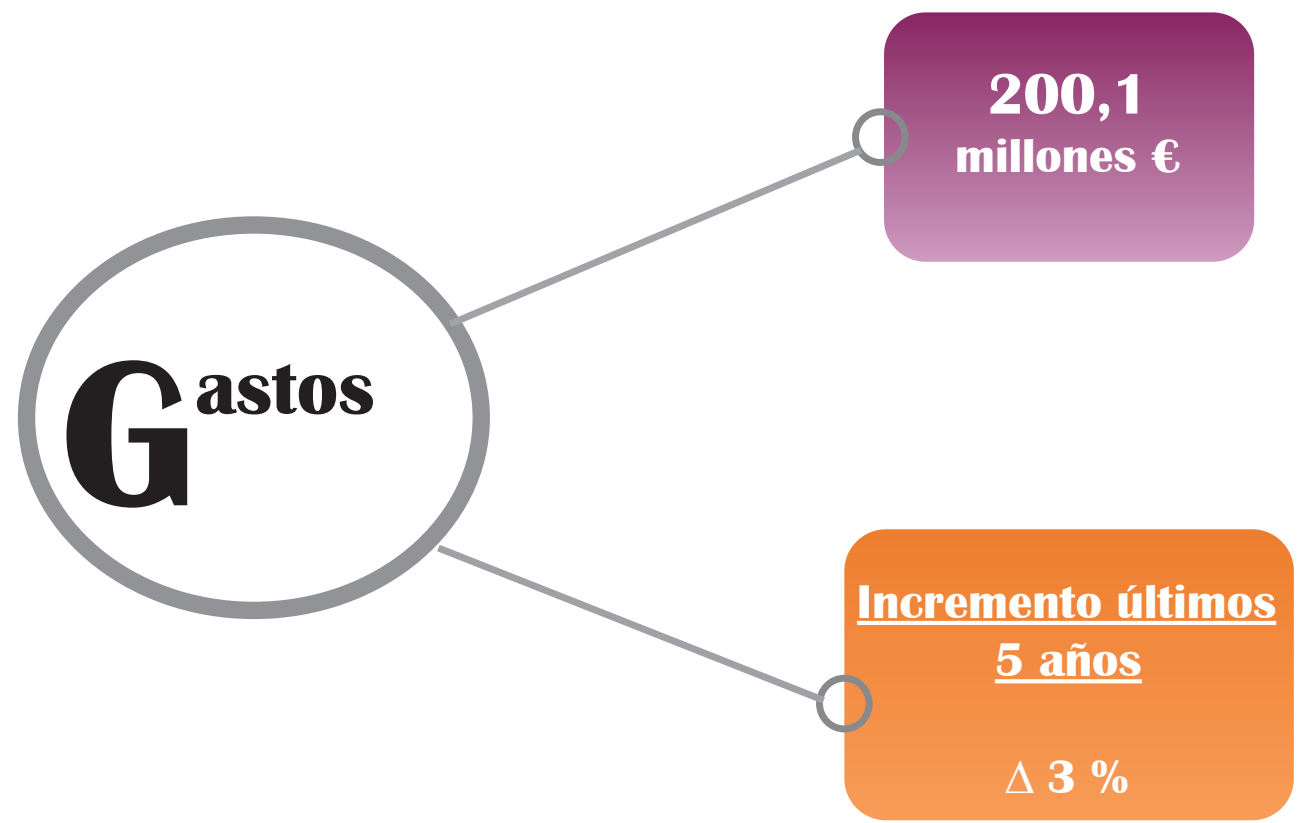

Principales conceptos de gasto (\%)

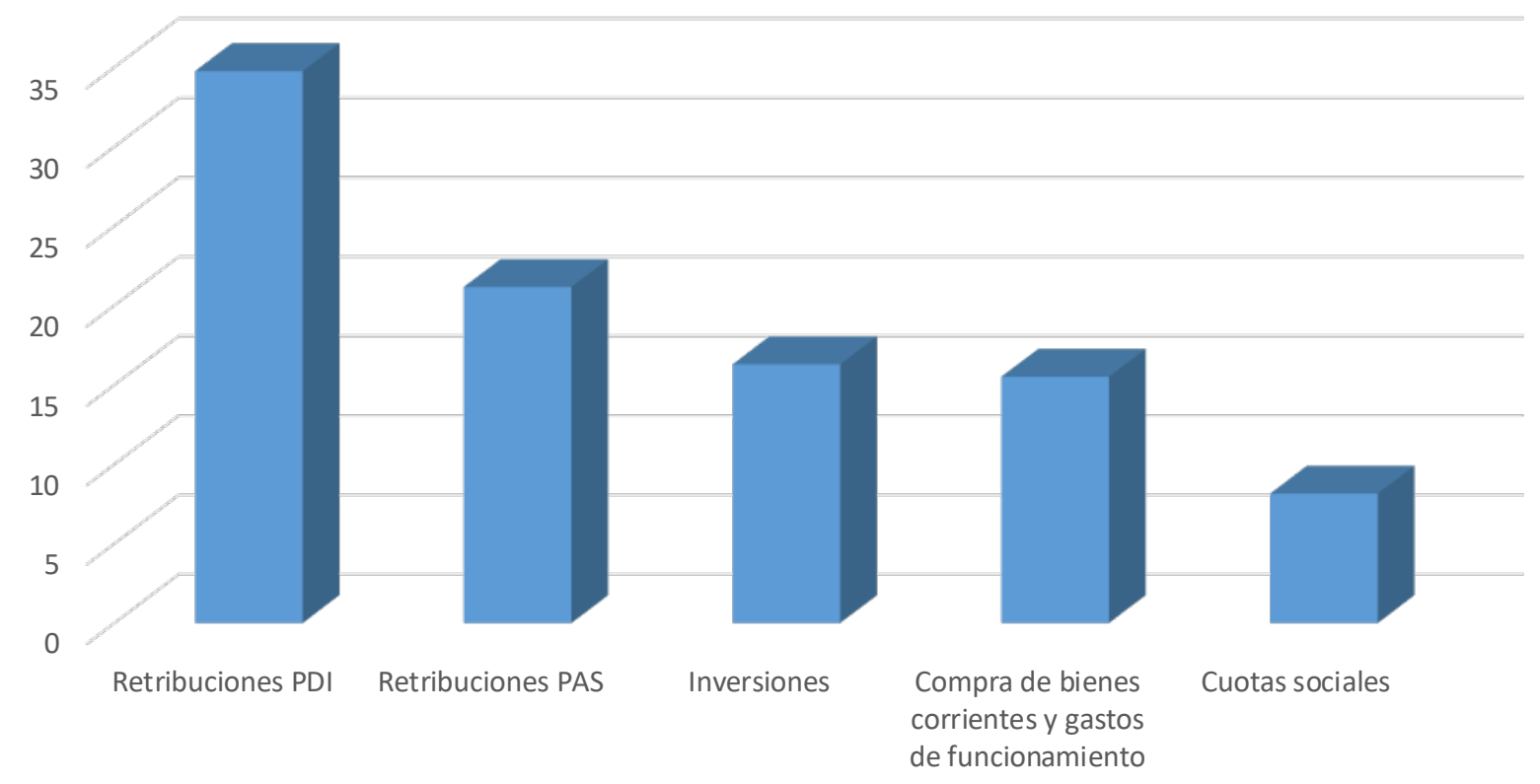


4

\section{Resultados}




\section{1. Éxito académico}

\section{Curso académico 2017/2018}

Fuente: Unidad Técnica de Calidad UA.

\section{Egreso de titulaciones oficiales}

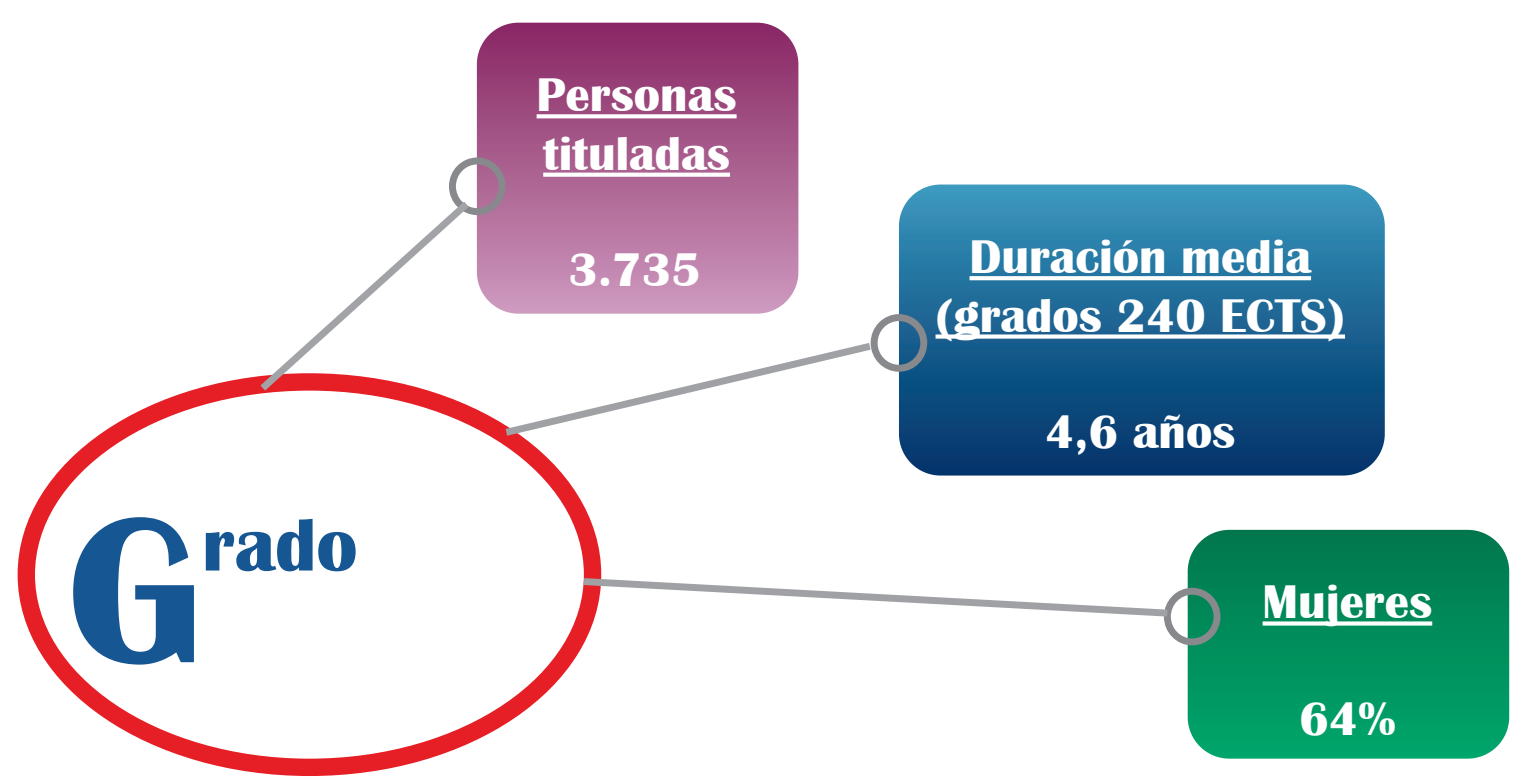

Distribución según rama de conocimiento y centro
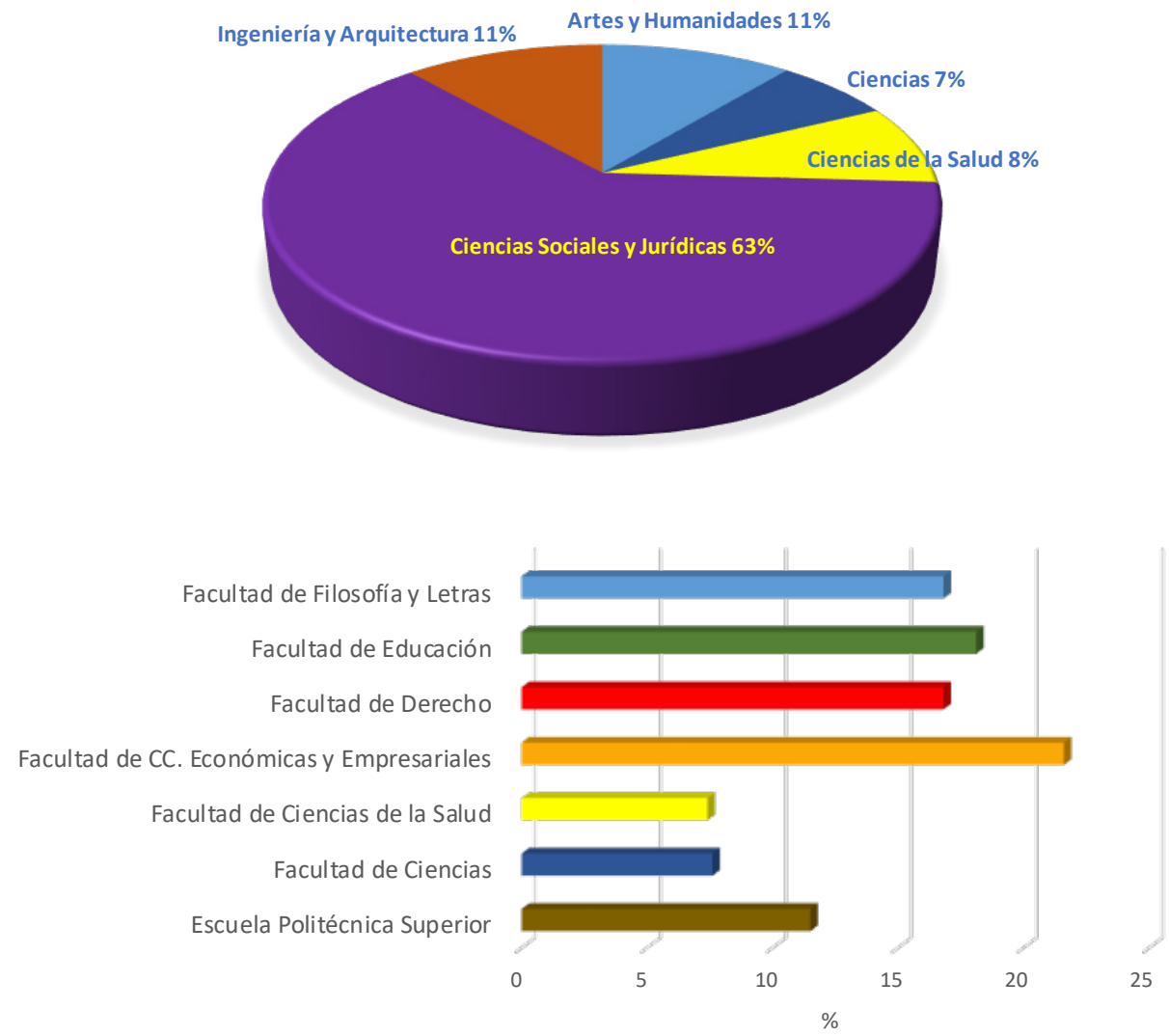


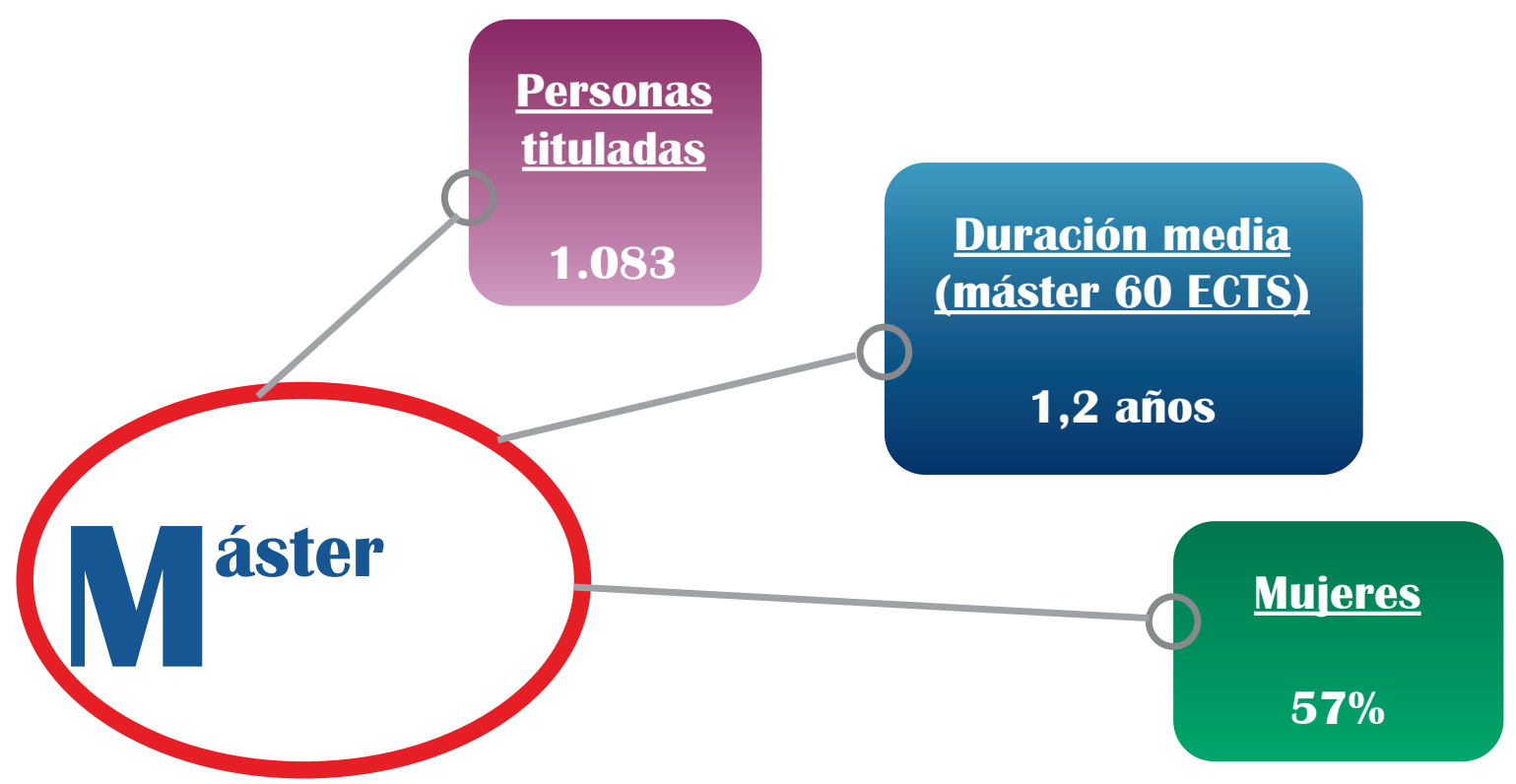

Distribución según rama de conocimiento y centro
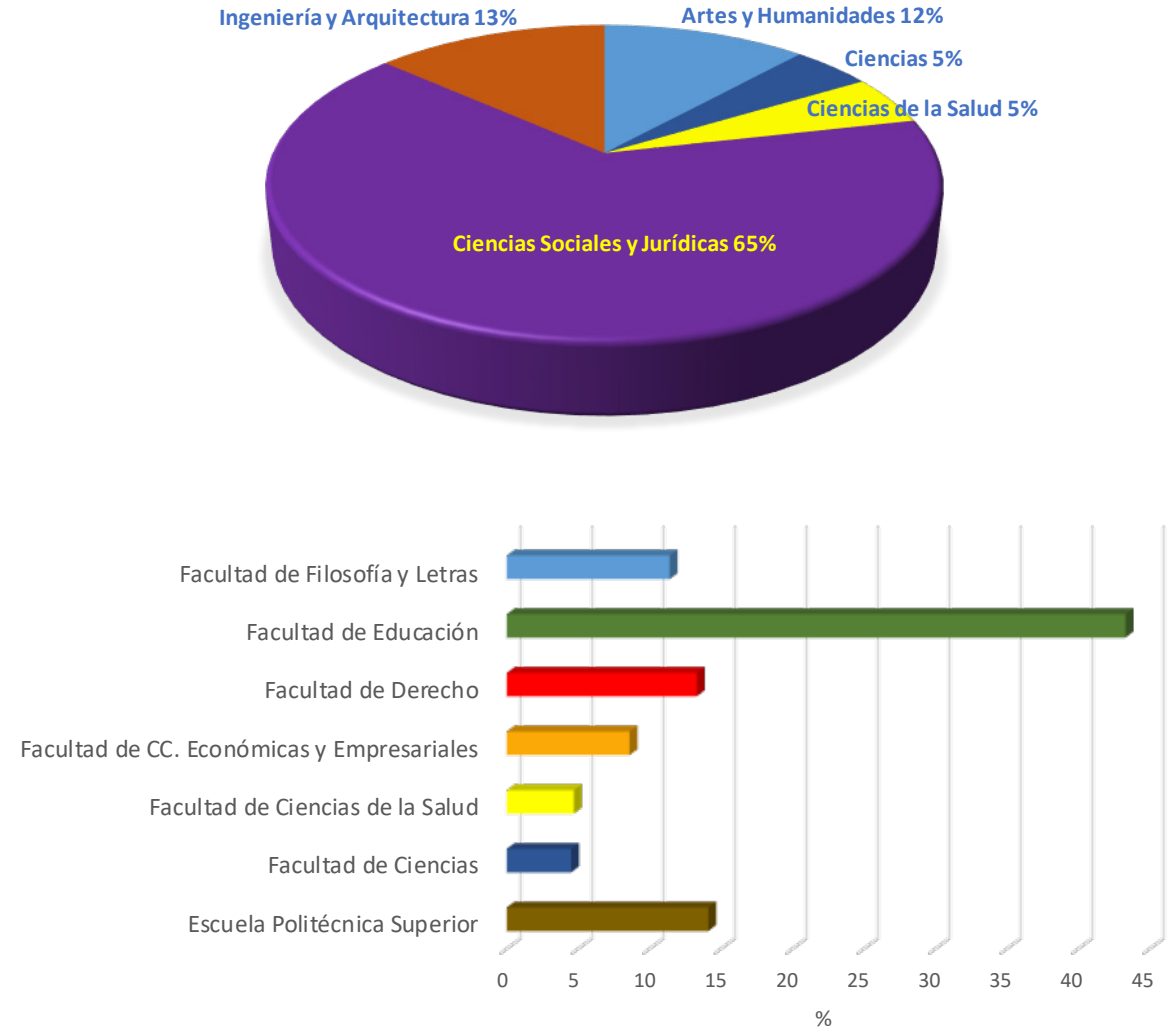


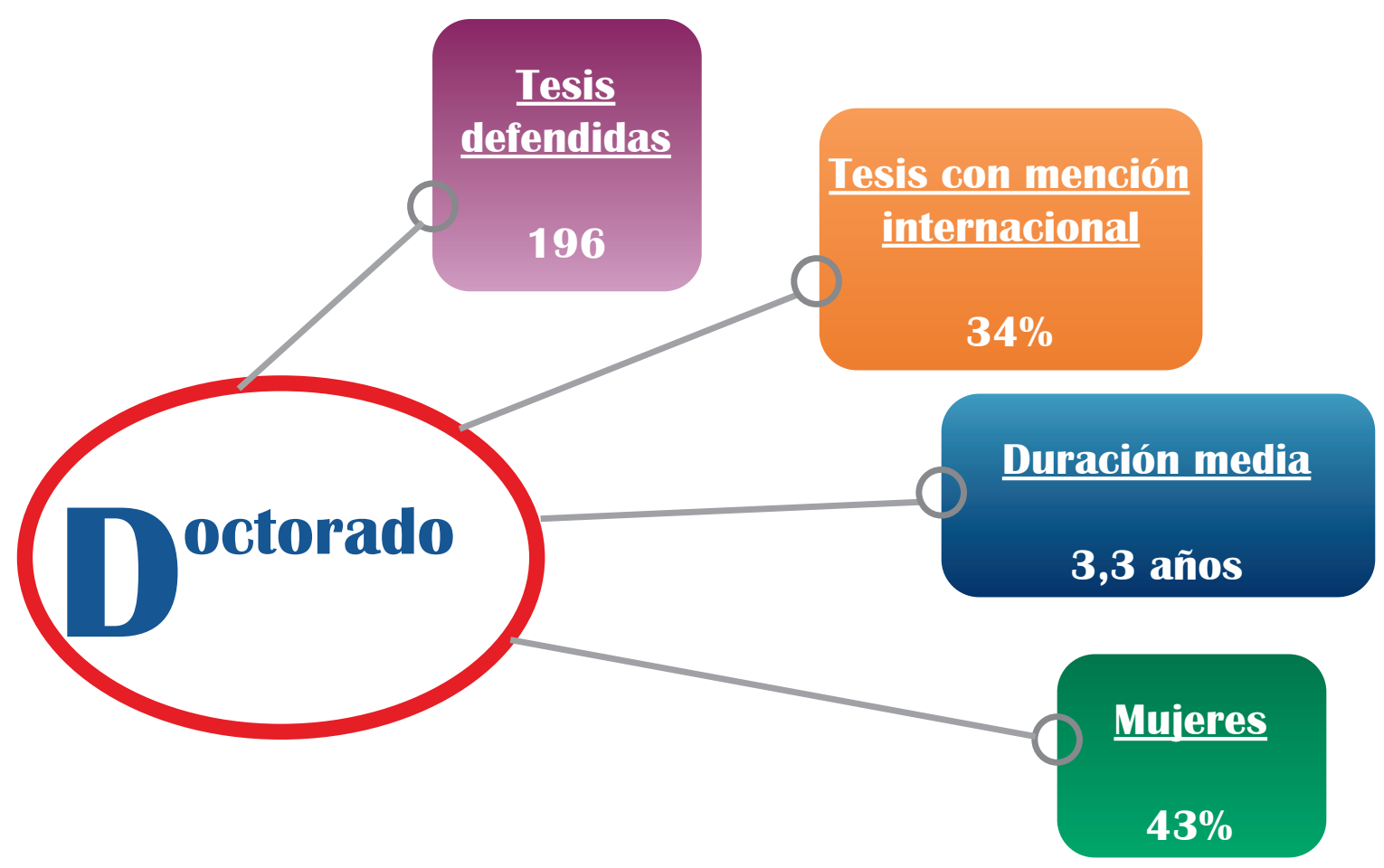

Distribución según rama de conocimiento

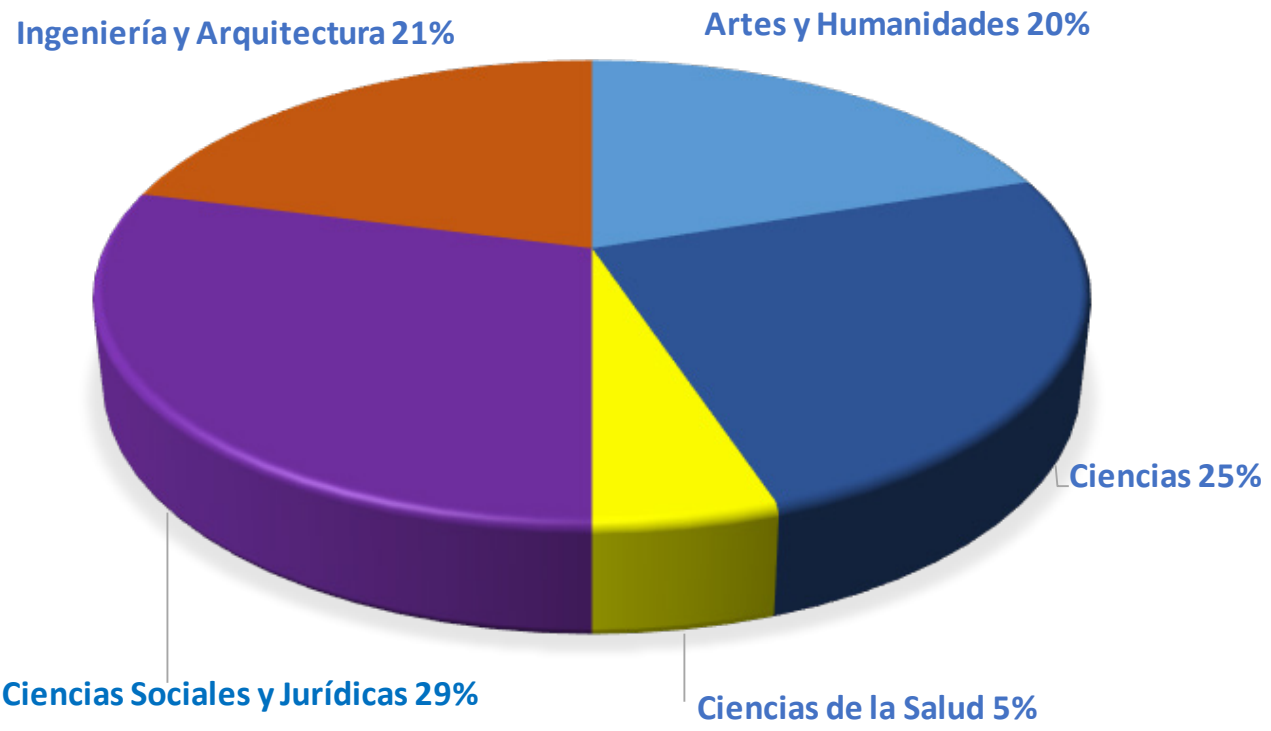


Egreso de titulaciones propias
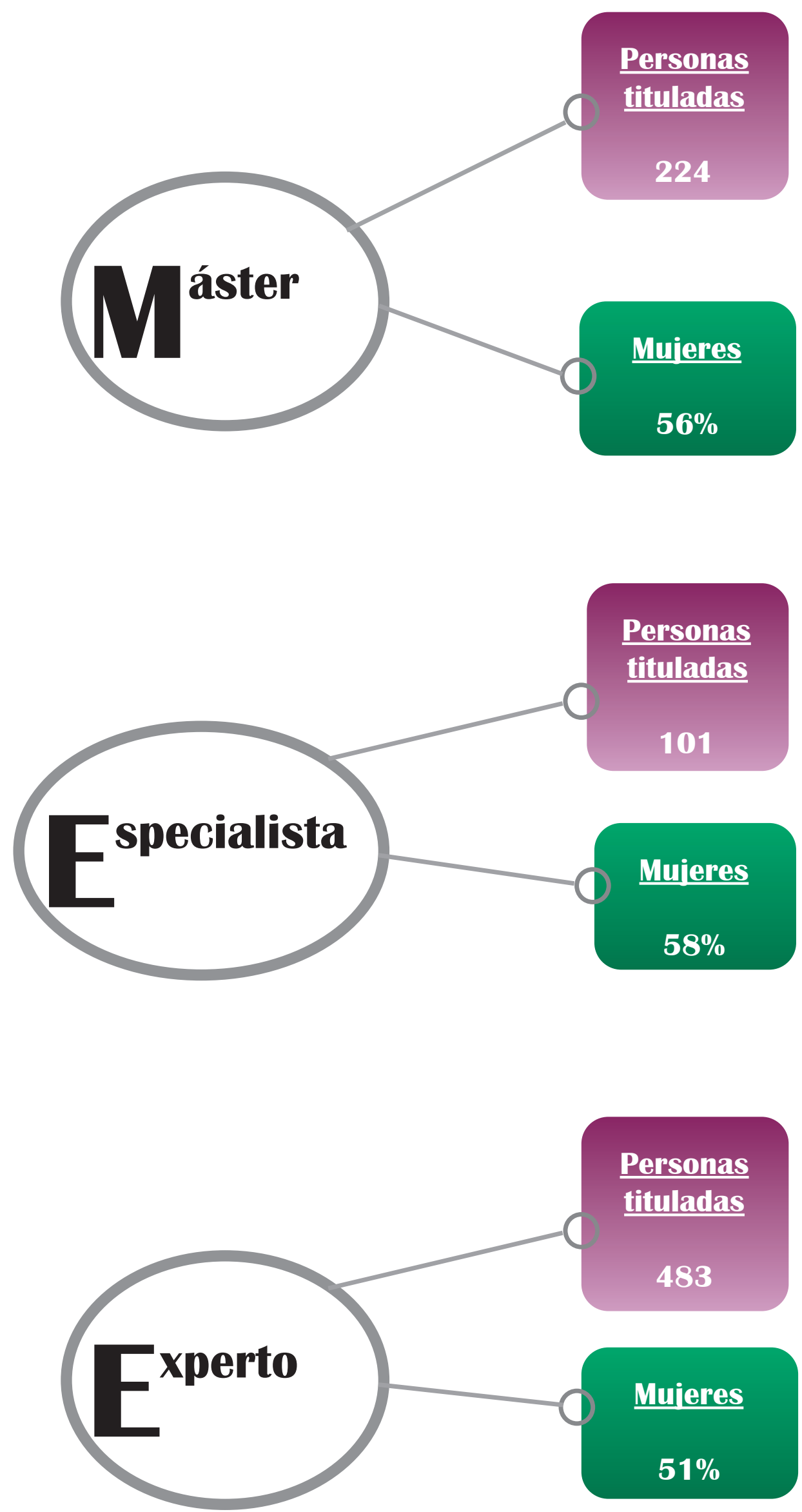


\section{Rendimiento en titulaciones oficiales}

\section{Curso académico 2017/2018}

Fuente: Sistema de Información de la Universidad de Alicante (SIUA).
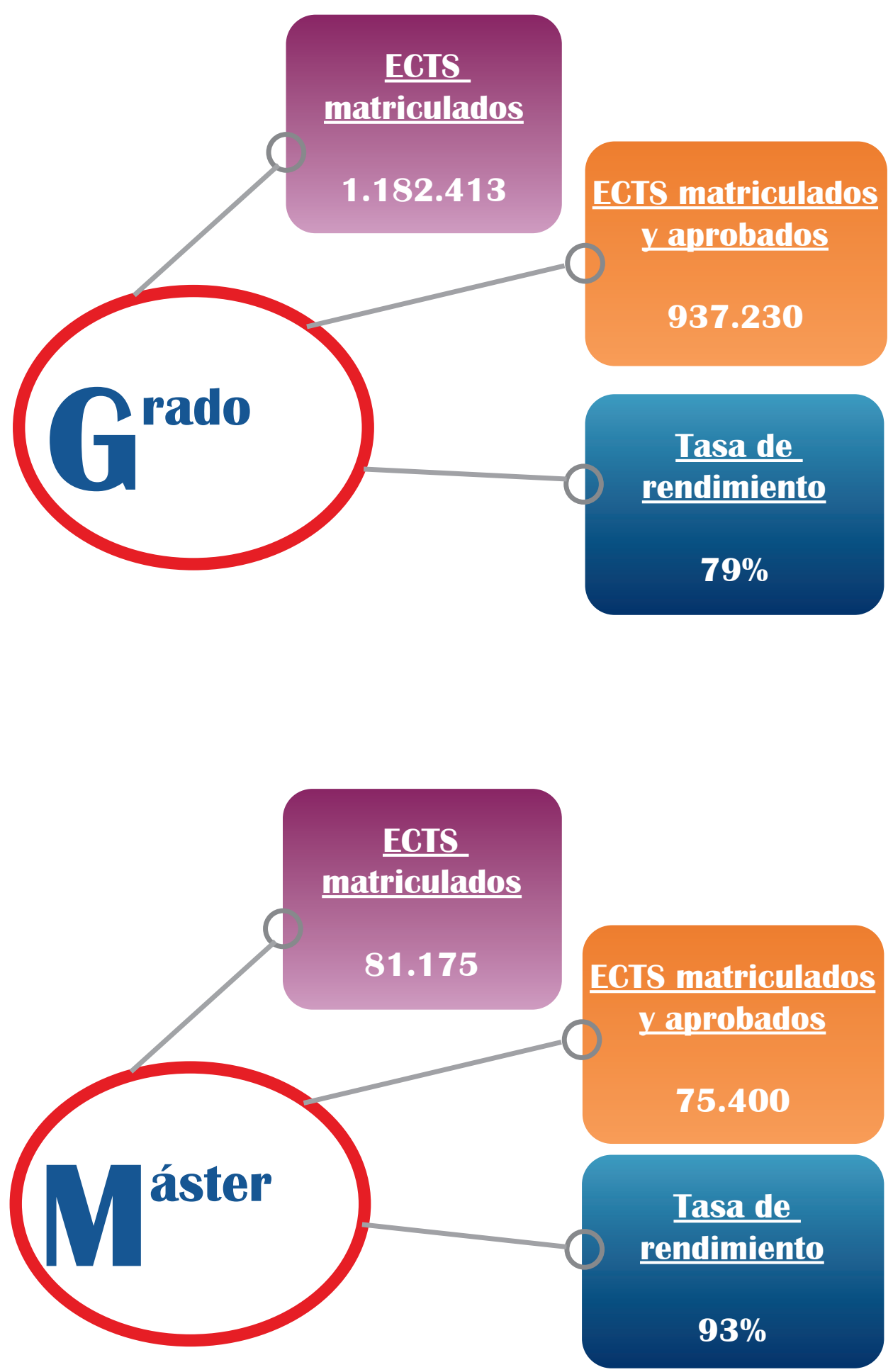


\section{Acreditación de titulaciones oficiales}

Año 2018

Fuente: Unidad Técnica de Calidad UA.

\section{Renovación de la acreditación}

\section{$100 \%$}

de las titulaciones presentadas para renovar la acreditación obtienen resolución favorable del Consejo de Universidades

Sellos internacionales de calidad
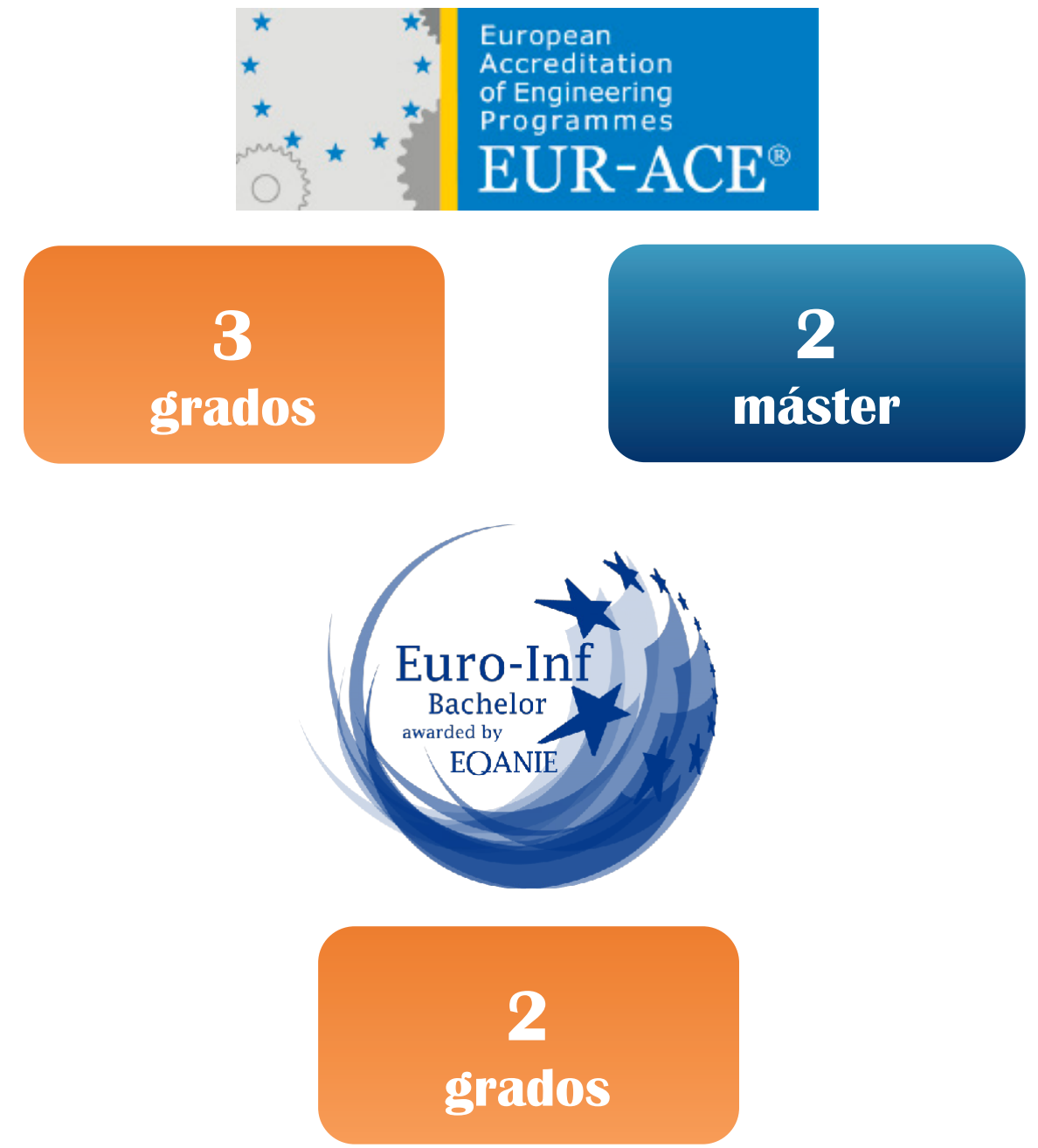


\section{Empleabilidad}

Curso académico 2018/2019

Fuente: Vicerrectorado de Estudiantes y Empleo UA.

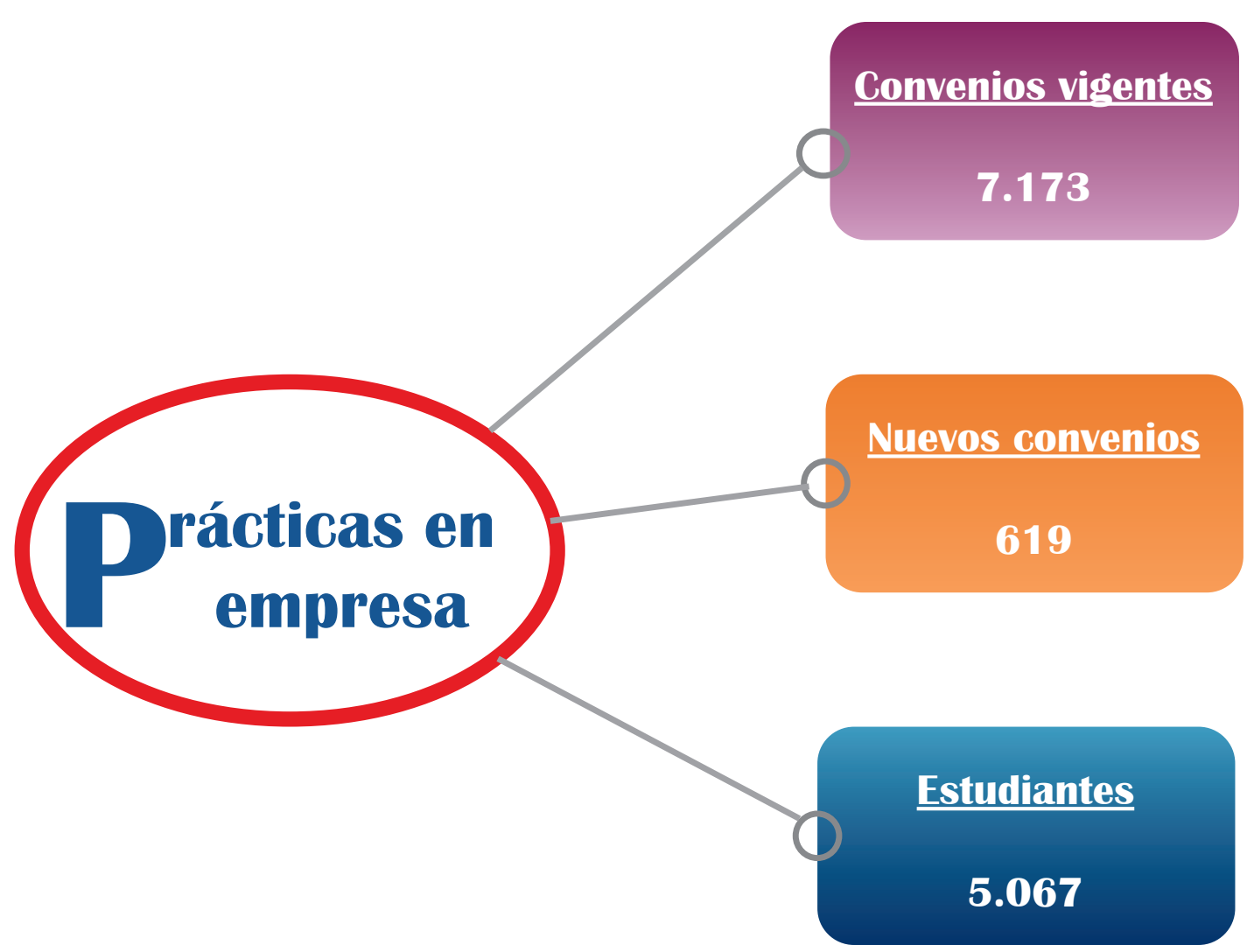




\subsection{I+D+I}

\section{Año 2018}

Fuentes: Servicio de Gestión de la Investigación y Vicerrectorado de Investigación y Transferencia de Conocimiento UA.

\section{Proyectos y otras ayudas competitivas}

\section{Ámbito europeo}

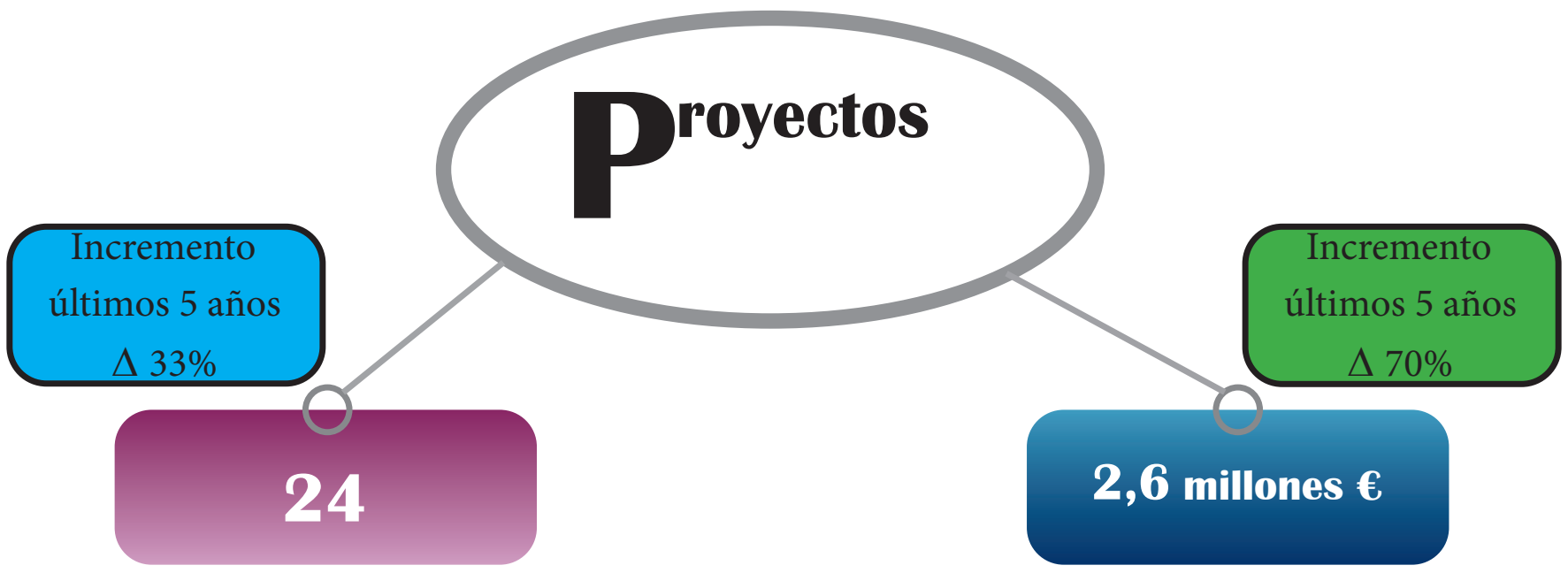

Ámbito estatal
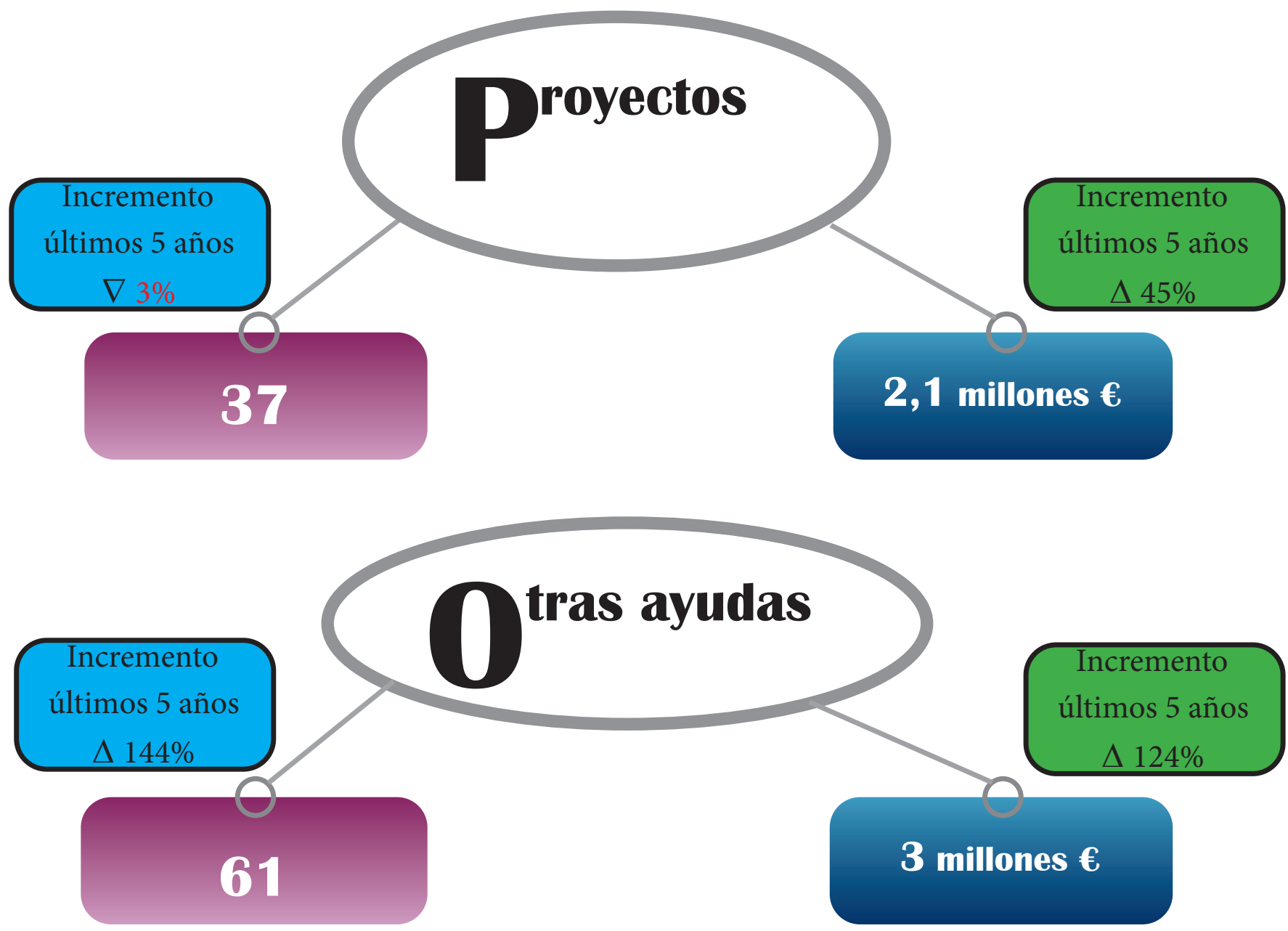


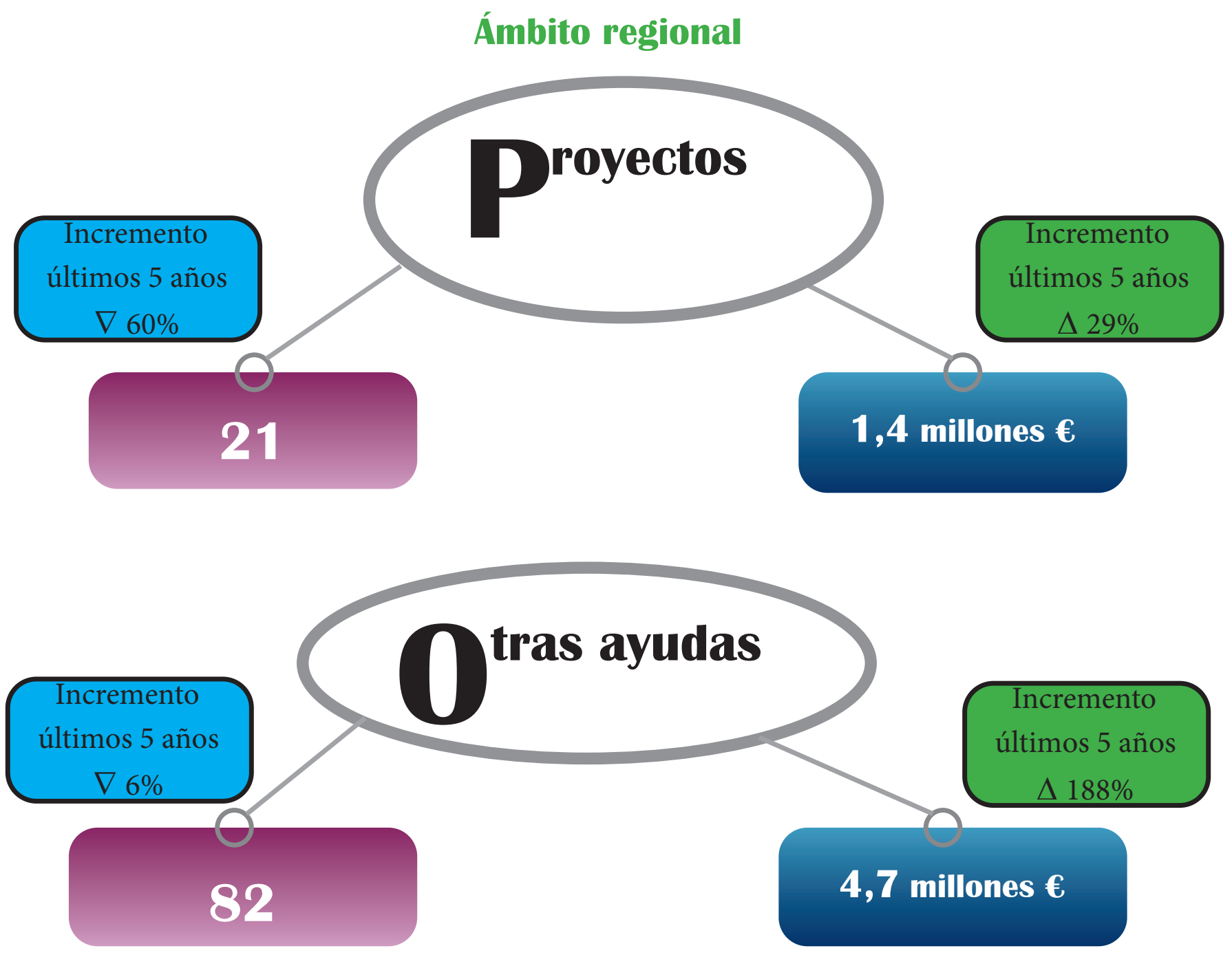

\section{Convenios y contratos}

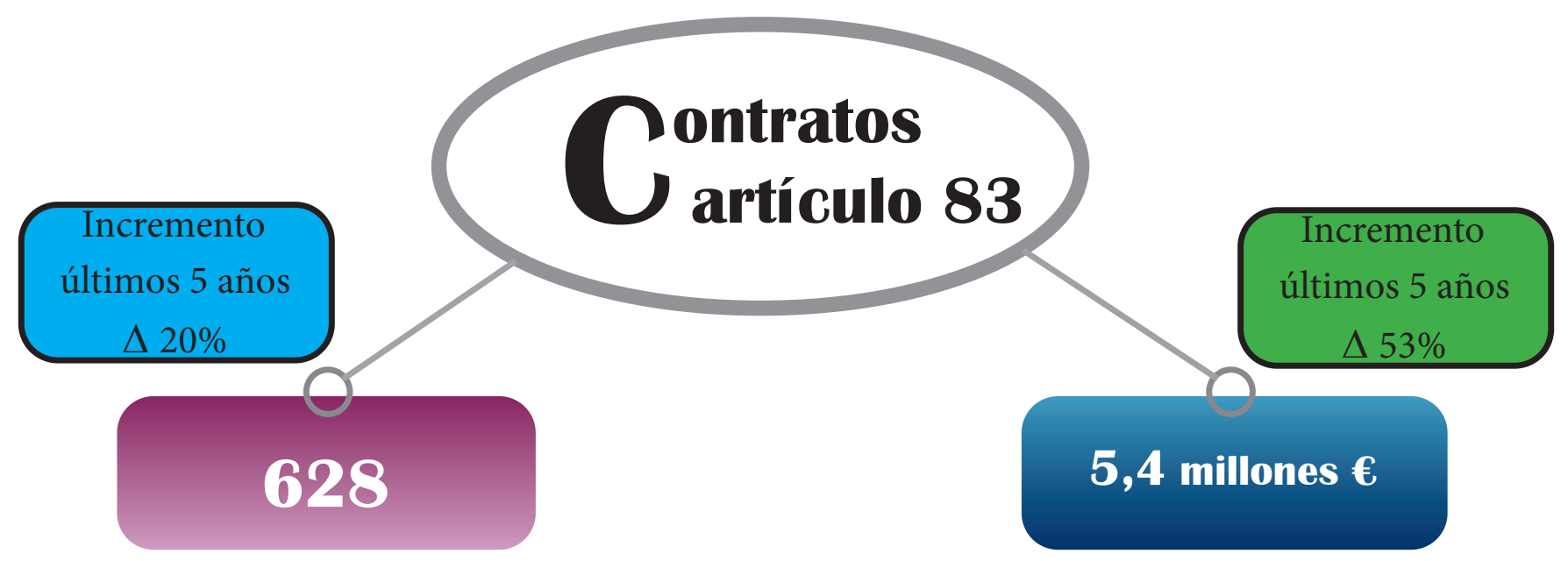




\section{Producción científica}

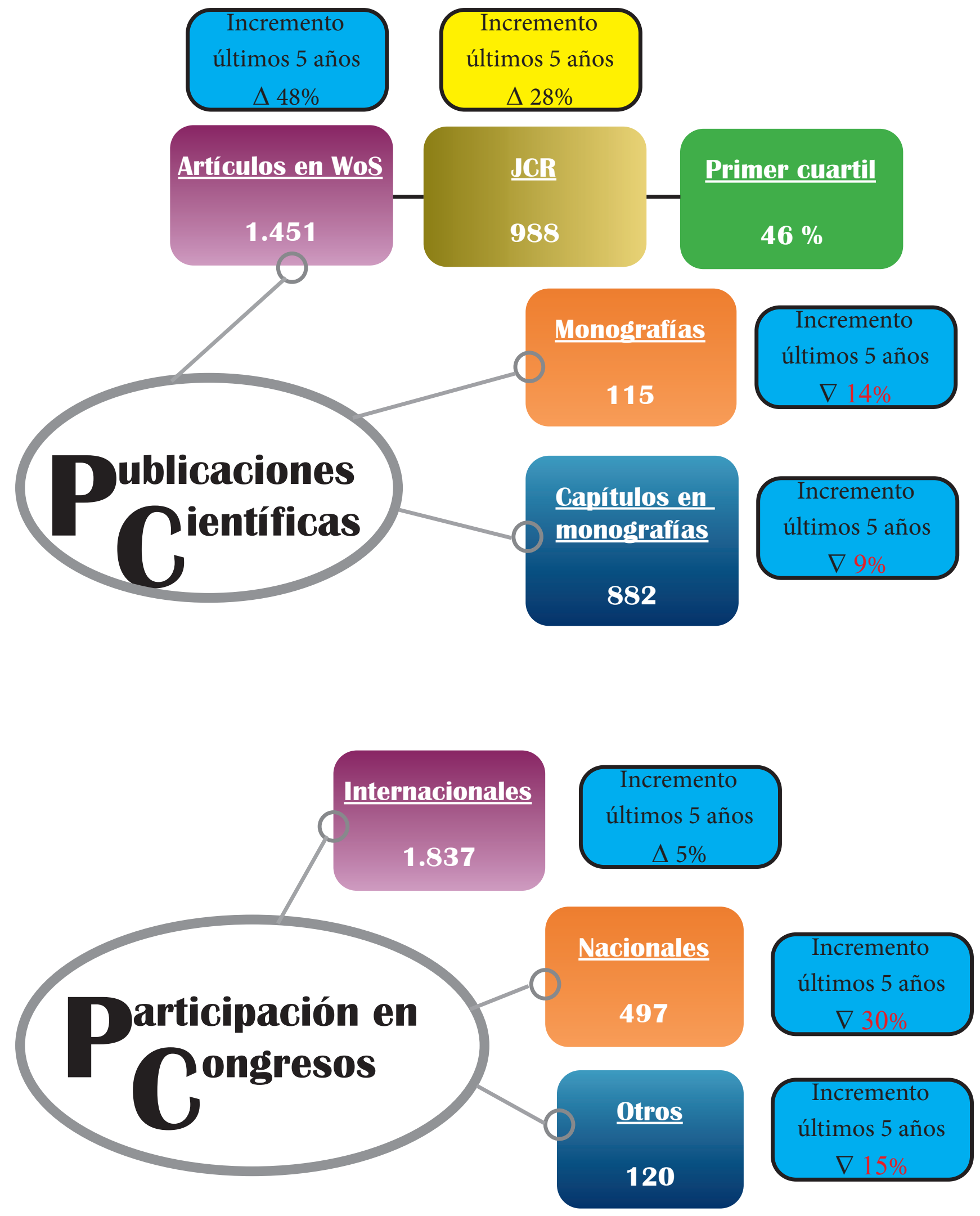




\section{Transferencia de conocimiento}
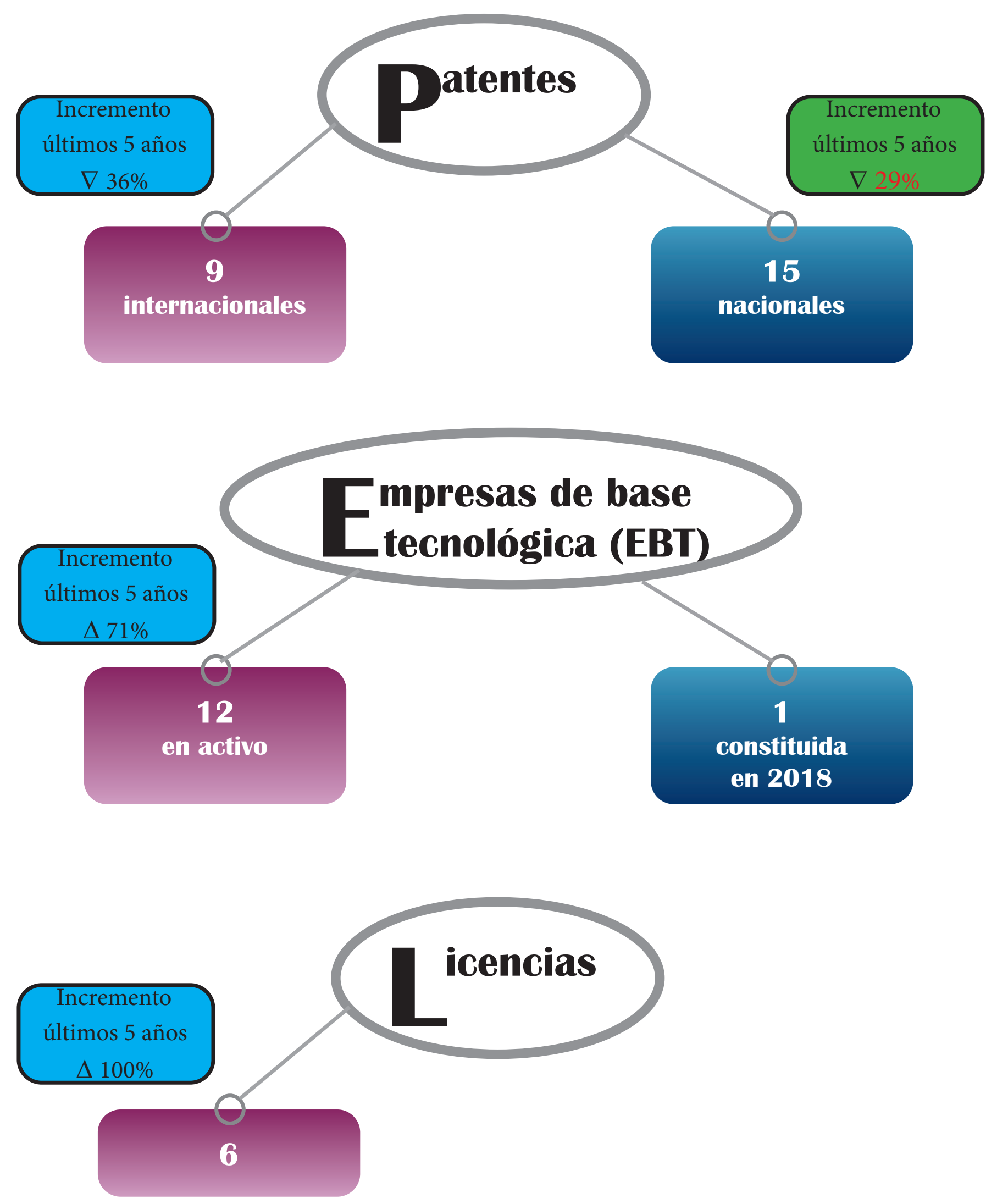


\section{Reconocimiento de la actividad investigadora}

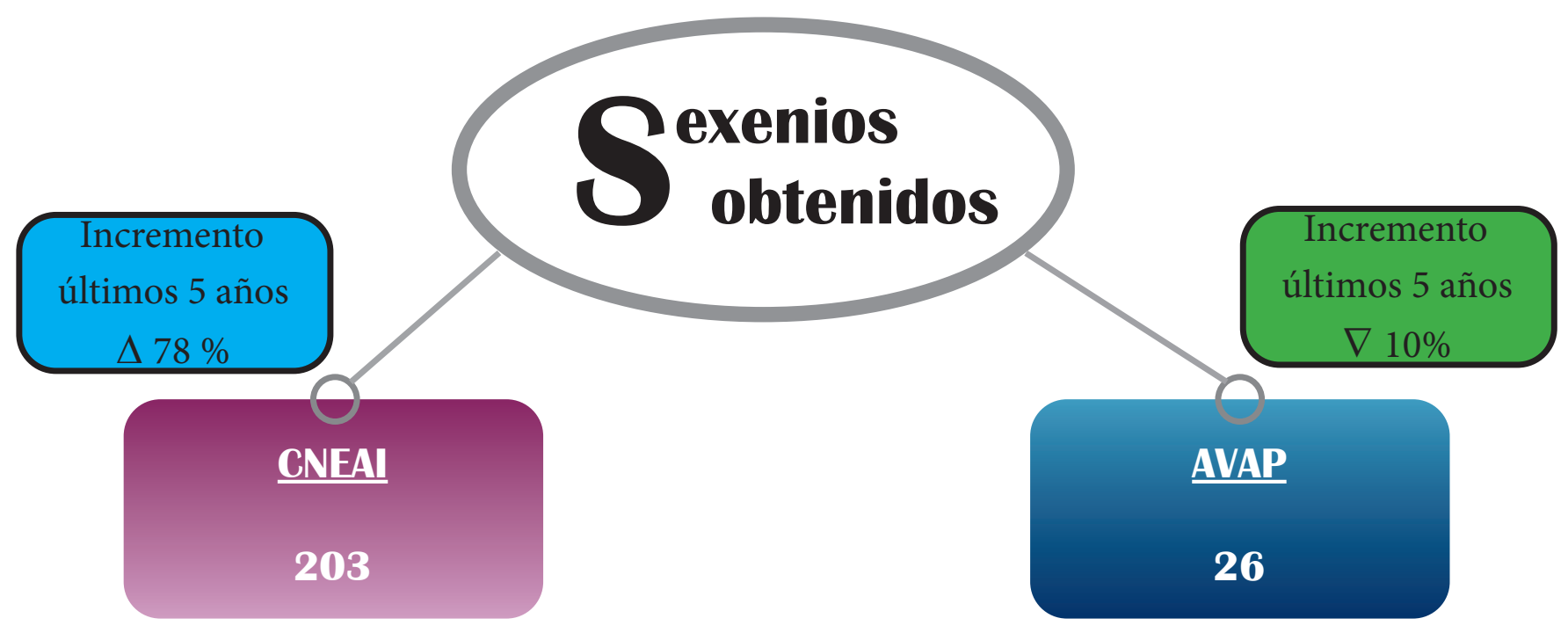




$$
5
$$

\section{Internacionalización}




\subsection{Estudiantes de nacionalidad extranjera}

Curso académico 2018/2019

Fuente: Unidad Técnica de Calidad UA.

\section{Titulaciones oficiales}
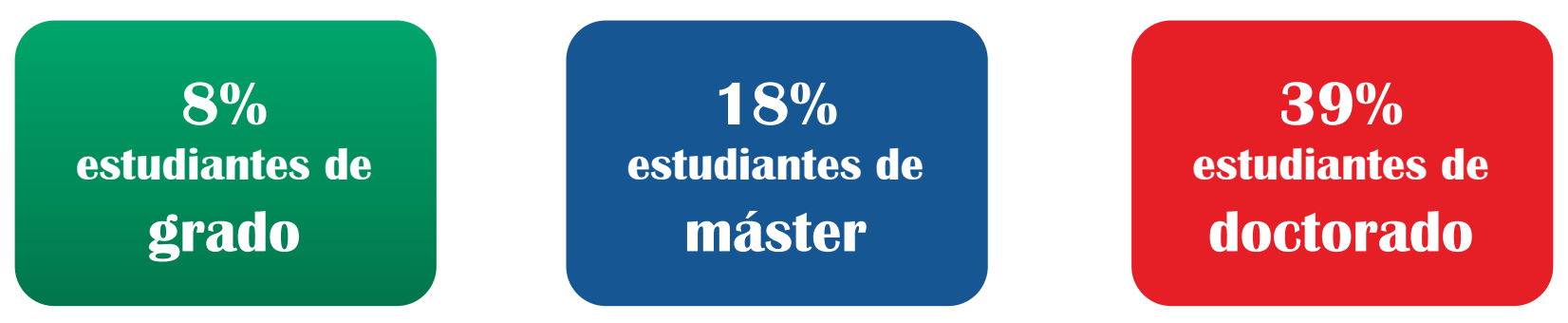

\section{Titulaciones propias}
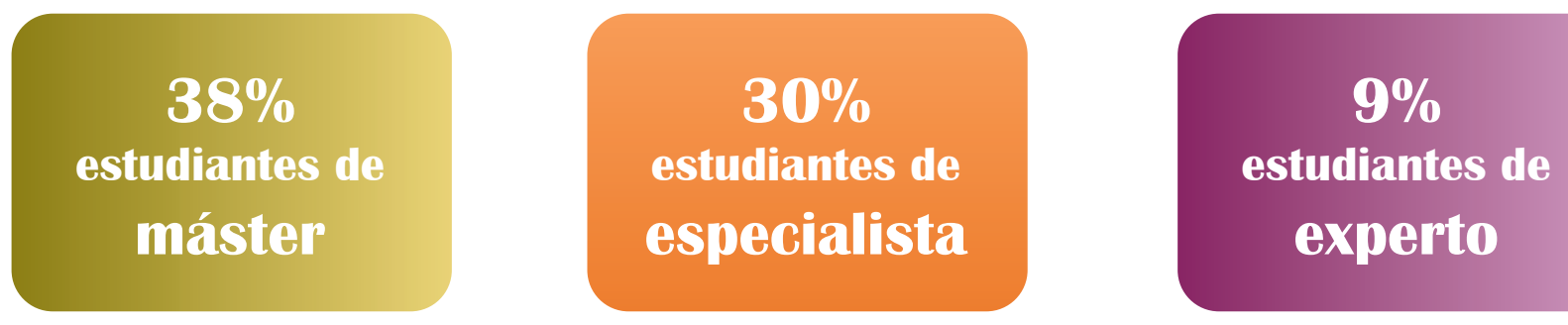


\section{2. Éxito académico}

Curso académico 2017/2018

Fuente: Unidad Técnica de Calidad UA.

Personas de nacionalidad extranjera egresadas de titulaciones oficiales
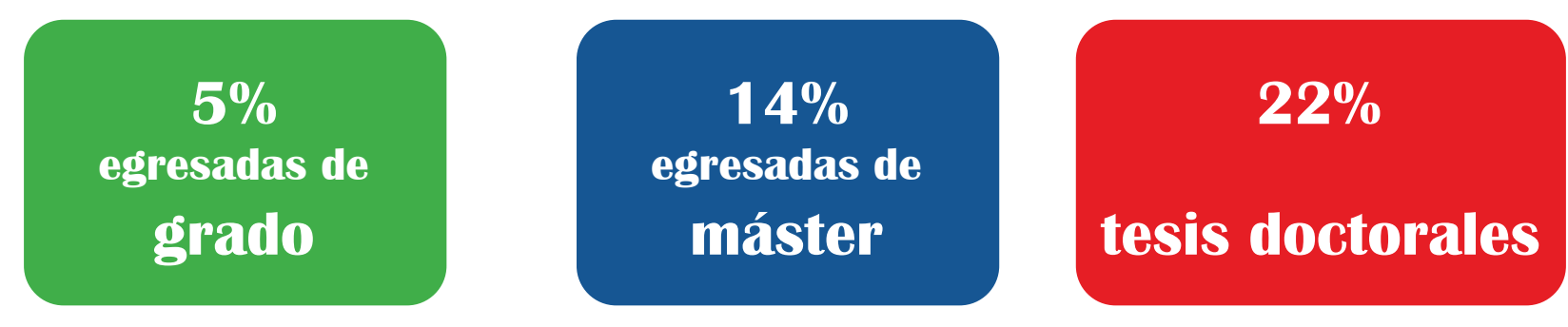

\section{Personas de nacionalidad extranjera egresadas de titulaciones propias}
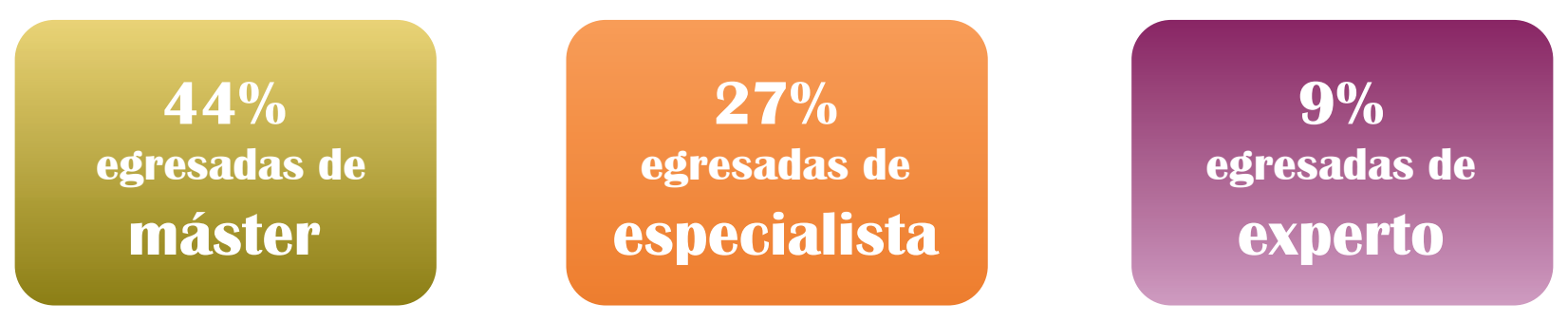


\subsection{Movilidad internacional de estudiantes}

Curso académico 2018/2019

Fuente: Servicio de Relaciones Internacionales UA.
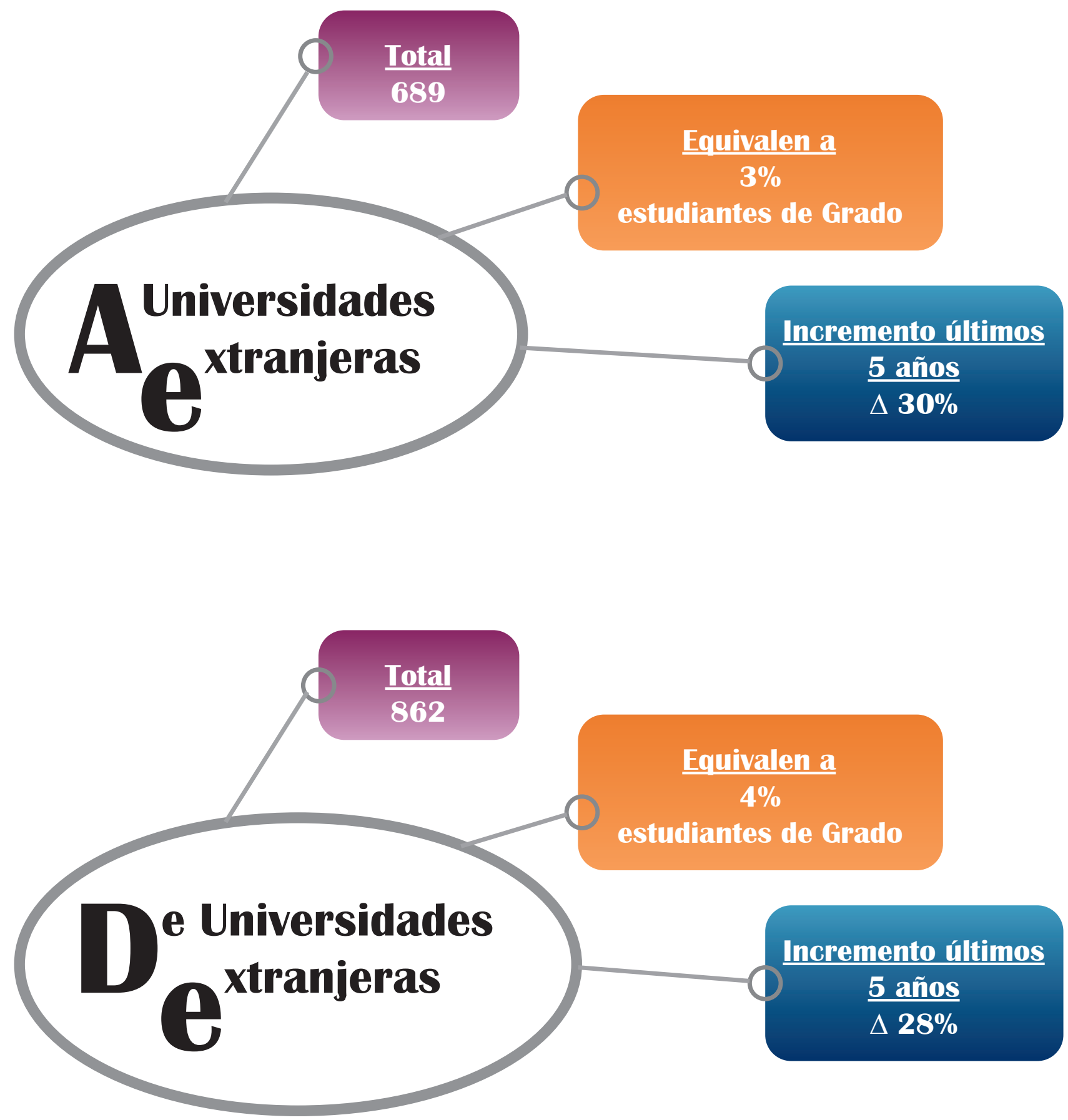

Ratio estudiantes enviados/estudiantes recibidos

0,8 


\subsection{Presencia en el mundo}

Año 2018

Fuentes: Servicio de Relaciones Internacionales y Oficina de Gestión de Proyectos Internacionales UA.
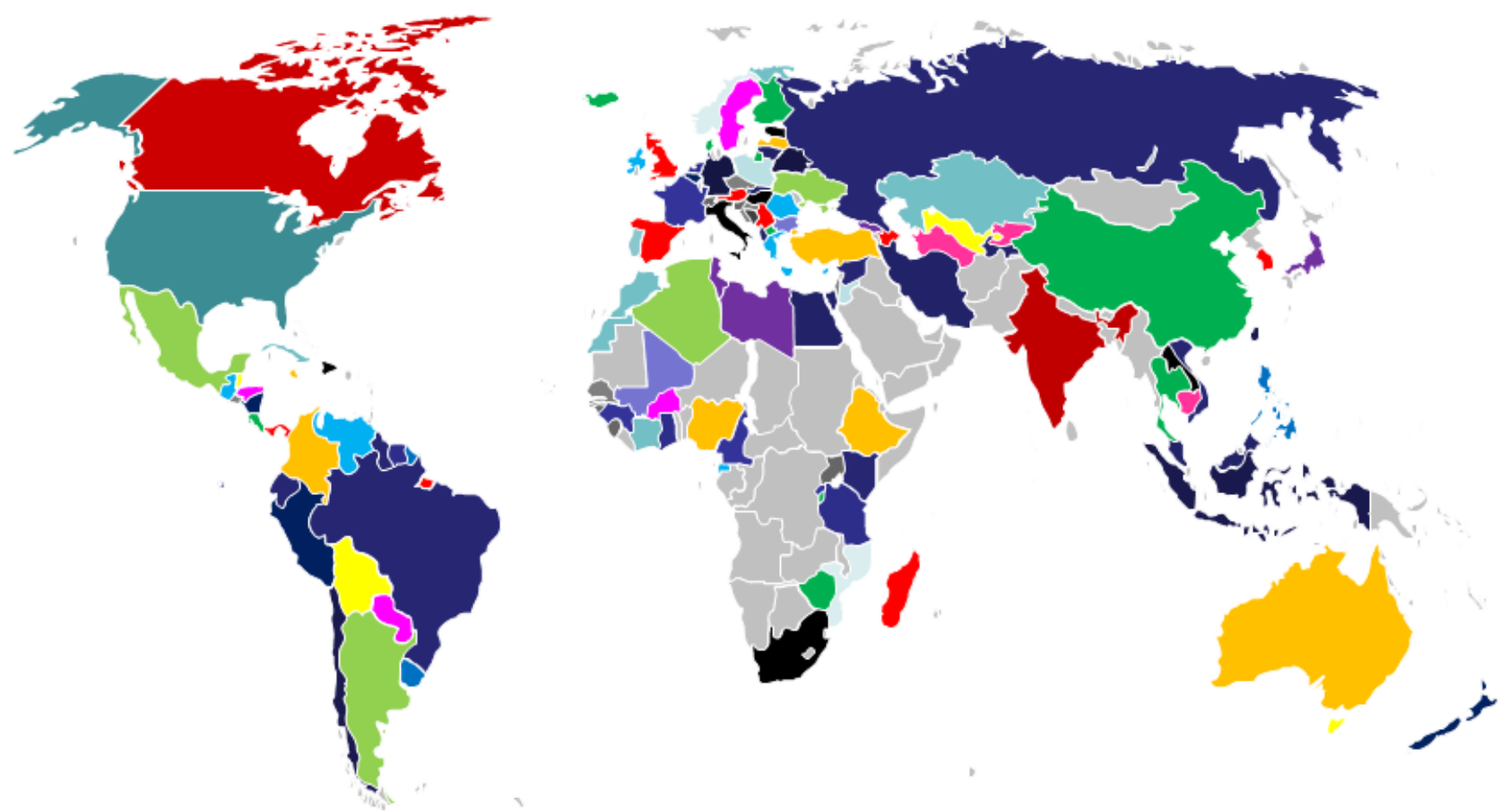

La Universidad de Alicante desarrolla acciones vinculadas con la movilidad, la cooperación, la investigación o la transferencia del conocimiento en 130 países. 
6

\title{
Responsabilidad social
}

\author{
y \\ objetivos de \\ desarrollo sostenible
}




\subsection{Plan de responsabilidad social}

Fuente: Vicerrectorado de Responsabilidad Social, Inclusión e Igualdad UA.

Aprobado por Consejo de Gobierno de 20 de julio de 2018, este plan trienal espera alcanzar 20 objetivos organizados en 7 ejes,

mediante la implementación de 66 acciones.

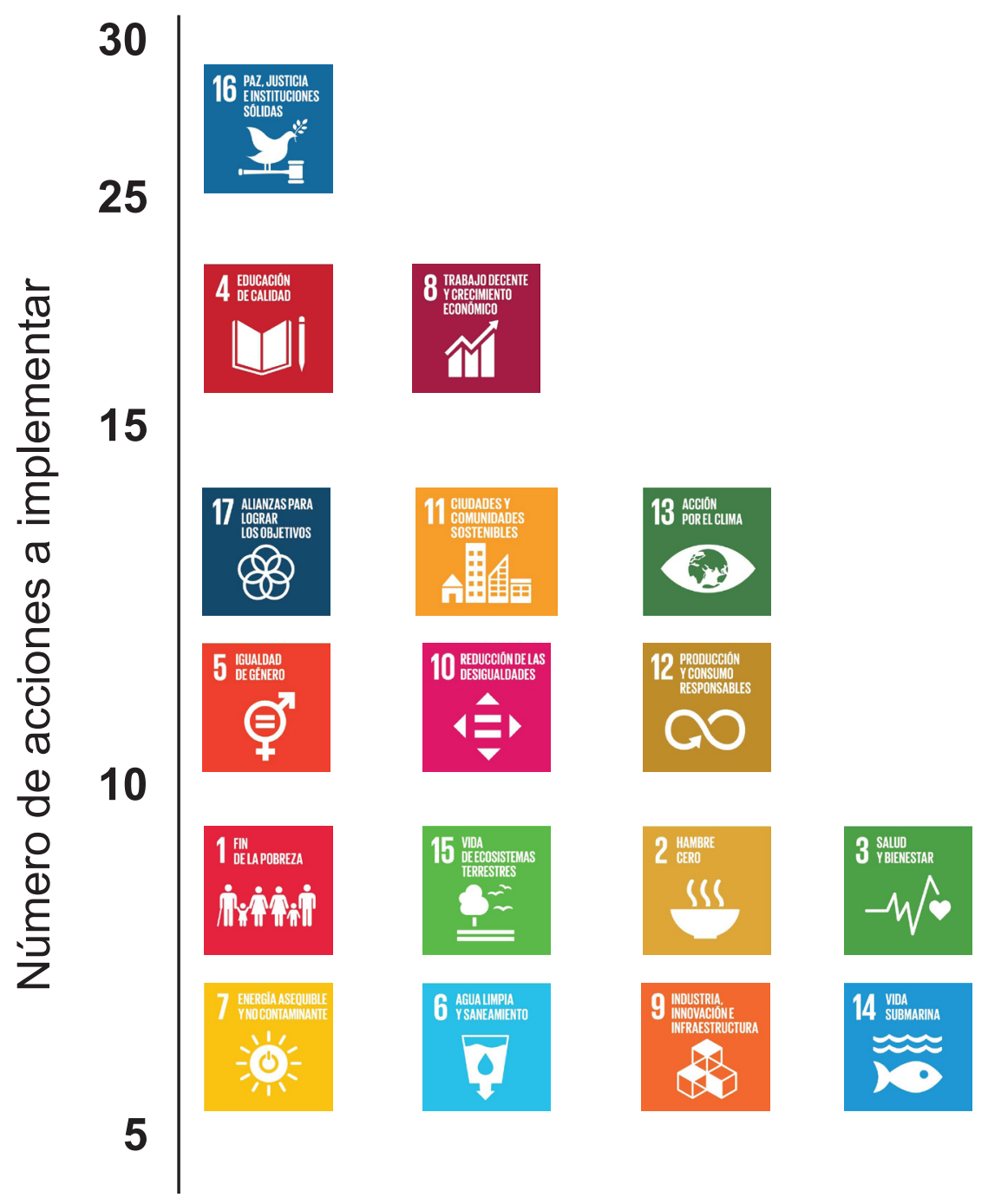

ODS a los que contribuyen 


\subsection{Estrategia plástico cero}

Fuente: Vicerrectorado de Responsabilidad Social, Inclusión e Igualdad UA.

Diseñada en 2018 para cumplir con el objetivo de reducir la gestión de residuos sólidos previsto en el Eje 5 Gestión socialmente responsable en la UA del Plan de Responsabilidad Social.

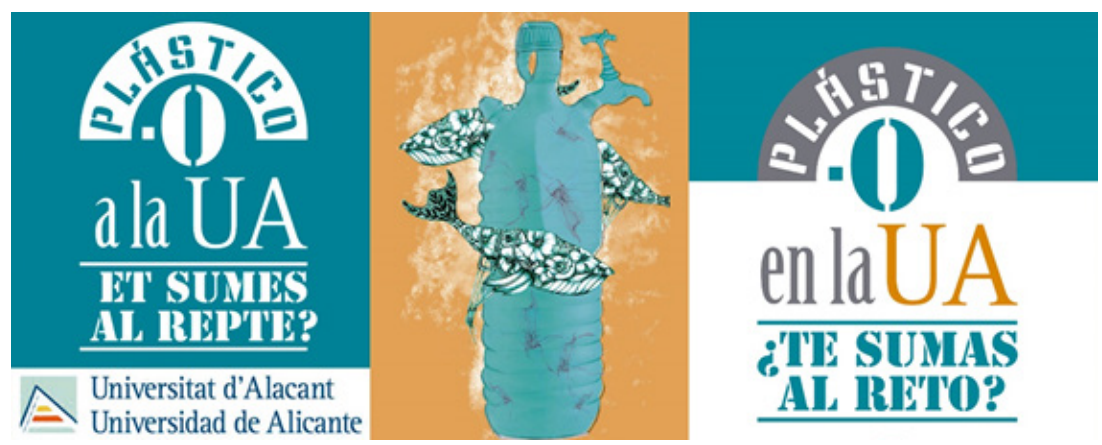

Se establecen 25 acciones específicas a realizar desde 2019 a 2023.

ODS a los que contribuyen
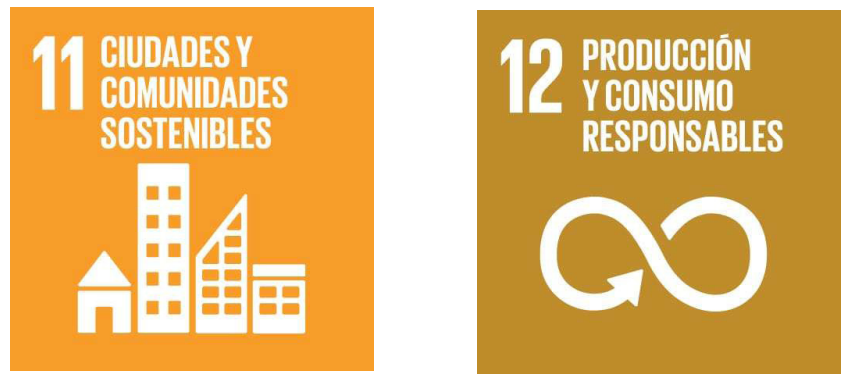


\subsection{Gestión de residuos}

\section{Año 2018}

Fuente: Oficina EcoCampus UA.
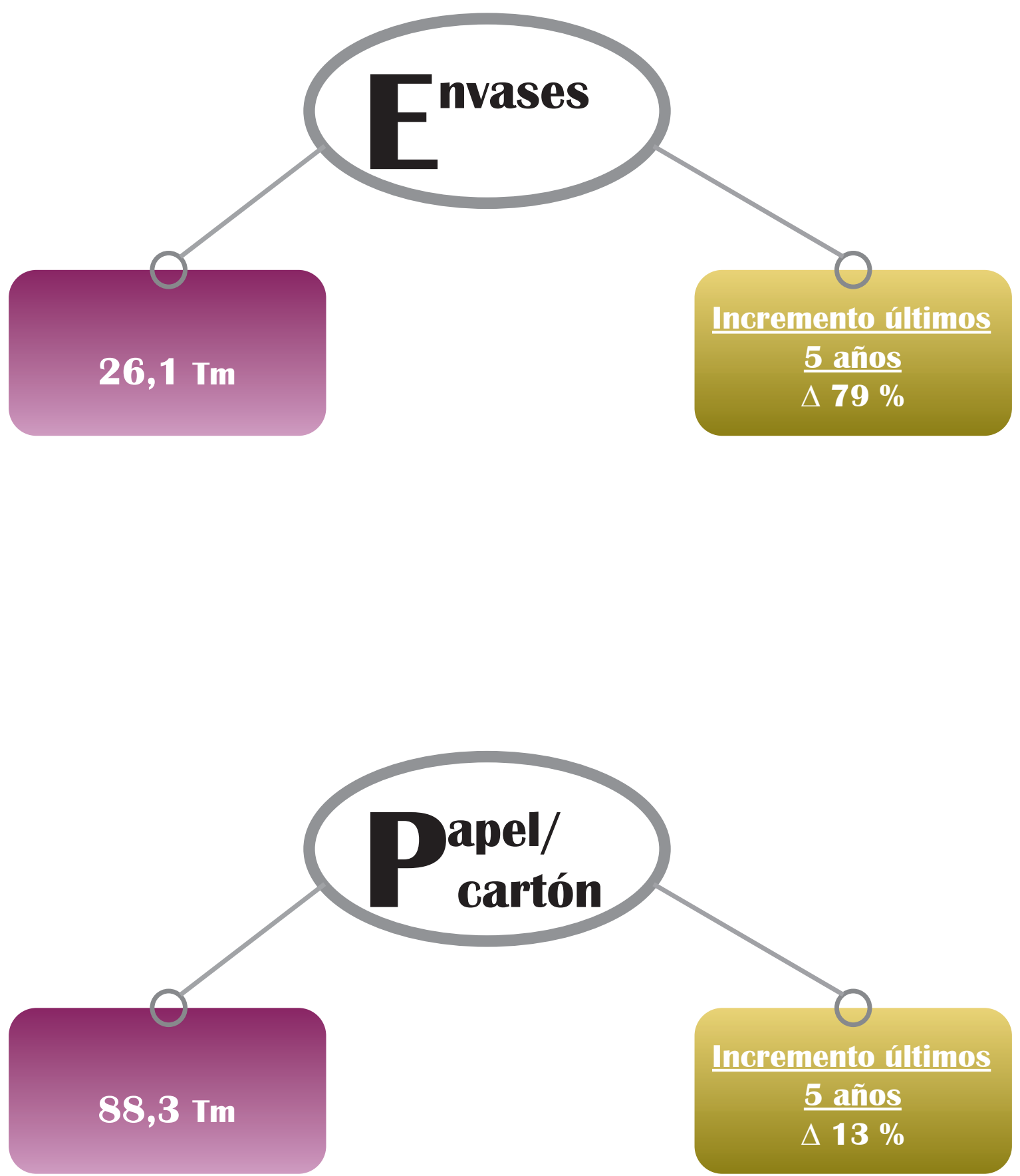


\subsection{Producción y consumo de energía} Año 2018

Fuentes: Servicios Técnicos de Investigación, Planta solar y Servicio de Infraestructuras y Servicios UA.

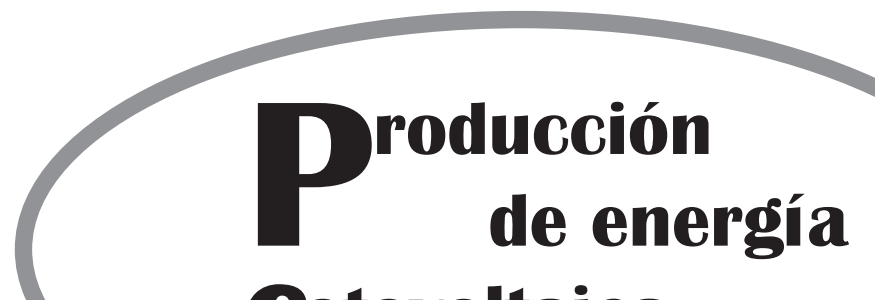

fotovoltaica

$140.160 \mathrm{kWh}$

\section{Consumo de} lectricidad Campus San Vicente

\section{5,9 \\ millones $k W h$}

\section{Consumo de}

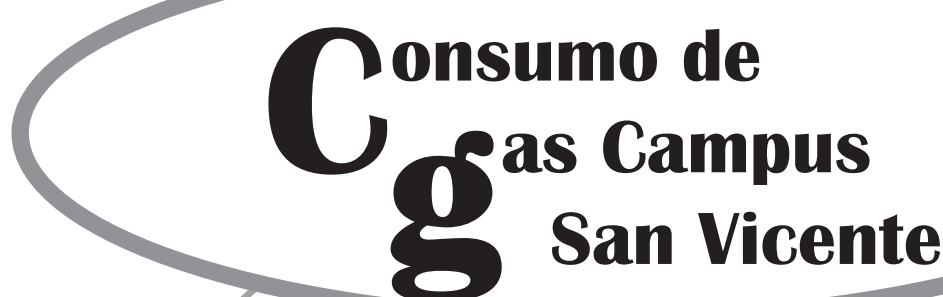

$147.394 \mathrm{~m}^{3}$

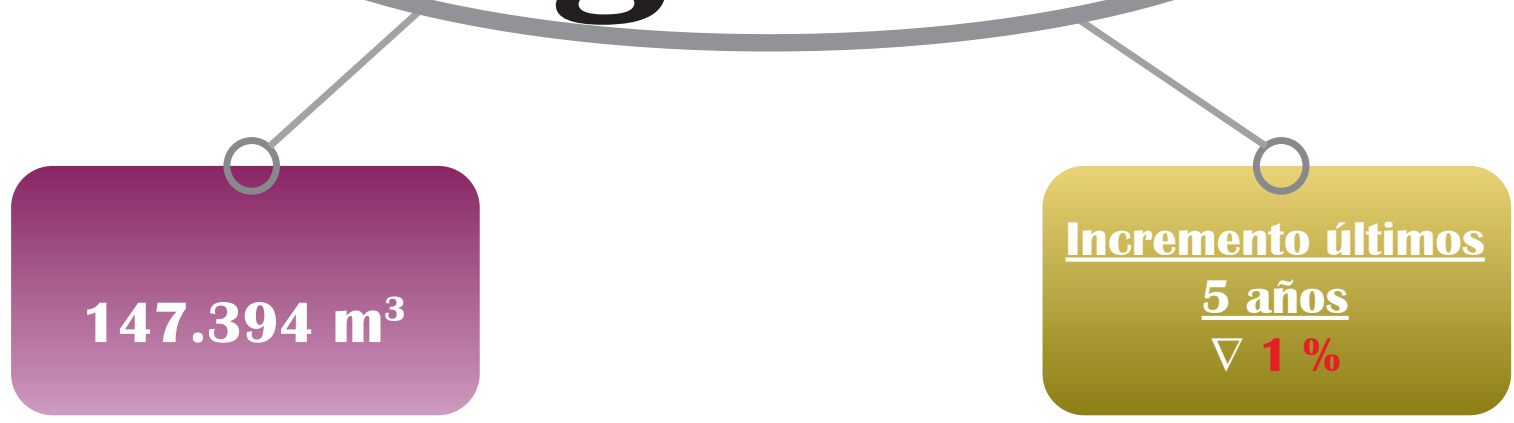




\subsection{Explotación y consumo de agua} Año 2018

Fuentes: Servicios Técnicos de Investigación, Planta de tratamiento de aguas y Servicio de Infraestructuras y Servícios UA.
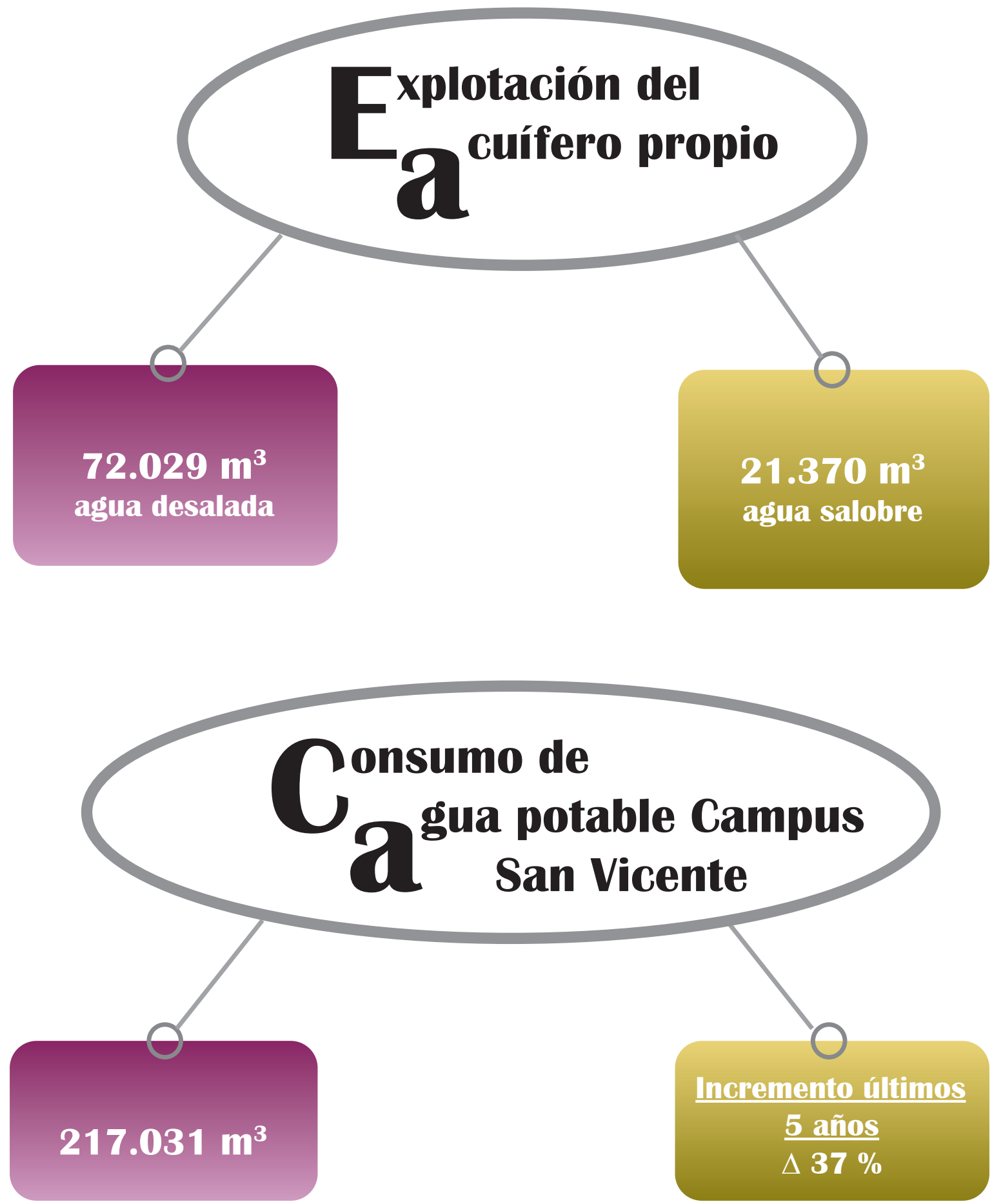


\section{La Universidad de \\ Alicante en los sistemas \\ universitarios valenciano \\ y estatal}




\subsection{Comunidad universitaria}

\section{Curso académico 2016/2017}

Fuentes: Sistema Integrado de Información Universitaria (SIIU) y Sistema de Información de las Universidades Valencianas Públicas (SIUVP).

* UU.PP. = Universidades públicas presenciales de España

Ratio de estudiantes por PDI

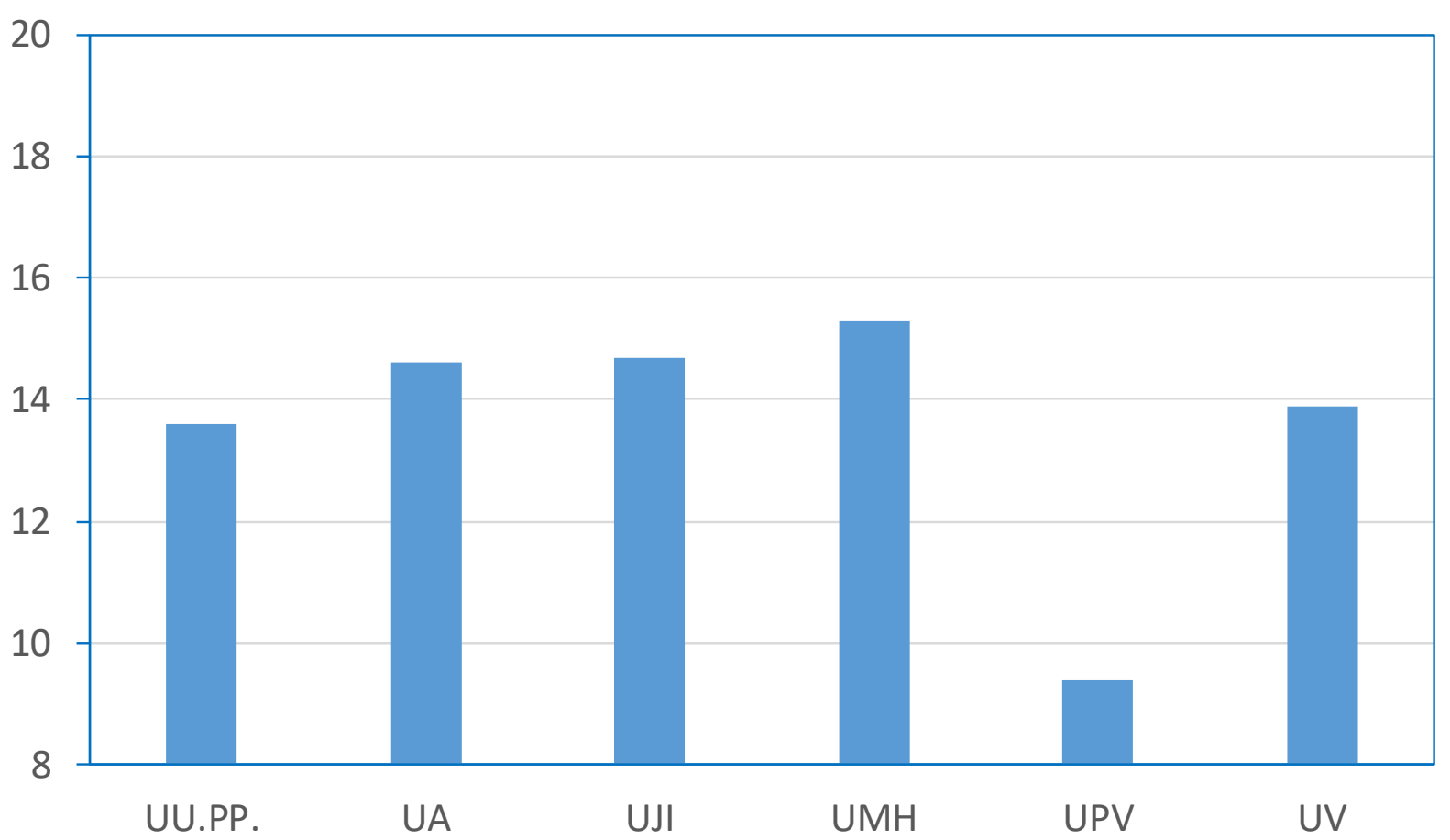

Ratio de estudiantes por PDI doctor

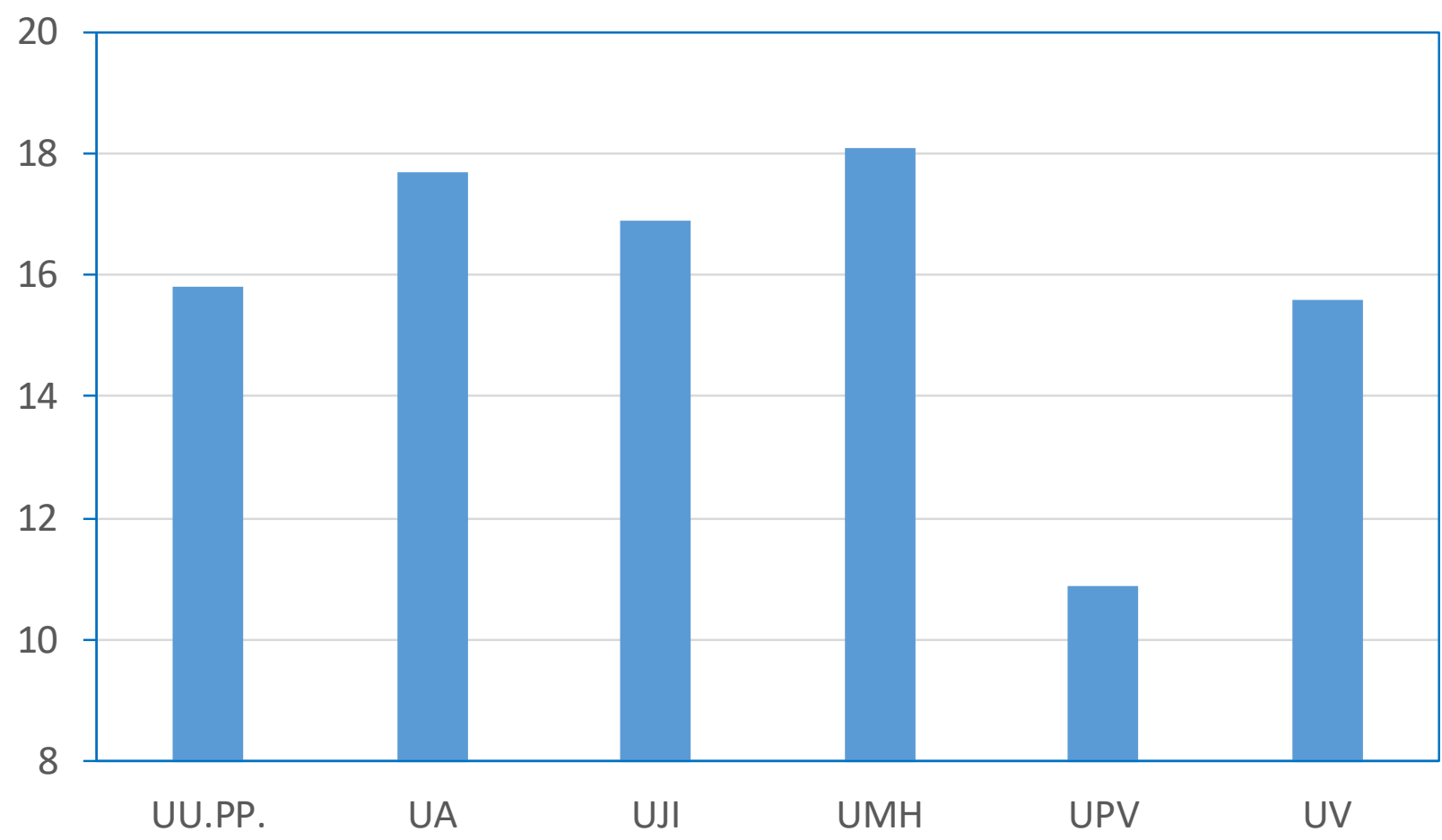




\section{PDI funcionario (\%)}

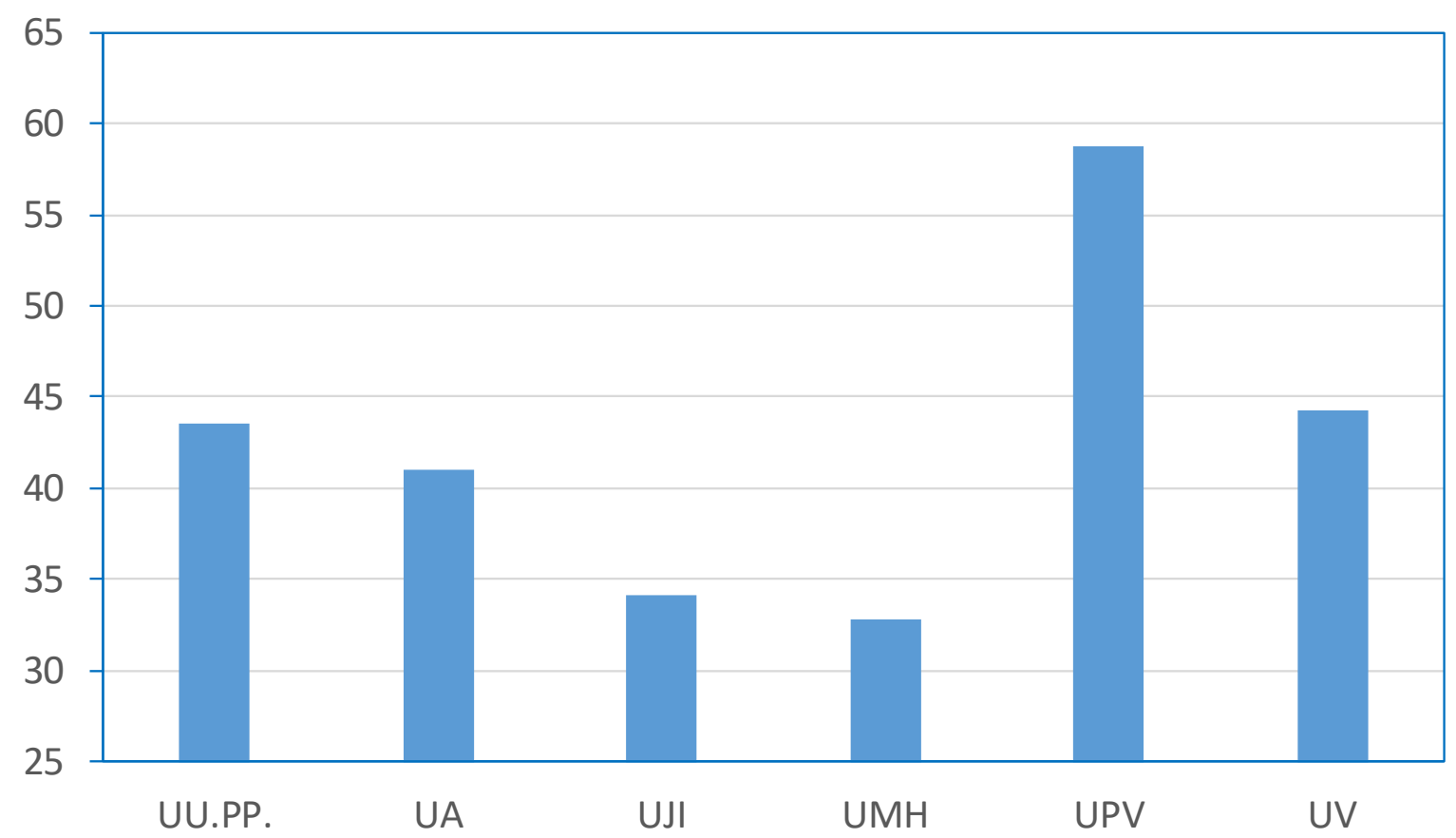

PDI funcionario de 50 años y más (\%)

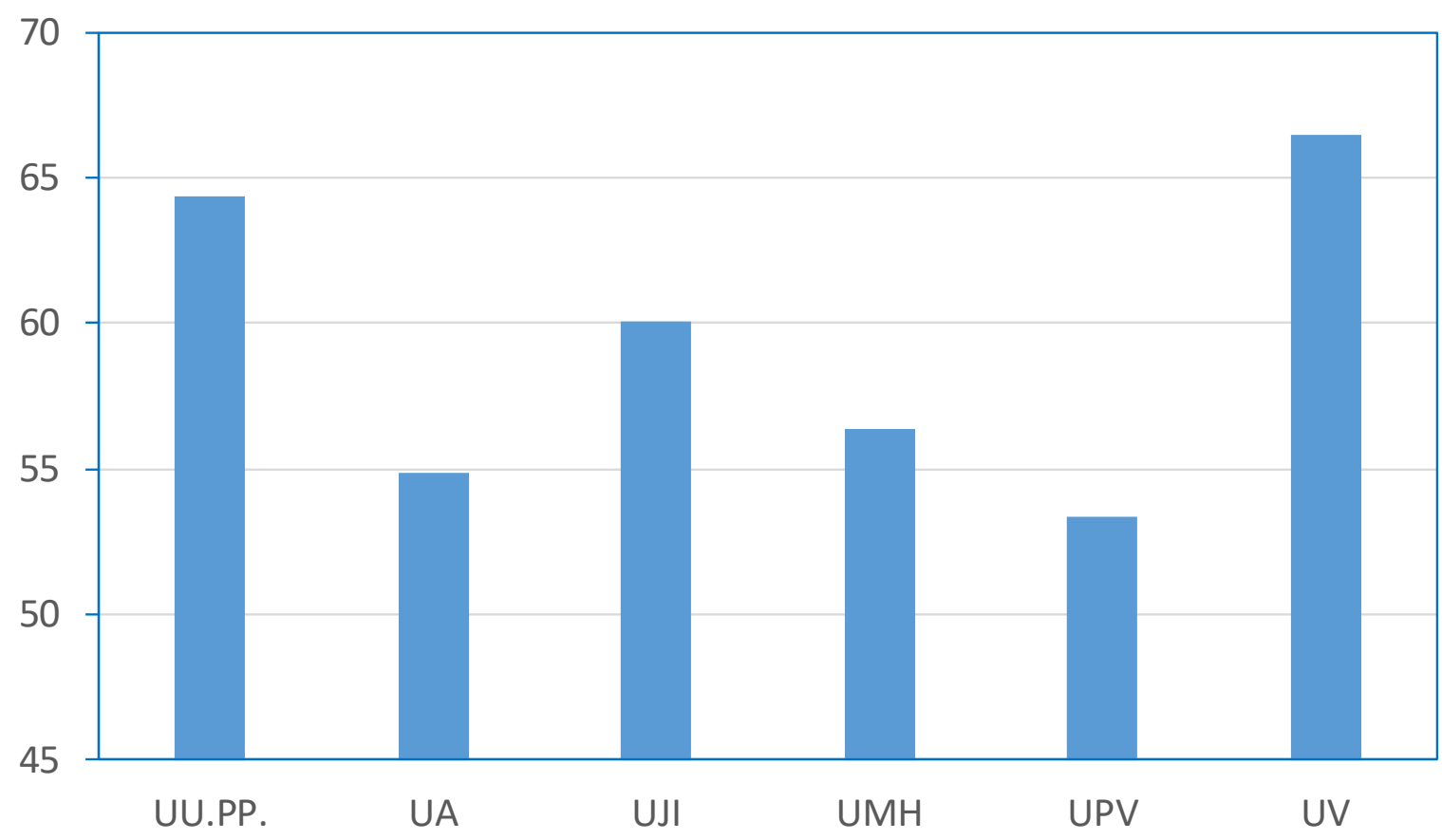


PDI mujer (\%)

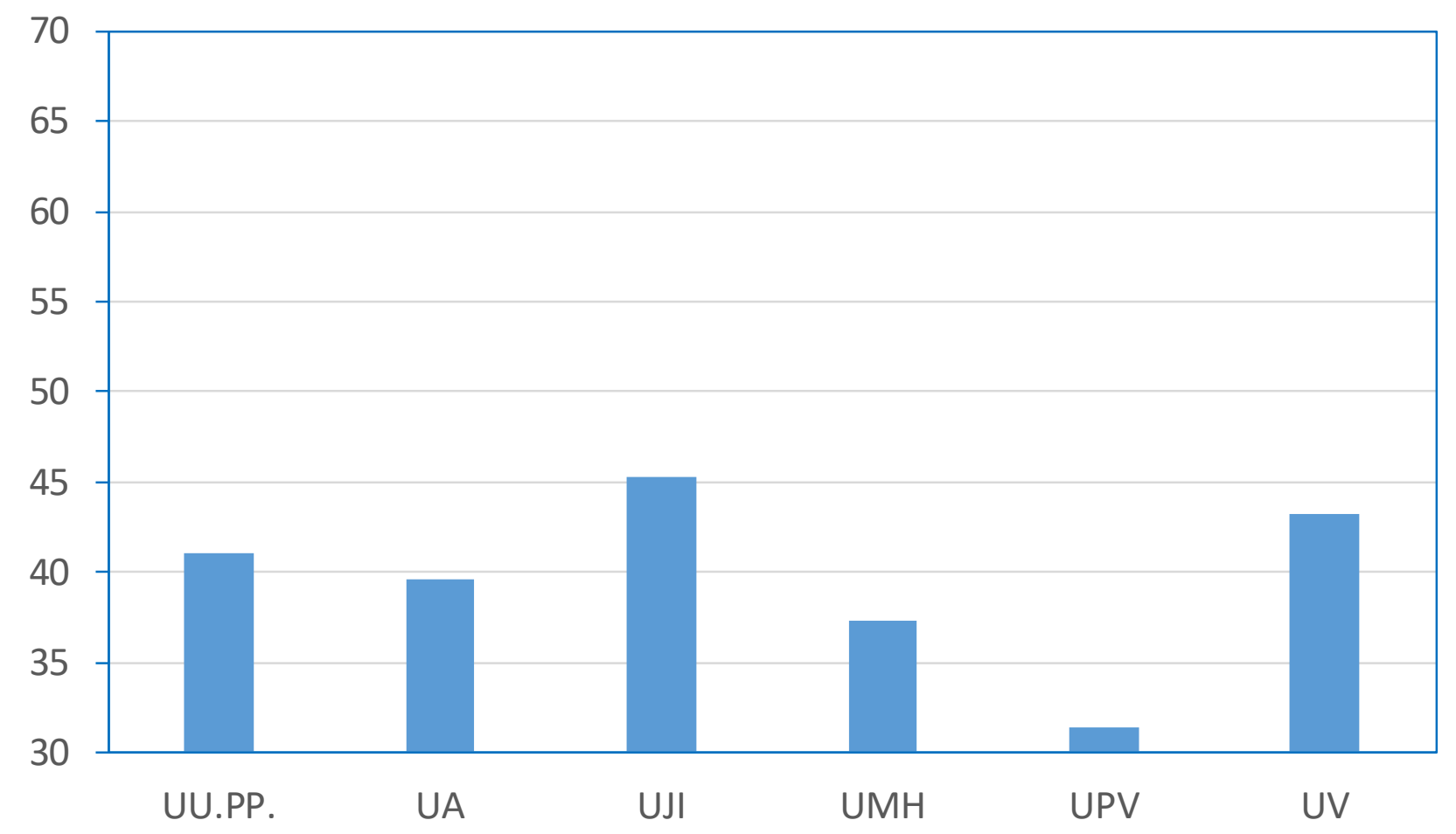

PAS mujer (\%)

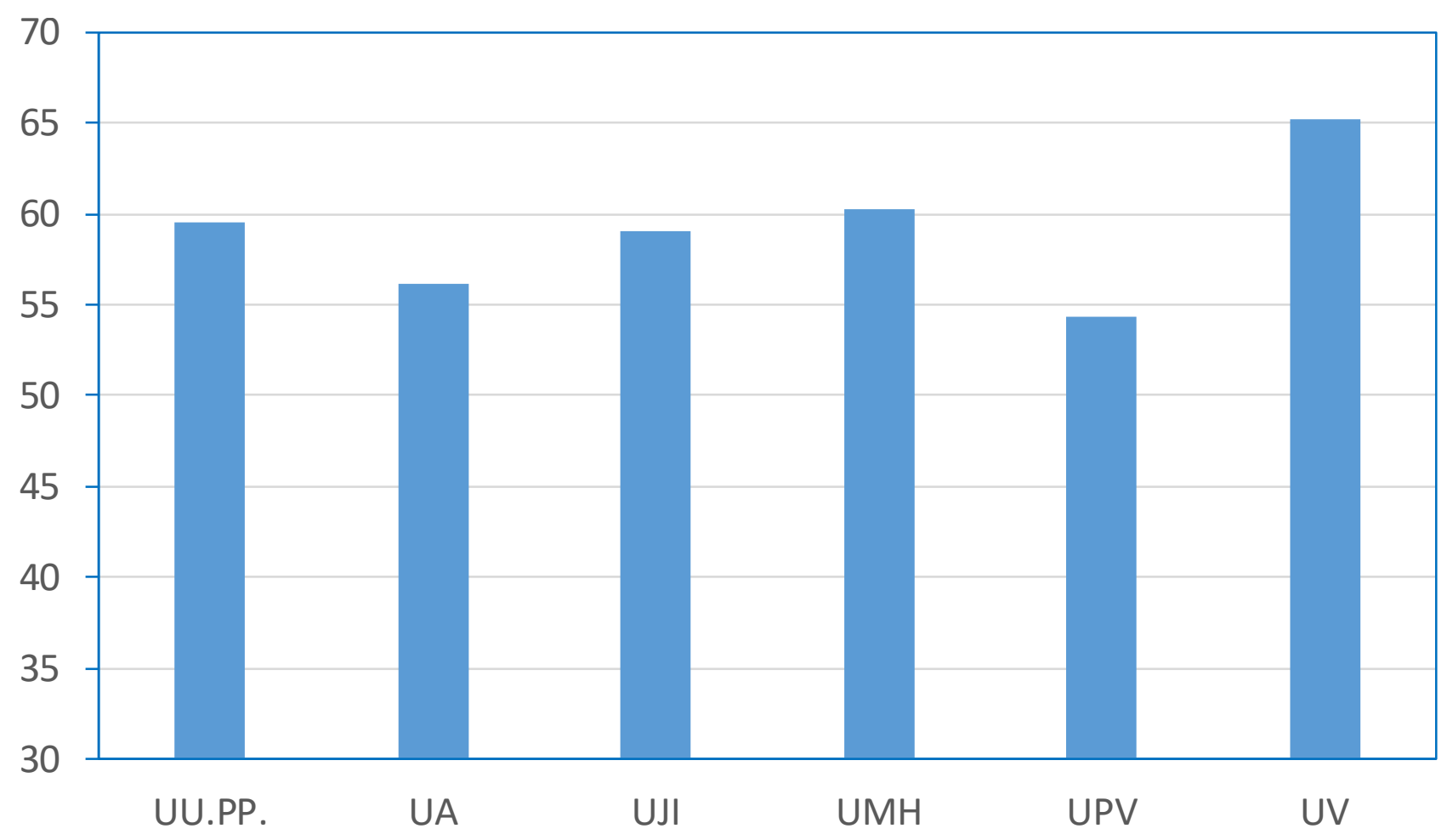


PAS funcionario (\%)

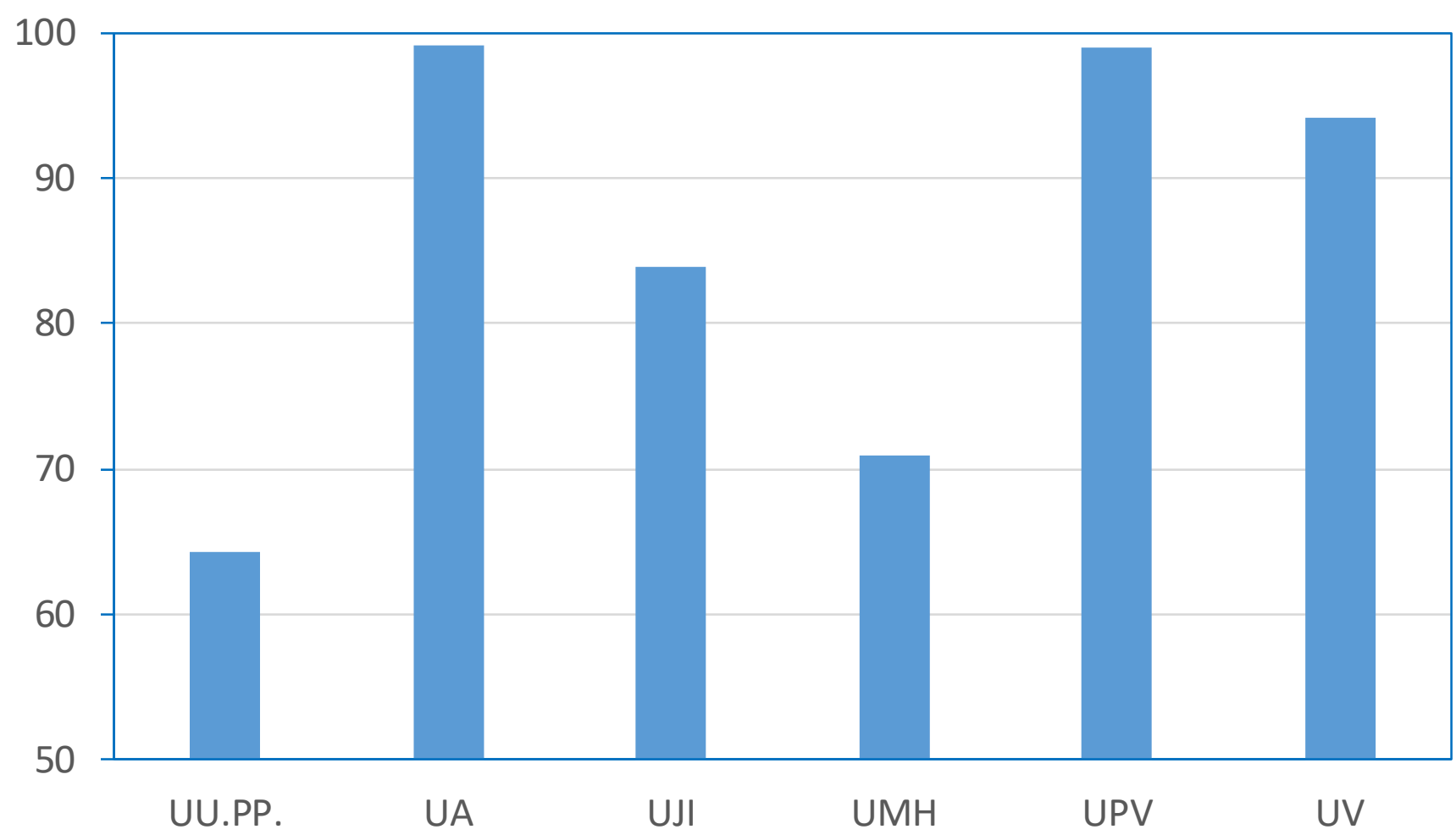

PAS de 50 años y más (\%)

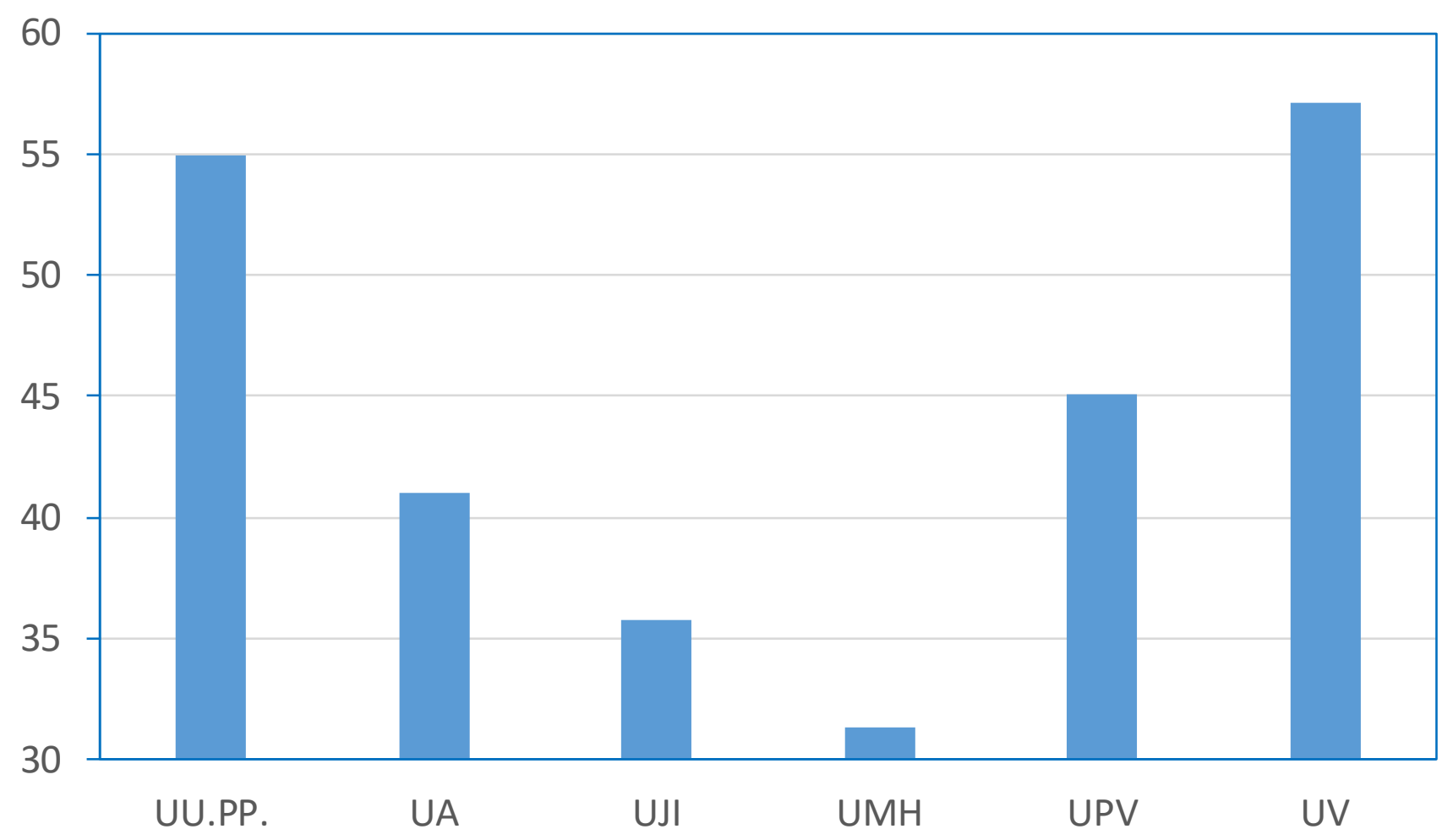


Ratio PDI/PAS

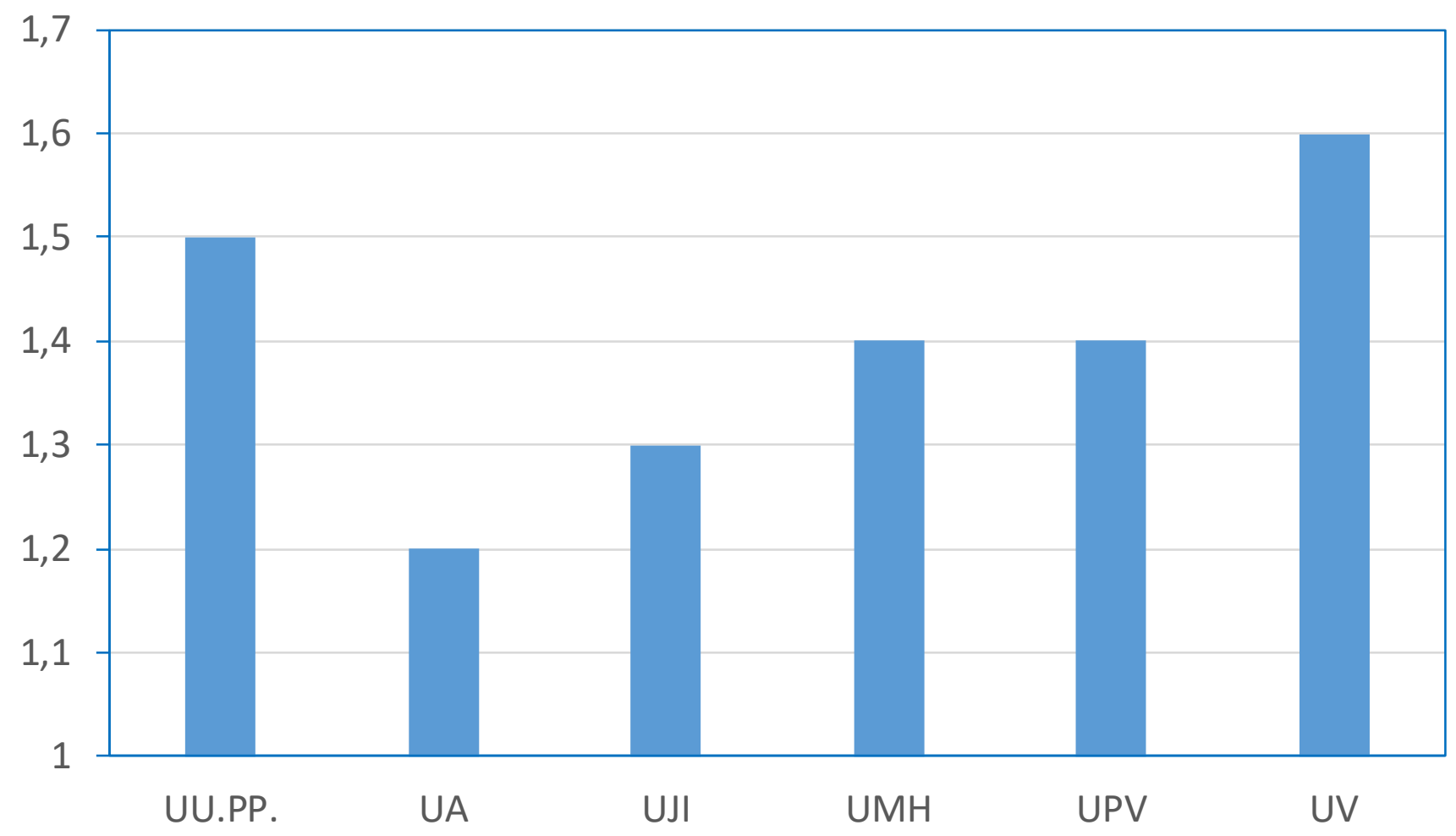




\subsection{Financiación}

\section{Año 2016}

Fuentes: Sistema Integrado de Información Universitaria (SIIU) y Sistema de Información de las Universidades Valencianas Públicas (SIUVP).

* UU.PP. = Universidades públicas de España

Gasto de personal sobre gasto total

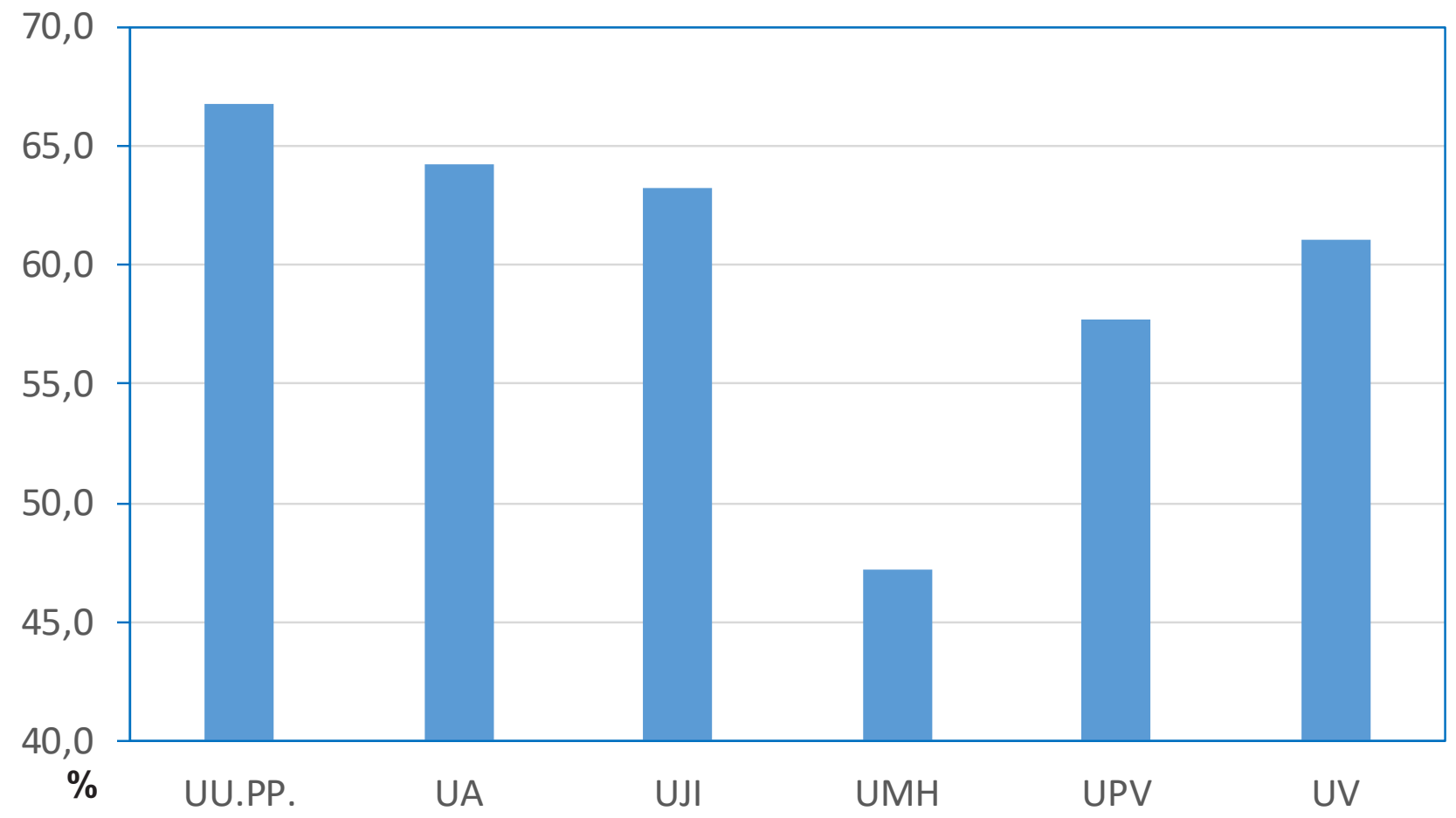

Cobertura del gasto de personal con ingresos por precios públicos y otros servicios

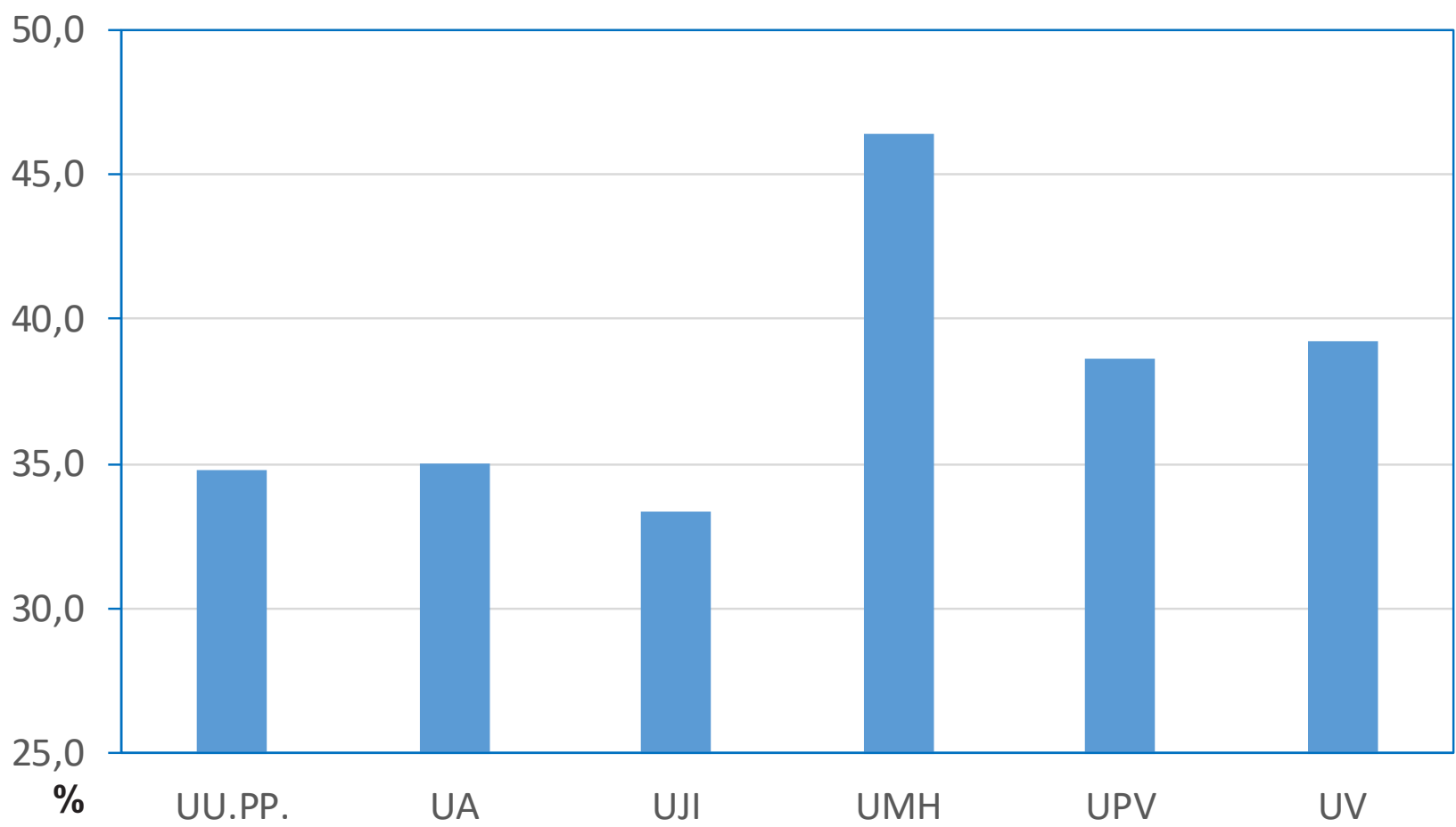


Recursos captados por tasas y precios públicos sobre el total de ingresos

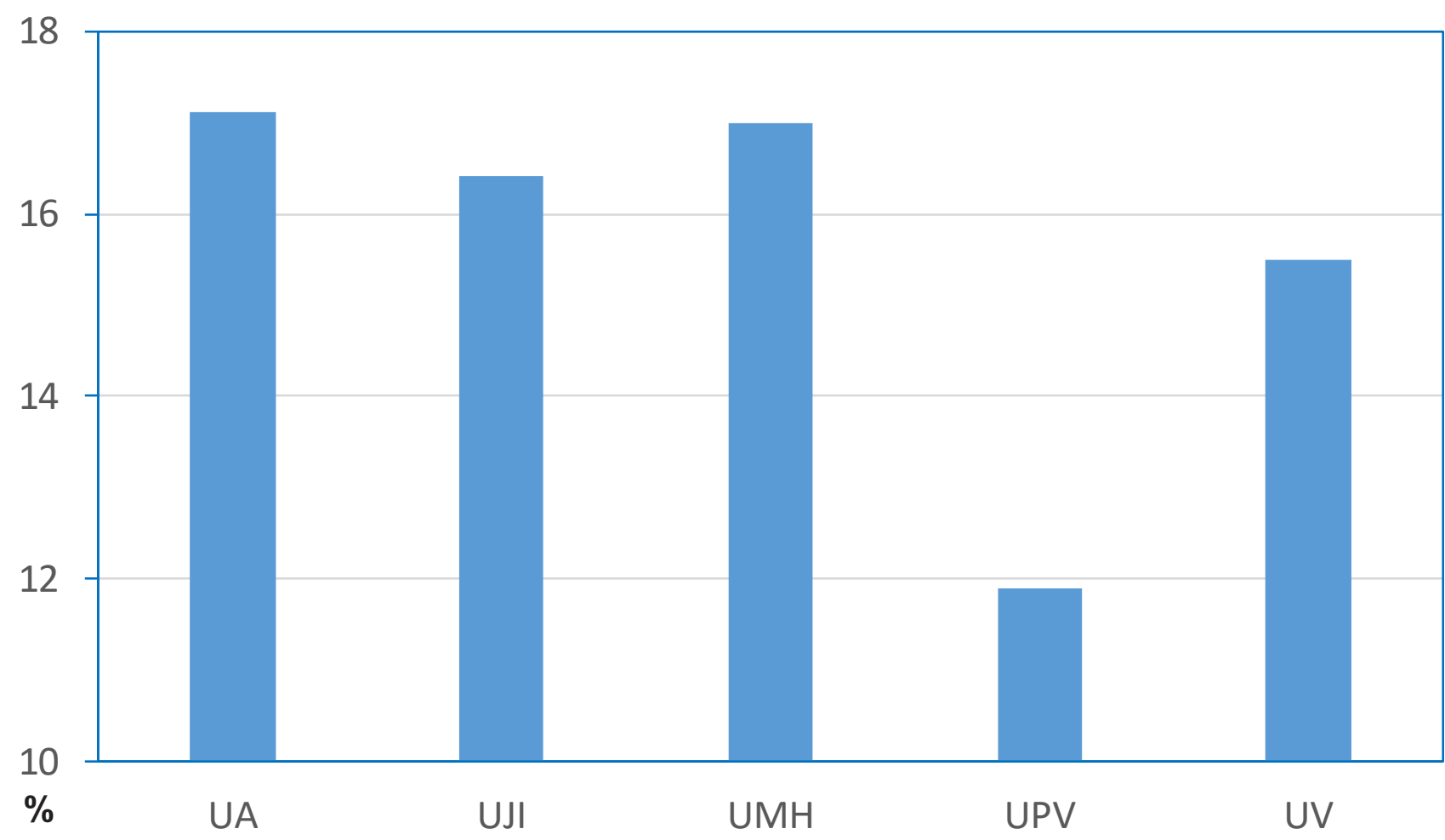

Recursos captados en I+D sobre el total de ingresos

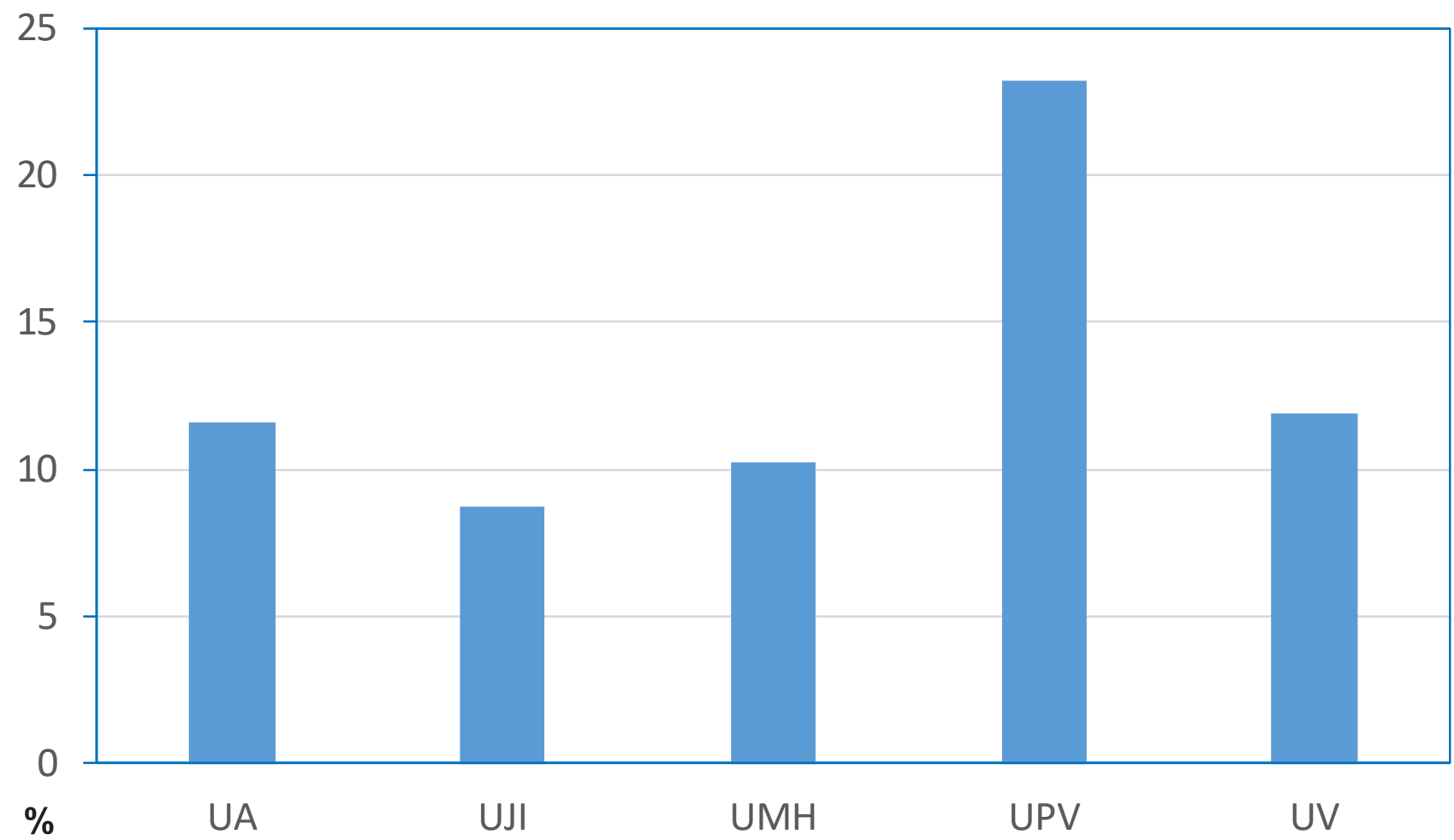




\section{3. Éxito académico}

\section{Curso académico 2016/2017}

Fuente: Sistema Integrado de Información Universitaria (SIIU).

* UU.PP. = Universidades públicas de España

Ratio créditos superados/créditos matriculados en estudios de grado (\%)

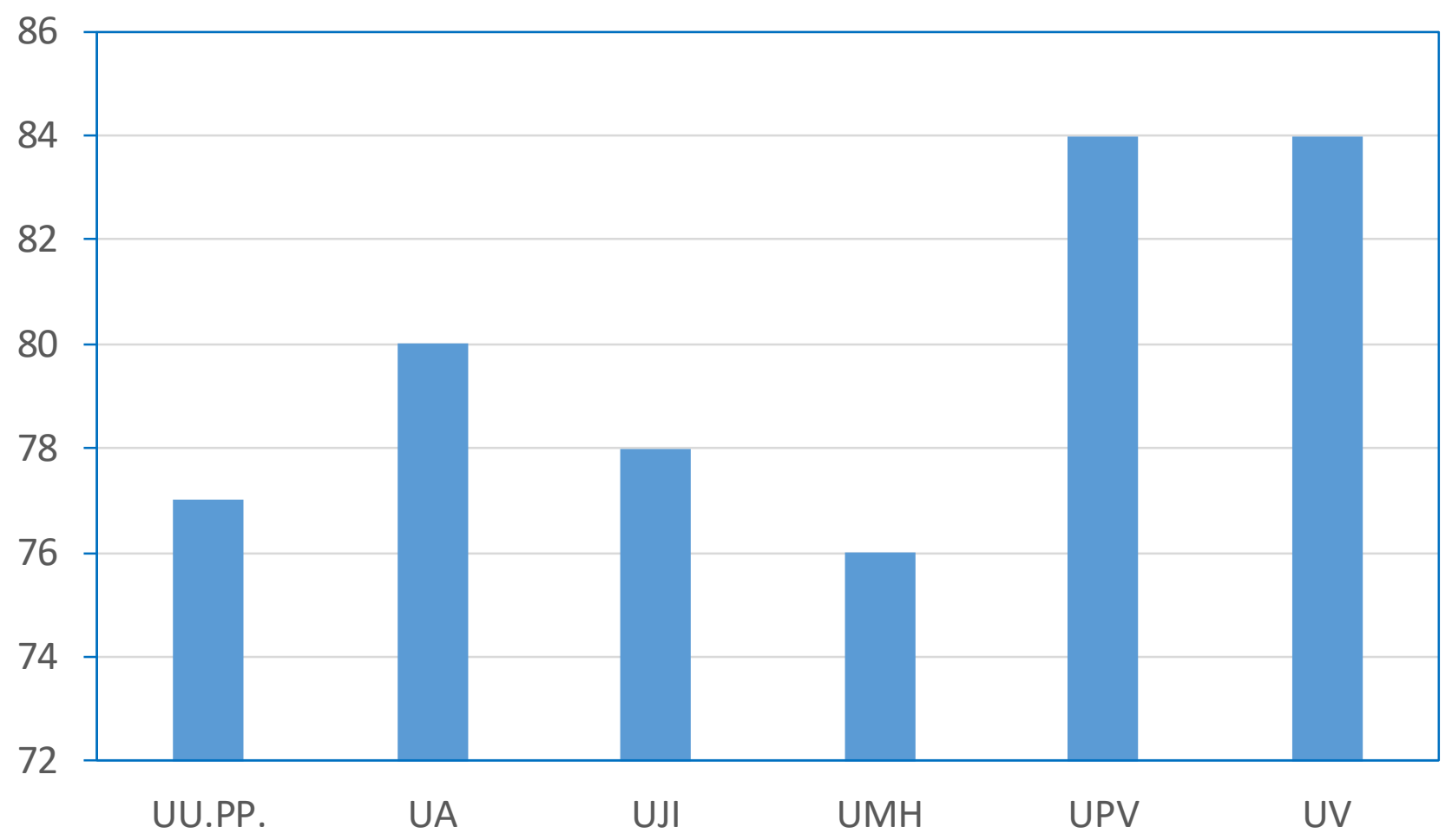

Ratio créditos superados/créditos matriculados en estudios de máster (\%)

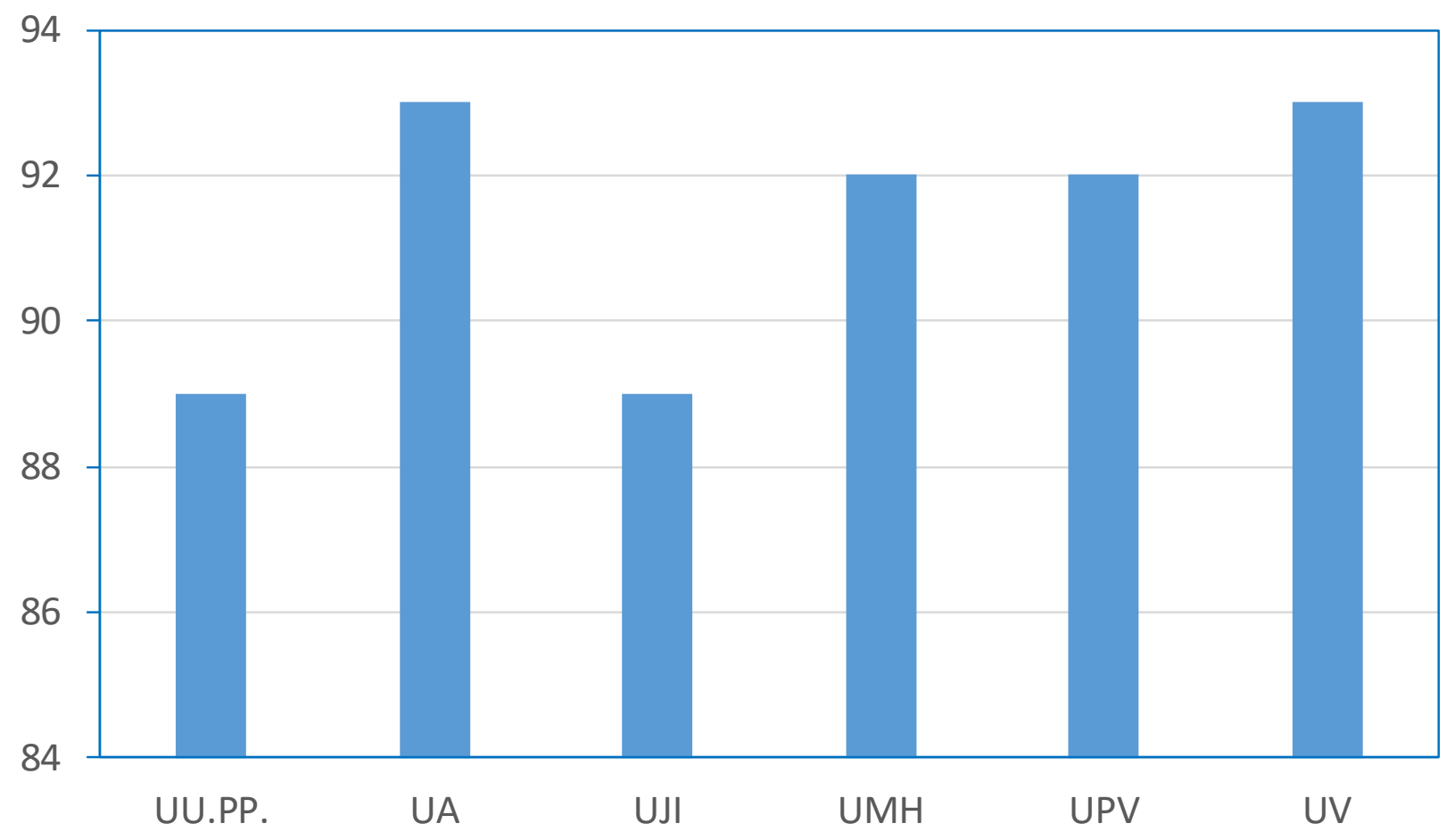


Duración media de los estudios de grado de 240 ECTS (años)

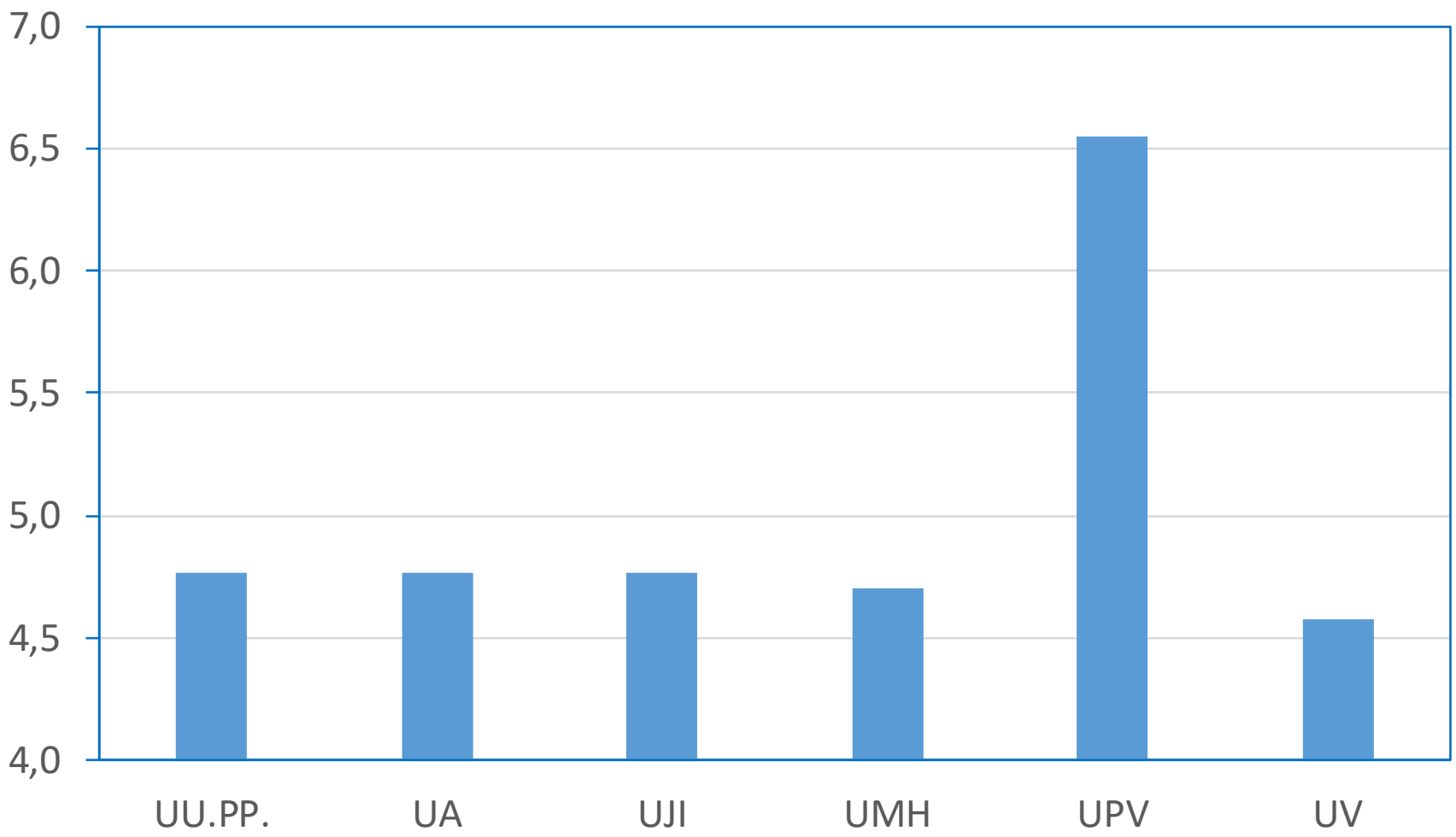

Duración media de los estudios de máster de 60 ECTS (años)

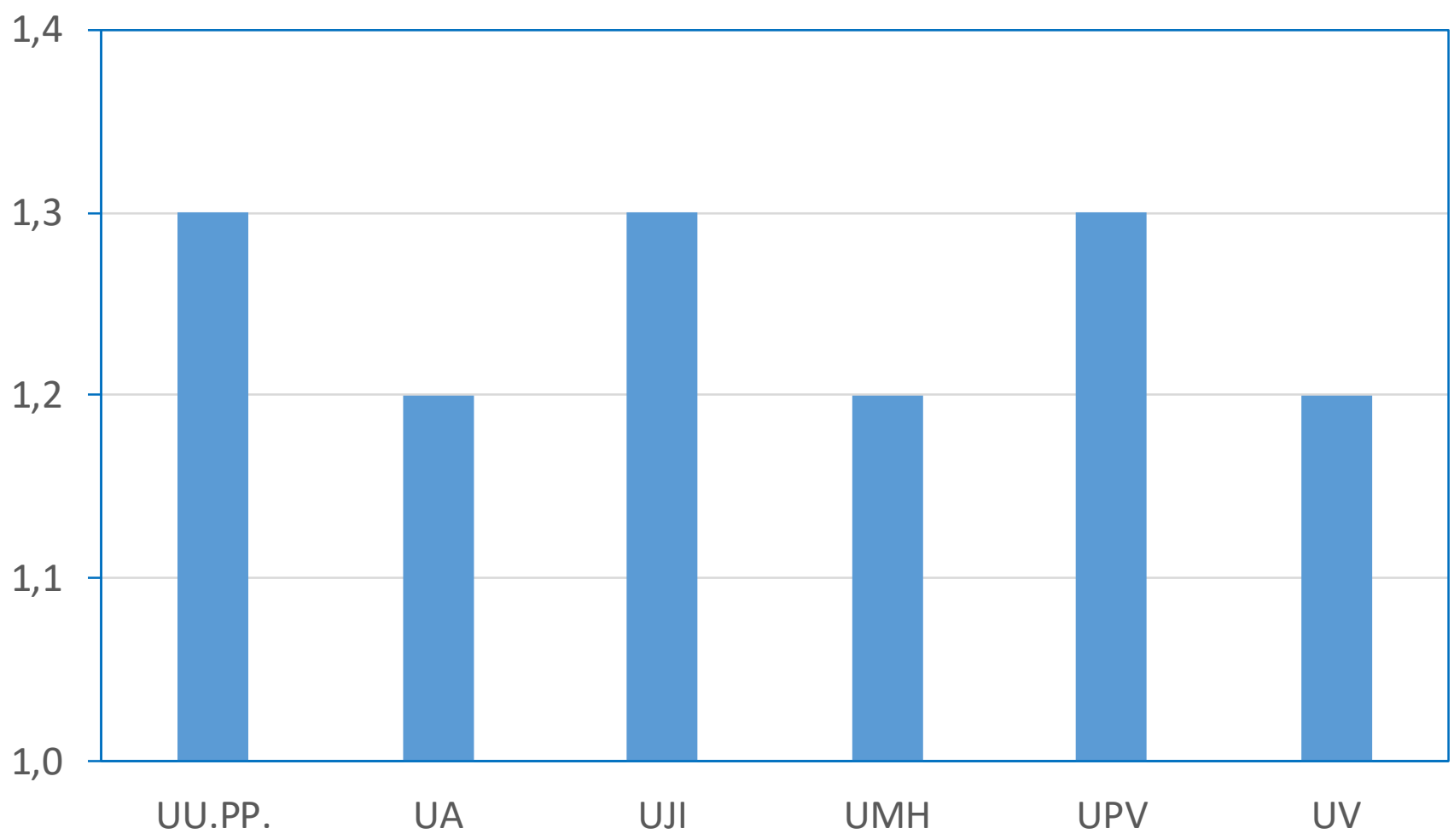




\subsection{I+D+I}

Fuentes: CRUE, La universidad española en cifras 2016/2017, Sistema Integrado de Información Universitaria (SIIU) y Sistema de Información de las Universidades Valencianas Públicas (SIUVP).

* UU.PP.= Universidades públicas presenciales de España

Promedio producción científica anual en Web of Science por PDI (2007-2016)

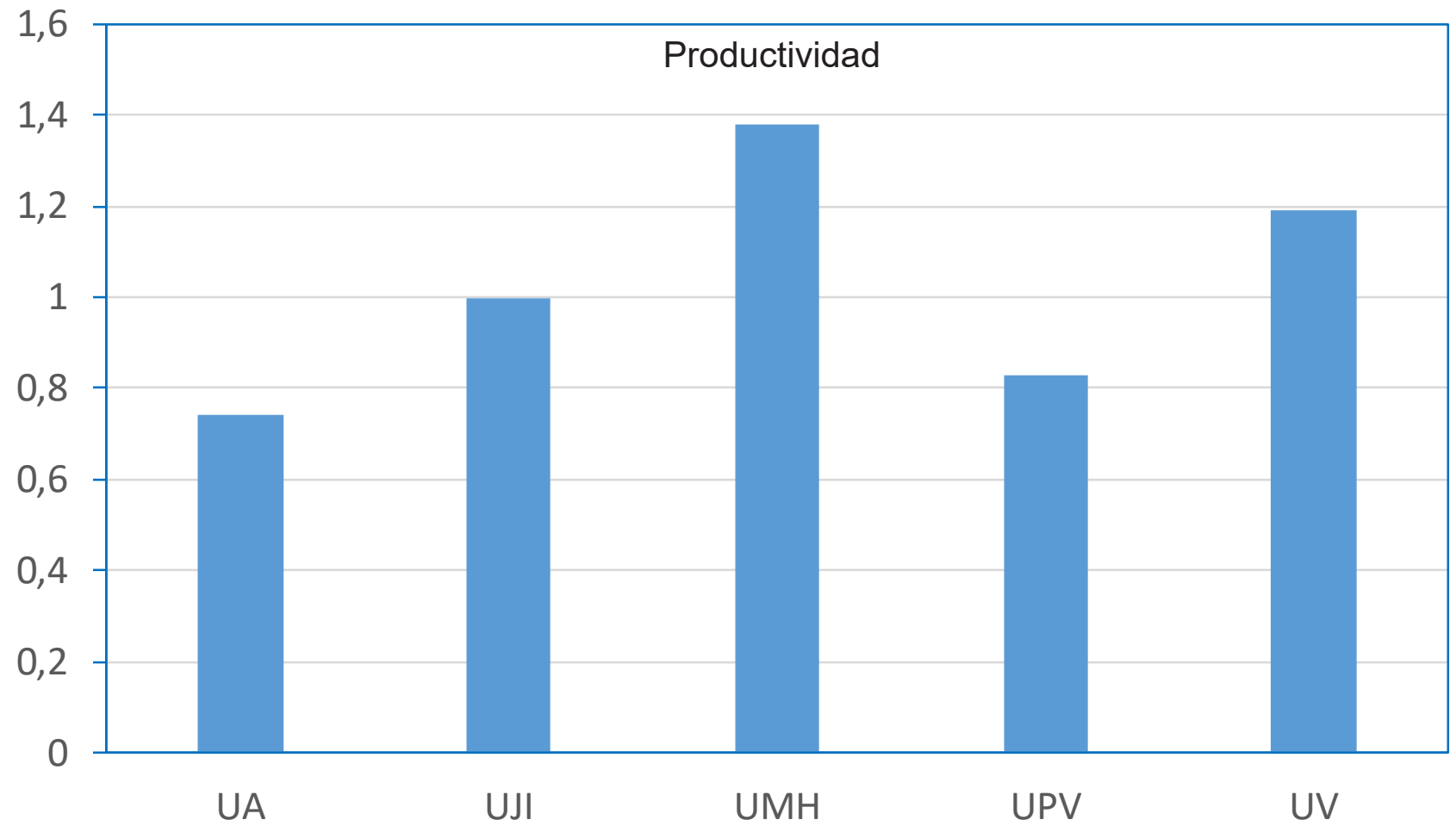

Promedio de citas de la producción científica en Web of Science (2007-2016)

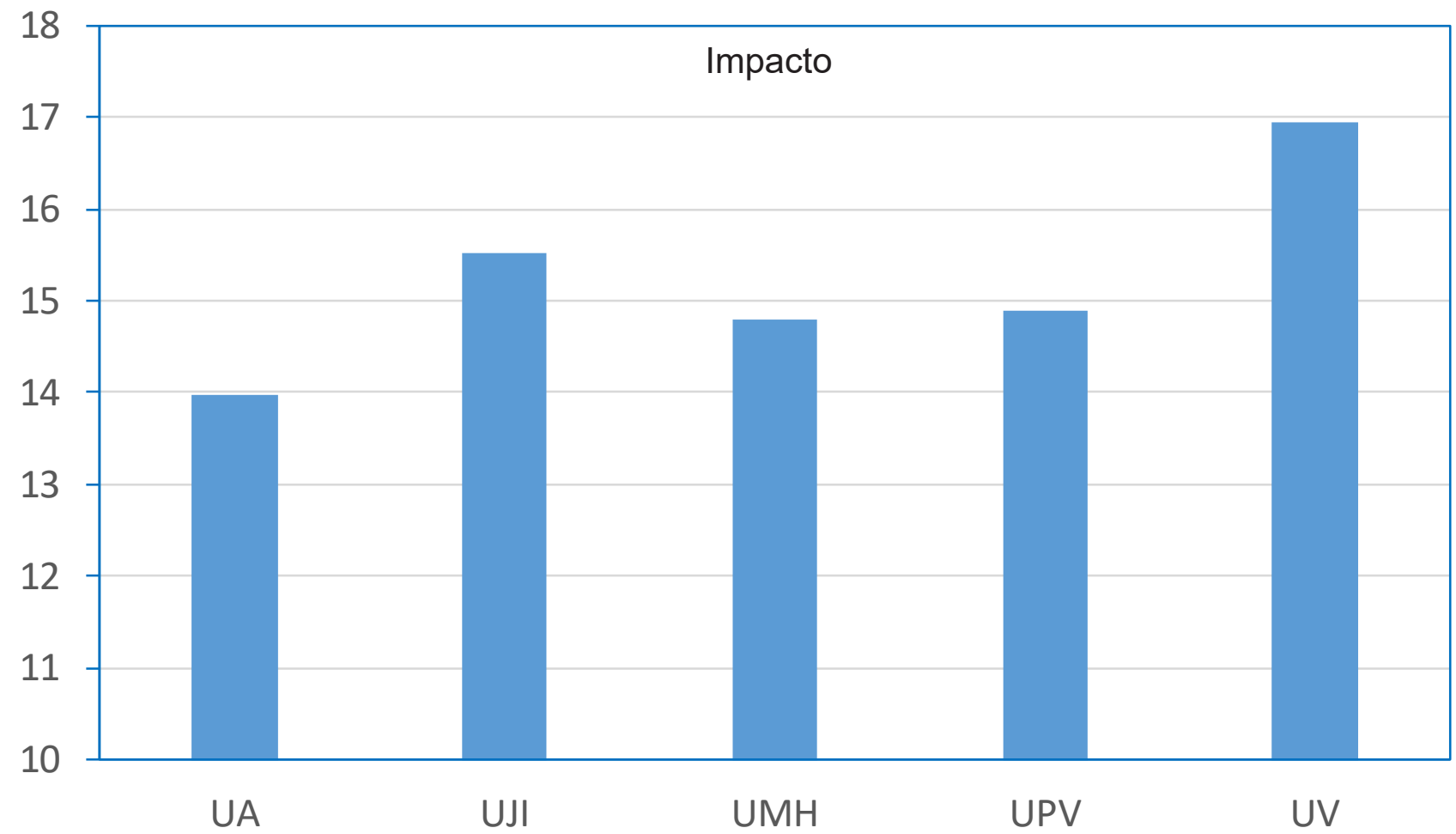


Producción científica en Web of Science (2007-2016) en revistas Q1

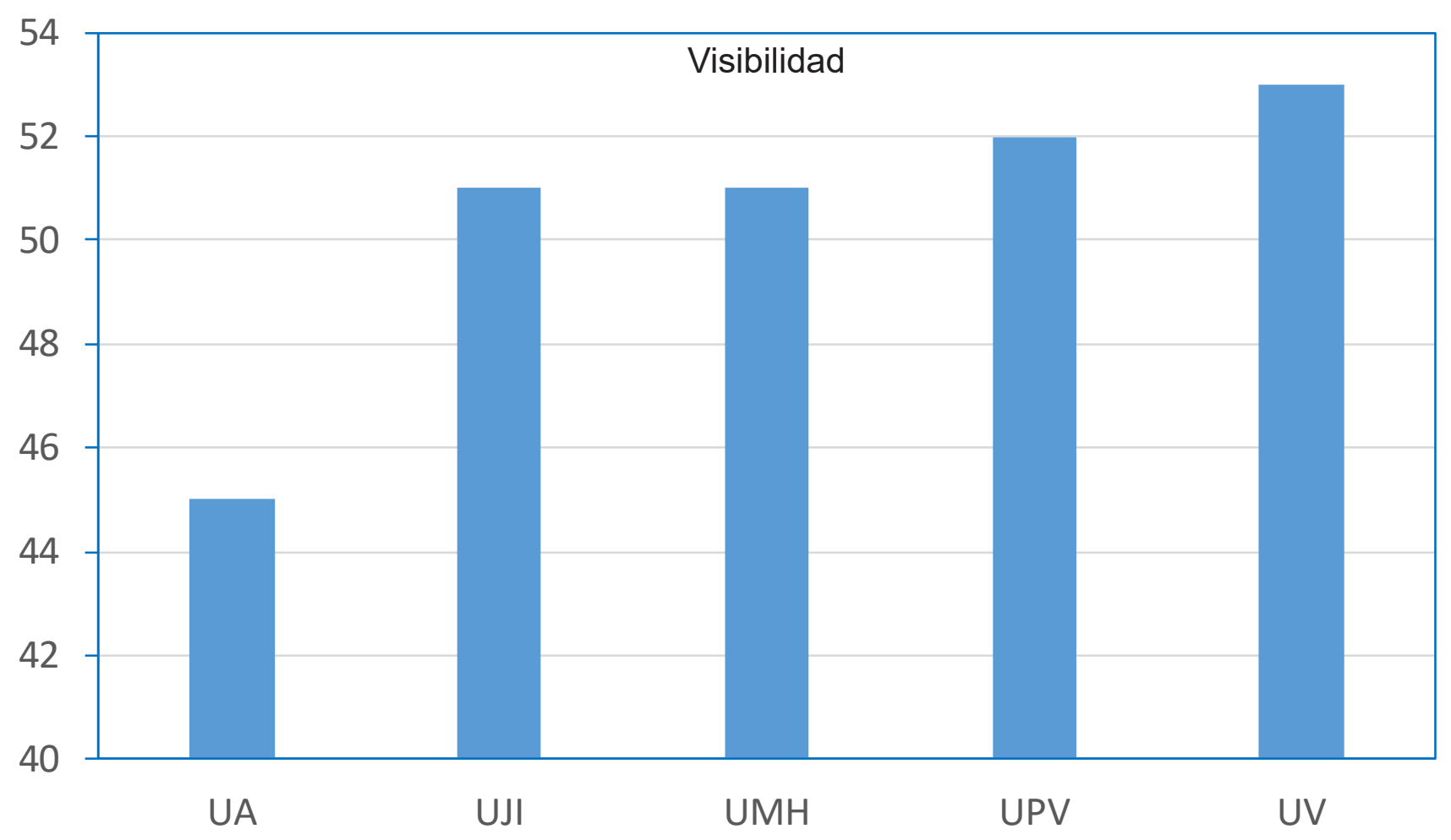

Número medio de sexenios por PDI funcionario. 2016

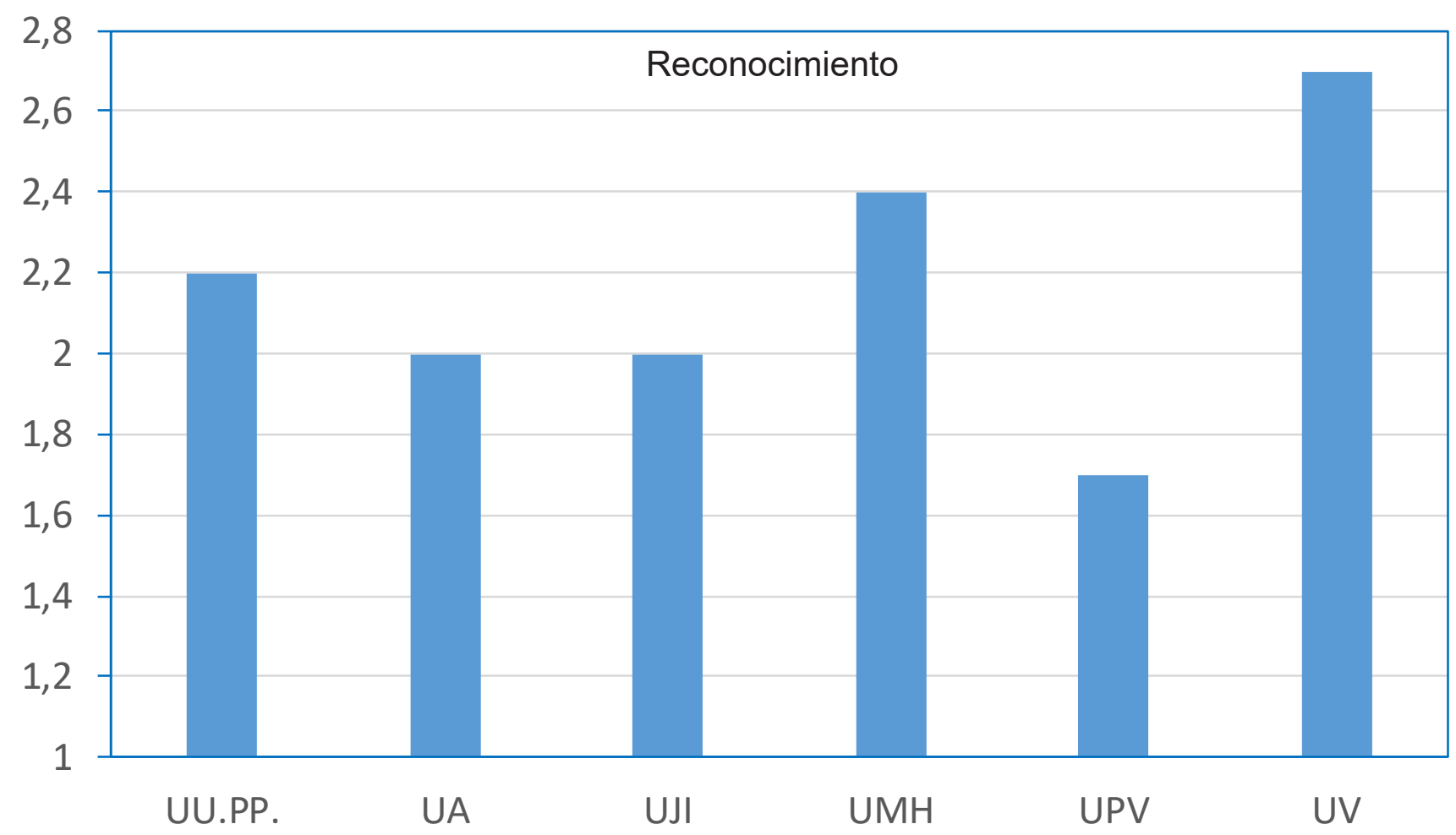


Patentes registradas en la OEPM por PDI doctor. 2017

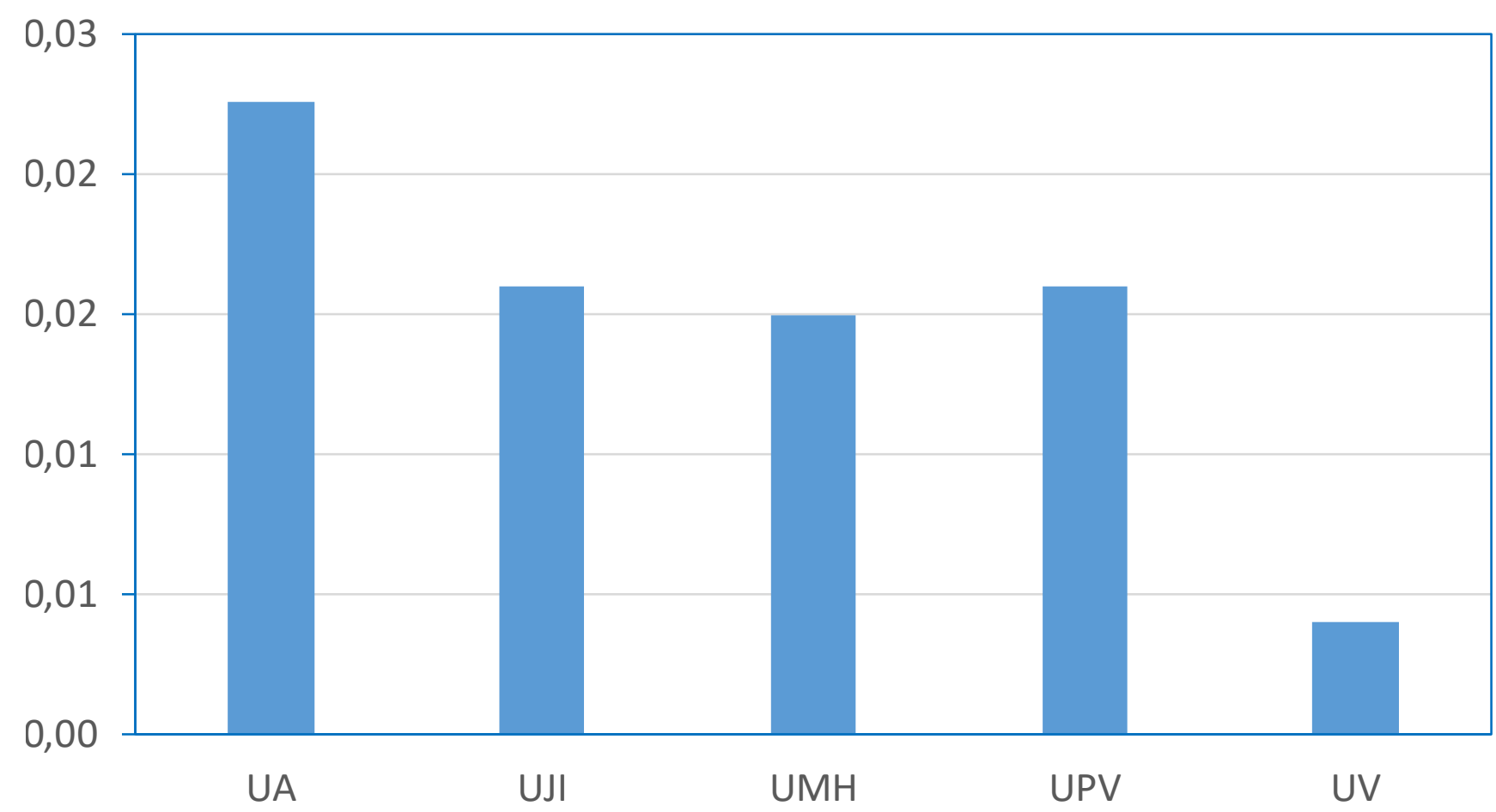

Tesis doctorales defendidas por PDI doctor. 2017/2018

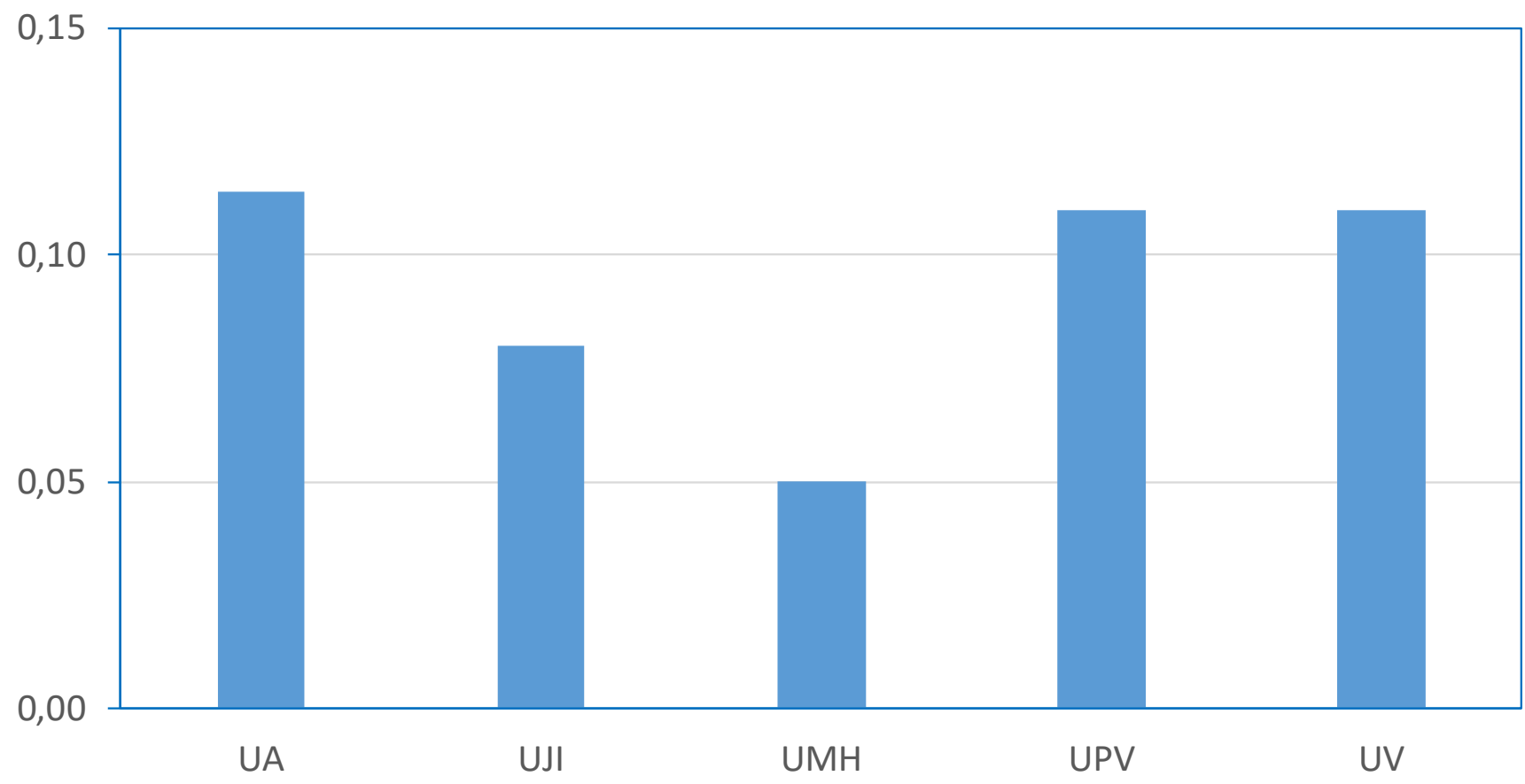


Recursos captados en I+D por PDI doctor. 2016

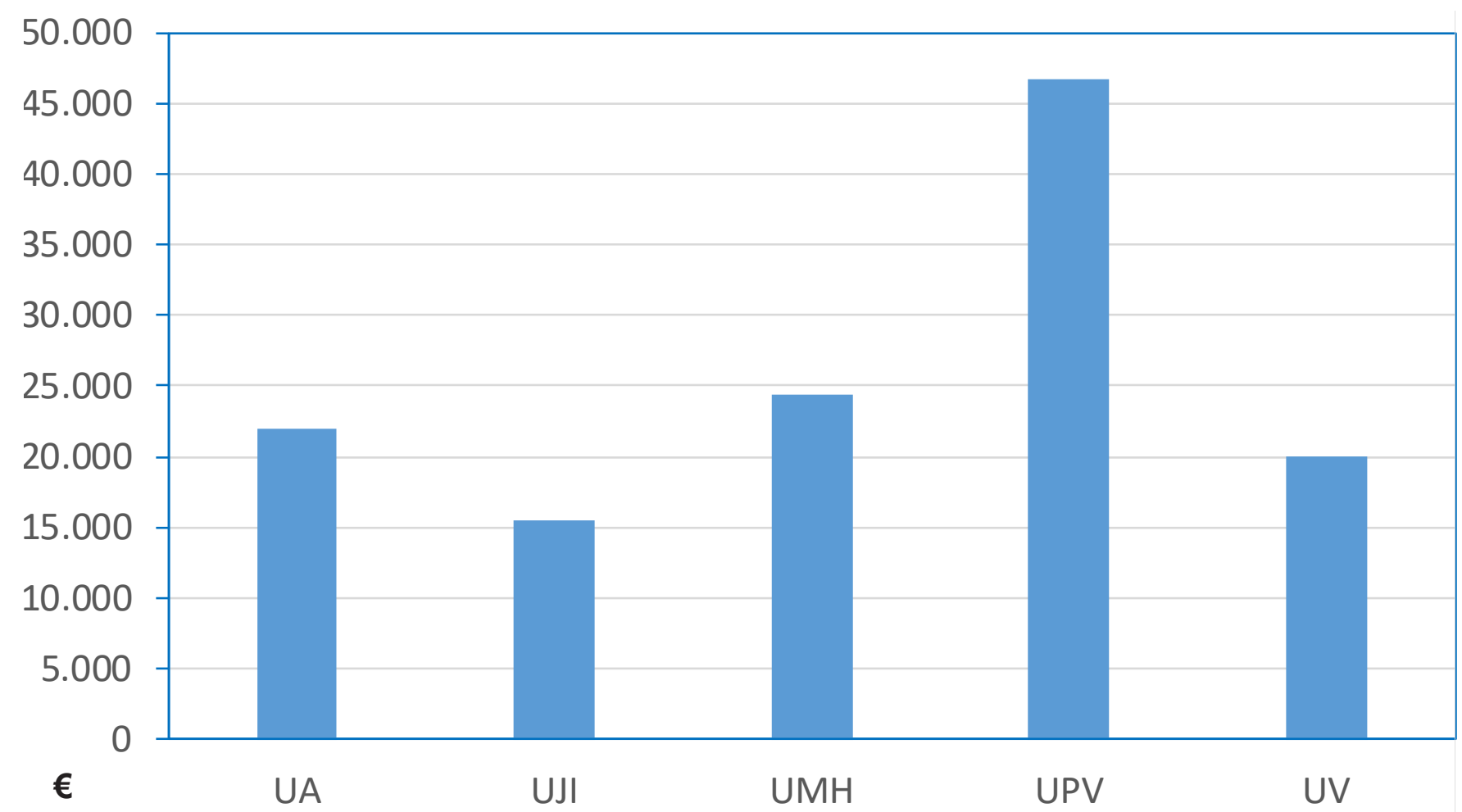

Recursos públicos captados en I+D por PDI doctor. 2016

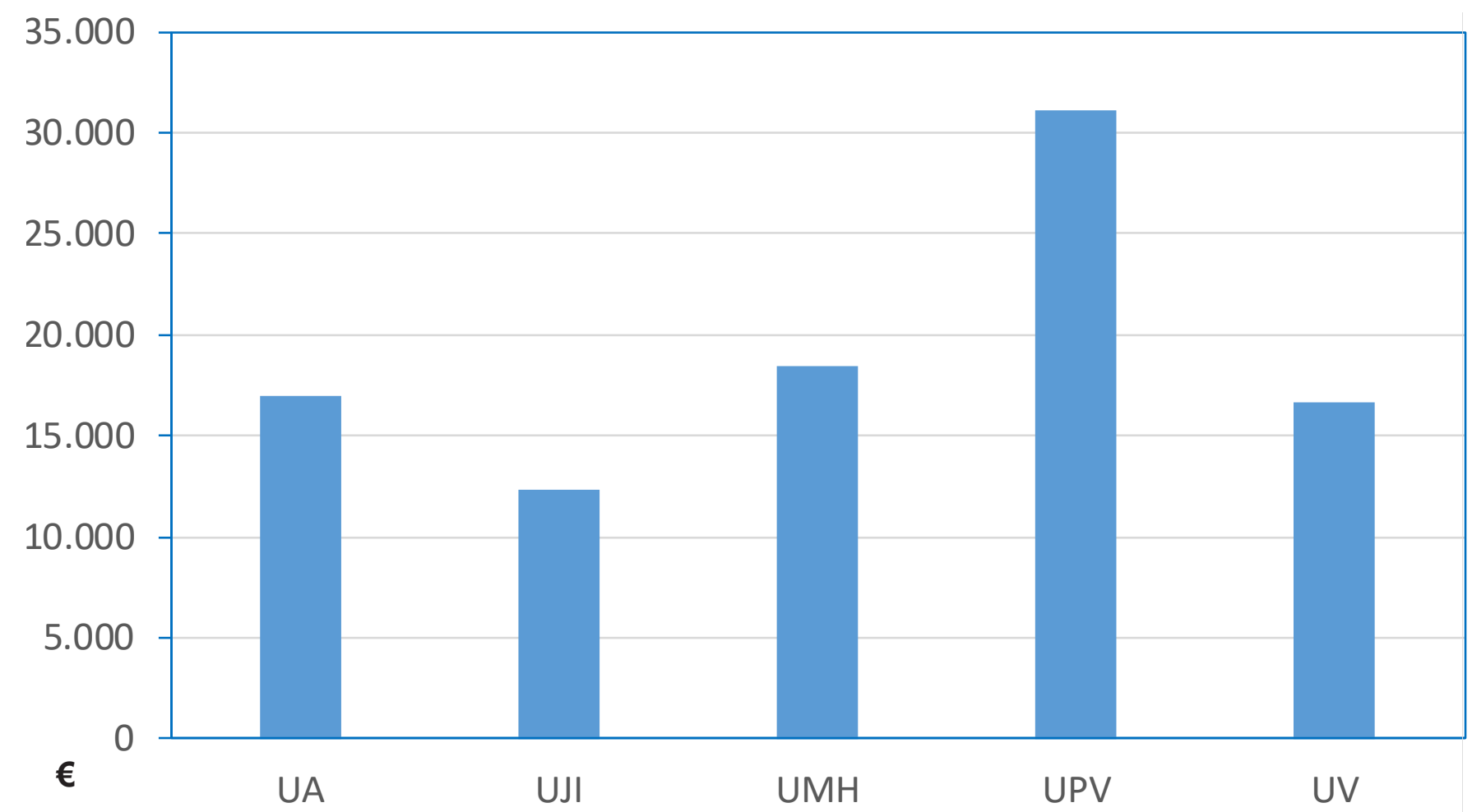


Recursos privados captados en I+D por PDI doctor. 2016

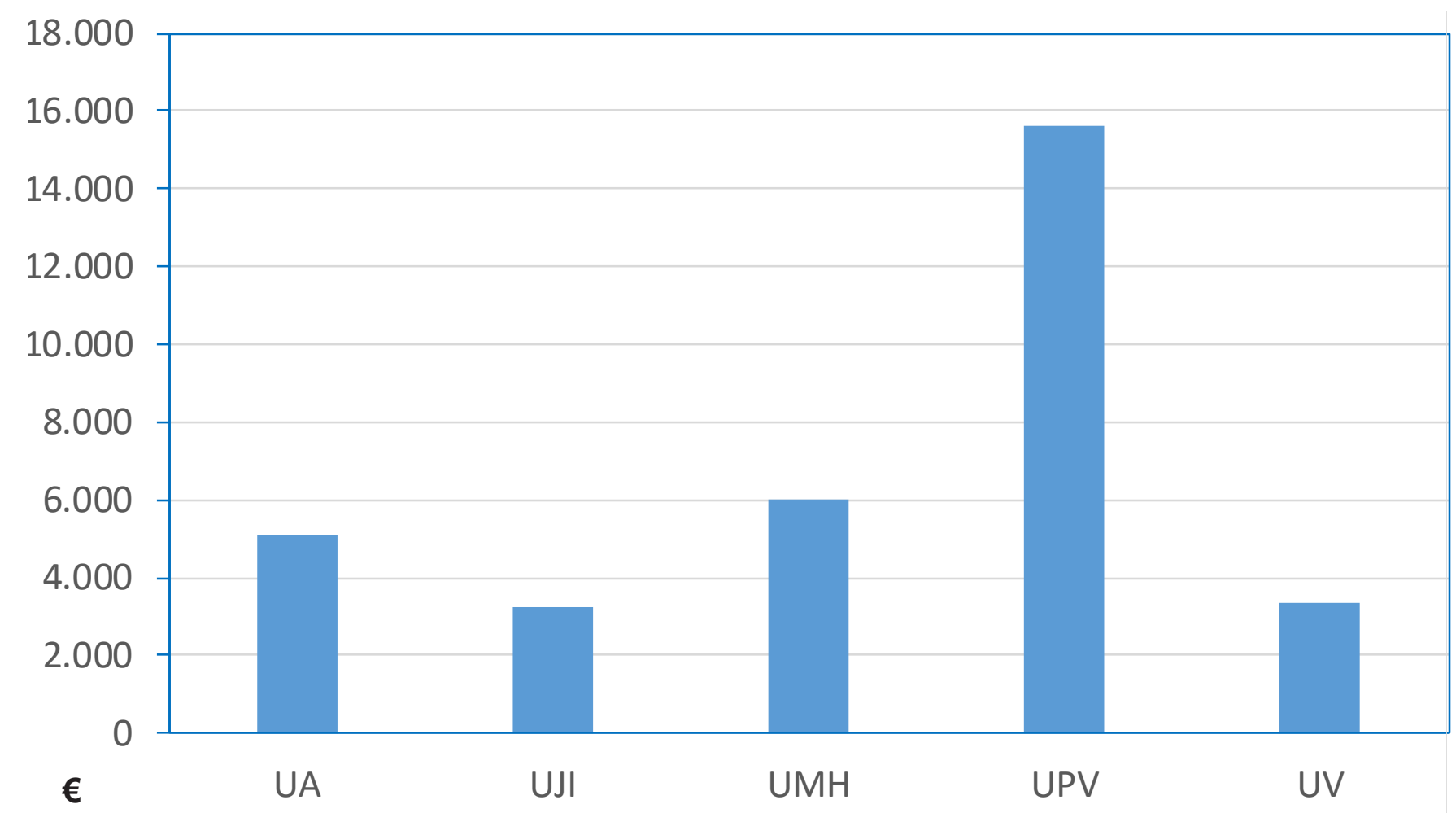




\subsection{Internacionalización}

\section{Curso académico 2016/2017}

Fuente: Sistema de Información de las Universidades Valencianas Públicas (SIUVP).

Estudiantes de nacionalidad extranjera en estudios oficiales de grado

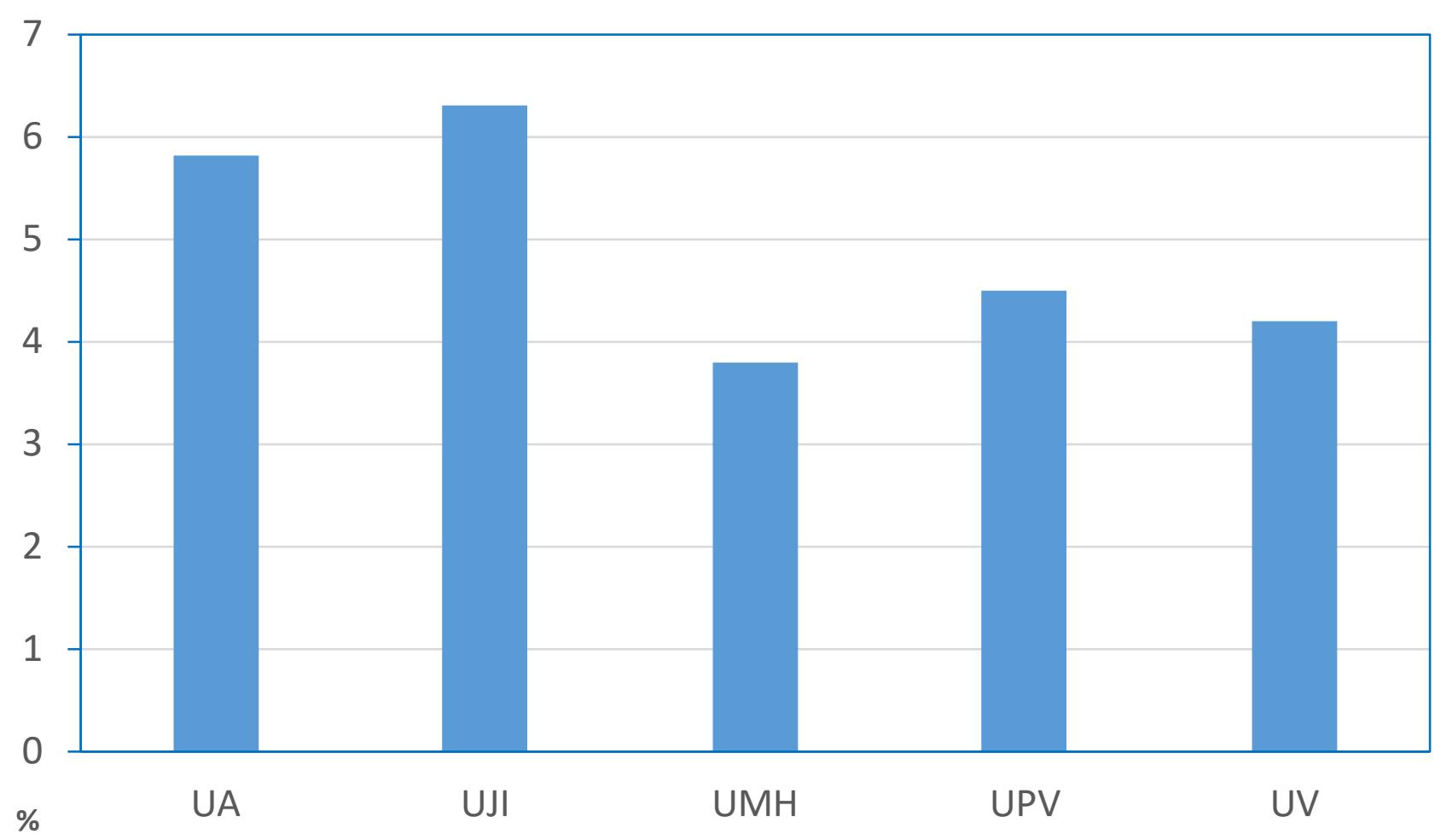

Estudiantes de nacionalidad extranjera en estudios oficiales de máster

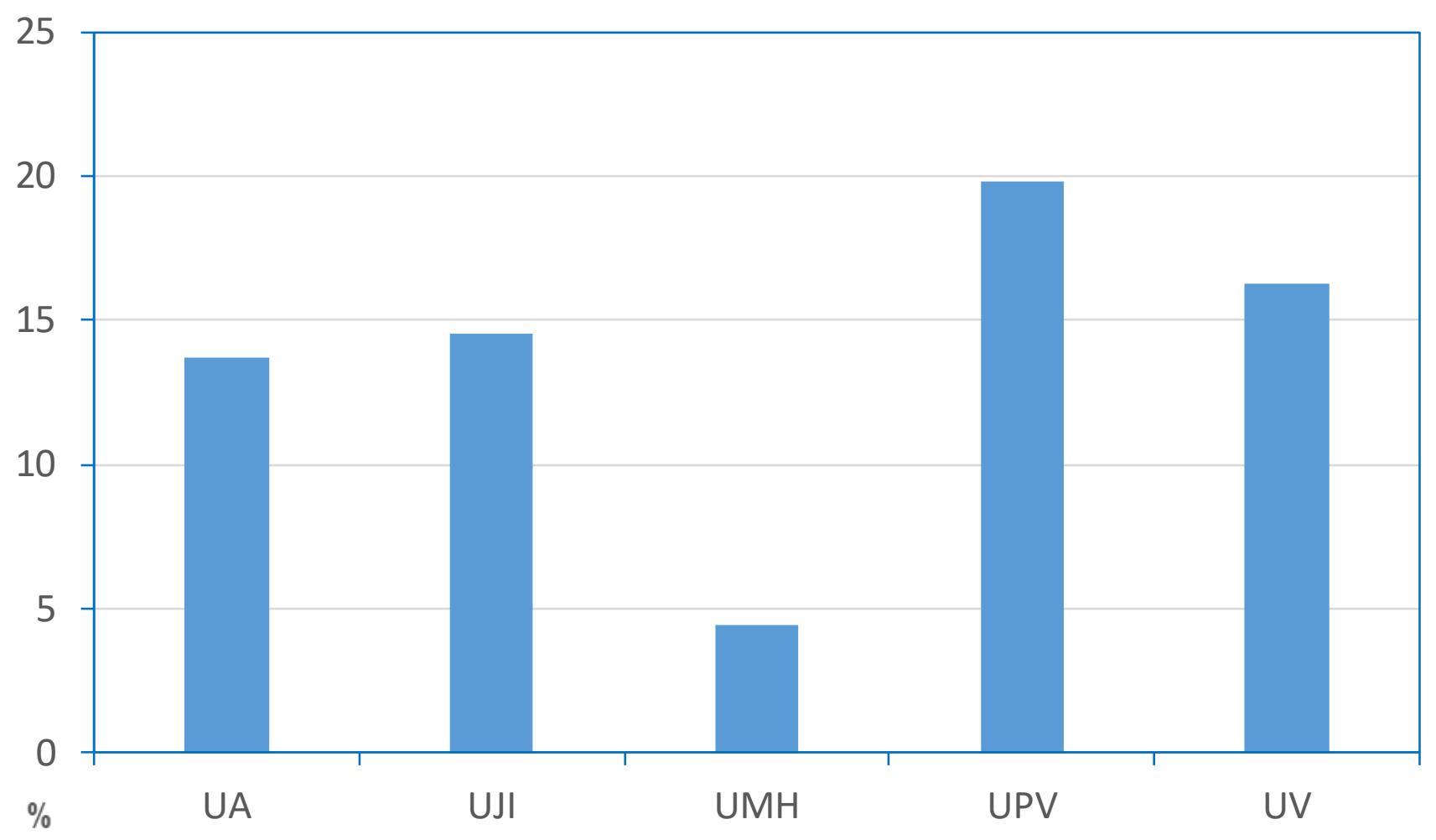


Estudiantes de nacionalidad extranjera en estudios de doctorado

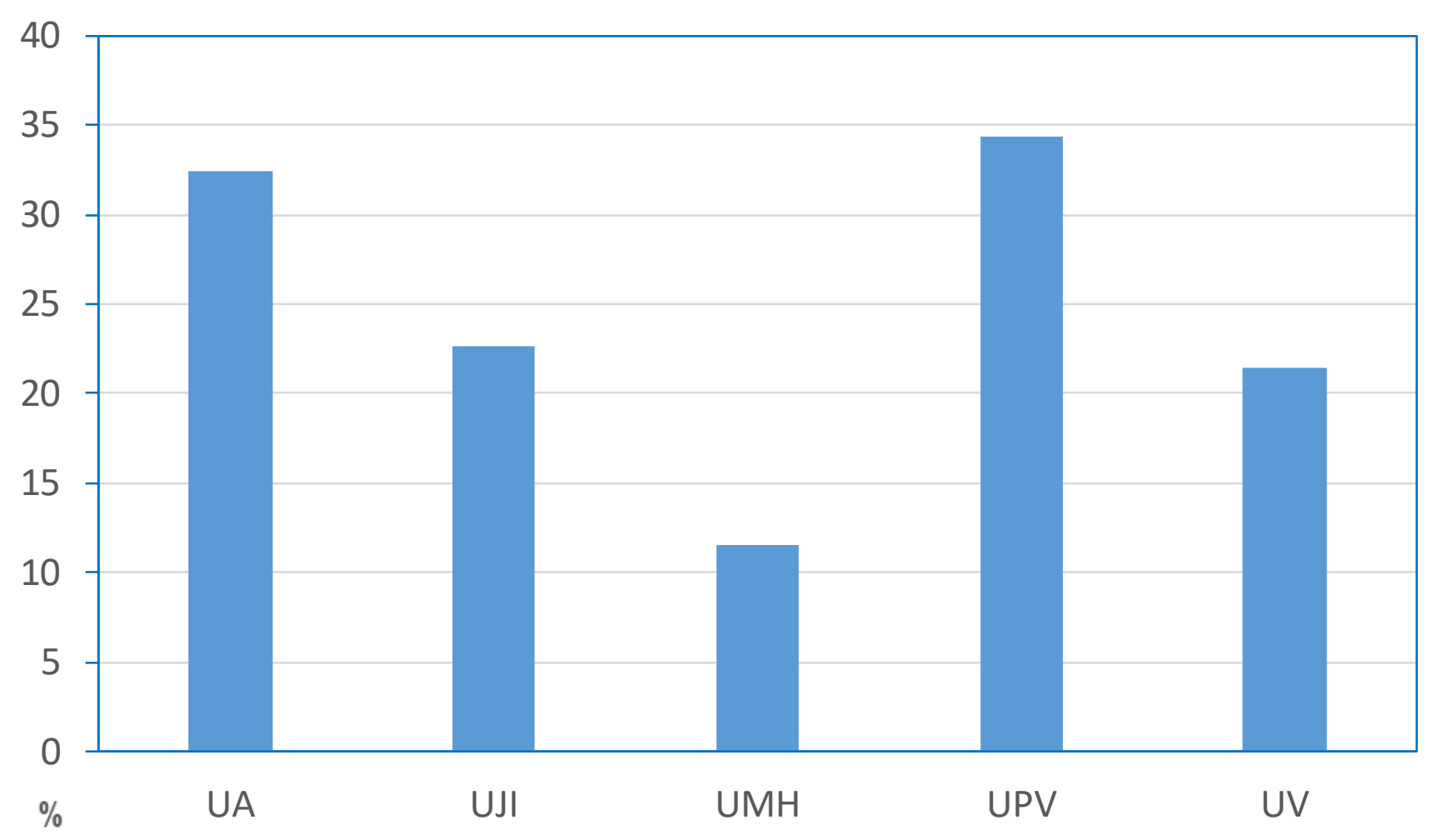


8

\section{Reconocimiento internacional}




\subsection{La UA en el ranking de Shangai}

Año 2018

Fuente: shangairanking.com

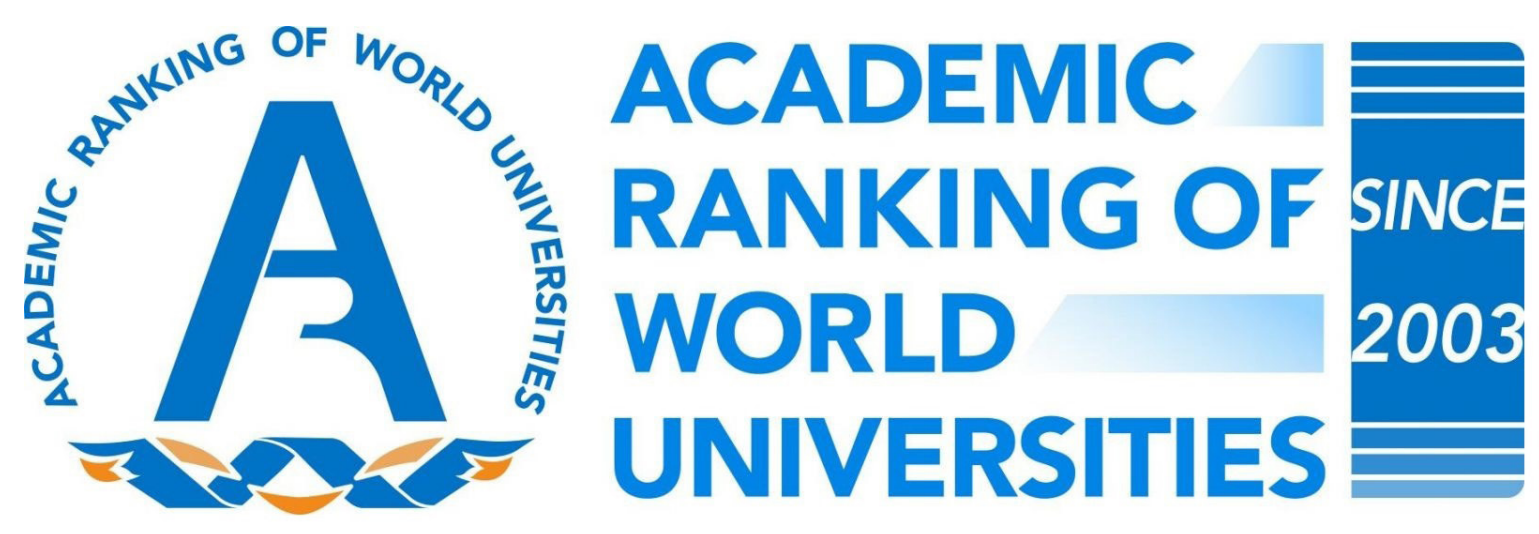

801-900 ARWU

Ranking by Subject

41 Hospitality \& Tourism Management

201-300 Chemical Engineering

301-400 Economics

401-500 Management

Environmental Science \& Engineering

Chemistry

Agricultural sciences 


\subsection{La UA en el ranking QS}

Año 2018

Fuente: topuniversities.com
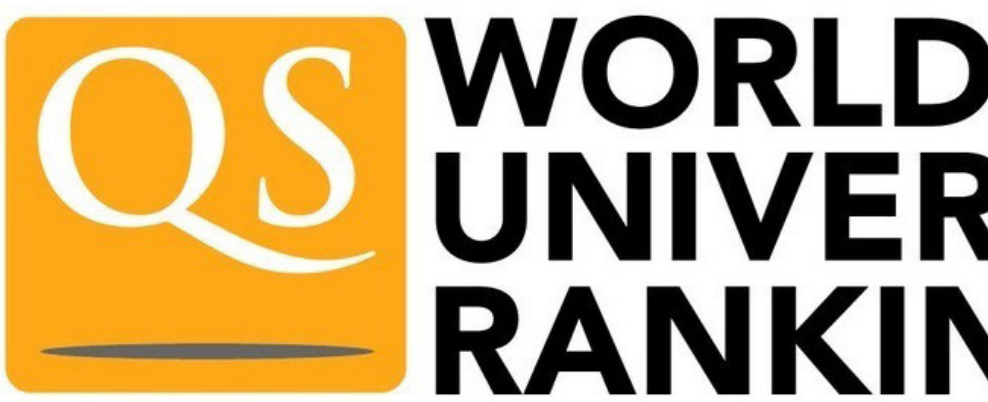

\#701-750 QS Global World Ranking

Ranking by Broad Subject Area

$=392$ Arts \& Humanities

Ranking by Specific Subject

\#251-300 Linguistics

Chemistry

\#351-400 Economy \& Econometry 


\subsection{La UA en el ranking Times Higher Education}

Año 2018

Fuente: timeshighereducation.com

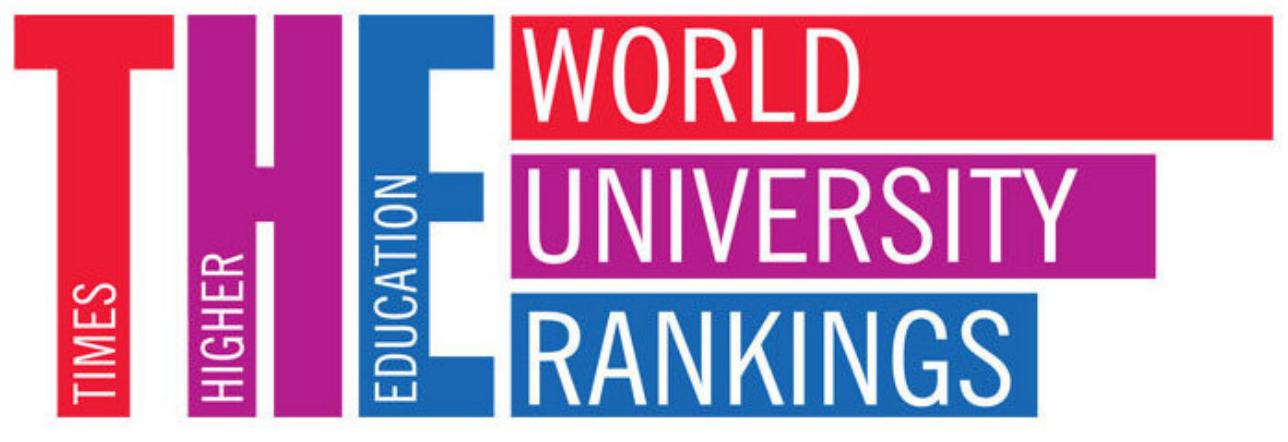

801-1000 World University Rankings

201-250 Young University Rankings

Ranking by subject

151-200 Gender equality

European Teaching

301-400 Engineering \& technology

Education

$401+$ Arts \& humanities

501-600 Computer Science

Life sciences

Physical sciences

501+ Bussines \& Economics

$601+$ Clinical, pre-clinical \& health

Social sciences 


\subsection{La UA en el ranking de Leiden}

\section{Año 2018}

Fuente: leidenranking.com

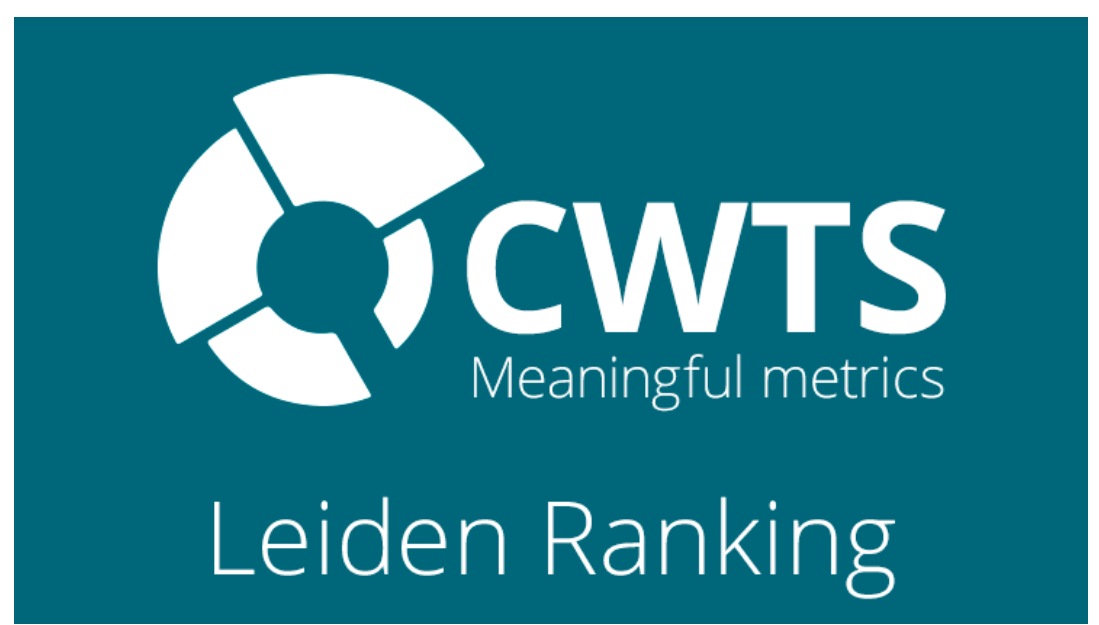

688 World

Ranking by field

426 Social sciences and humanities

471 Life and earth sciences

493 Physical sciences and engineering

527 Mathematics and computer sciences 


